\title{
Gestörtes Gleichgewicht Wiederherstellende Verfahren bei gestörtem Gleichgewicht
}

\section{E. Walther}

\section{Inhaltsverzeichnis}

1 Einführung ...71

2 Grundlagen ... 72

2.1

2.2

Entwicklung der Strukturen des Gleichgewichtsorgans ... 72

Anatomie, Physiologie und Pathophysiologie des vestibulären Systems ... 72

2.3 Vestibularisdiagnostik... 75

$3 \quad$ Akute einseitige Vestibularisstörung ...75

3.1 Diagnostik und Ursachen ... 75

3.2 Medikamentöse Therapie... 77

3.3 Vestibuläre Kompensation....77

4 Benigner paroxysmaler Lagerungsschwindel ...78

4.1 Ursachen...78

4.2 Symptomatik und Varianten ... 78

4.4 Physikalische Therapie...79

4.5 Chirurgische Therapie ... 80

4.6 Fakten der evidenzbasierten Medizin ... 82

5 Morbus Menière... 82

5.1 Differenzialdiagnostik und Therapieansätze ... 82

5.2

5.3 Intratympanale Applikation von Medikamenten ...83

5.3.1 Aminoglykosidtherapie...83

5.3.2 Labyrinthanästhesie ... 85

5.3.3 Glukokortikoidtherapie... 86

5.3.4 „Osmotische Induktion“...86

5.4 Beeinflussung von Mittelohrdruck, -mechanik und Hydrodynamik des Innenohres ... 86

5.5 Chirurgische Therapie ... 87

5.5.1 Funktionserhaltende Labyrinthchirurgie ... 87

5.5.1.1 Saccotomie... 87

5.5.1.2 Cochleosacculotomie ... 88

5.5.2 Ausschaltung der Labyrinthfunktion ... 88

5.5.2.1 Neurektomie des Nervus vestibularis ... 88

5.5.2.2 Labyrinthektomie... 89

5.6 Zusammenfassende Bemerkungen...89

$6 \quad$ Funktionsstörungen der Otolithenorgane ... 90

7 Bilaterale Vestibulopathie... 90

$8 \quad$ Gestörtes Gleichgewicht im Alter ...91

$9 \quad$ Kinetosen ... 91

Literatur (Hinweis: erscheint nur in der Online-Ausgabe)

Institutsangaben

Klinik für Hals-, Nasen-, Ohrenheilkunde und Plastische Kopf- und Halschirurgie, Universitätsklinikum Aachen (Direktor: Univ.-Prof. Dr. med. M. Westhofen)

Korrespondenzadresse

PD Dr. med. Leif Erik Walther · Klinik für Hals-, Nasen-, Ohrenheilkunde und Plastische Kopf- und Halschirurgie, Universitätsklinikum Aachen · Pauwelsstraße 30·52074 Aachen ·E-mail: LWalther@ukaachen.de 


\section{Zusammenfassung}

In diesem Referat wird die Therapie ausgewählter Erkrankungen des Gleichgewichtsorgans und der nachgeschalteten Neurone erläutert, mit denen der HNO-Arzt in Praxis und Klinik täglich befasst ist. Die Behandlung dieser Störungen kann symptomatisch oder kausal ausgerichtet sein. Medikamentöse, physikalische und chirurgische Strategien stehen zur Wiederherstellung von Körpergleichgewicht, Blickfunktion und Koordinationsvermögen zur Verfügung (Tab.1). Eine Prophylaxe oder Prävention ist bei einigen wenigen Störungen mit Schwindelbeschwerden möglich (z.B. bilaterale Vestibulopathie, Kinetosen, Höhenschwindel, Tab. 2). Die physikalische Therapie des gutartigen Lagerungsschwindels kann ambulant durchgeführt werden (Repositionsoder Befreiungsmanöver). Für die Behandlung des Morbus Menière stehen Medikamente zur Anfallstherapie bzw. Prophylaxe zur Verfügung. Es gibt funktionserhaltende (Saccotomie) und ablative chirurgische Verfahren (z. B. Labyrinthektomie, Neurektomie des Nervus vestibularis). In der Praxis hat sich das Vorgehen im Rahmen einer Stufentherapie bewährt. Beim erworbenen beiderseitigen Vestibularisausfall ist die Behandlung der Grunderkrankung (z.B. Cogan-Syndrom) von Bedeutung. Gleichgewichtstraining verbessert das Gleichgewichtsempfinden des Patienten, führt jedoch nie zu einer vollständigen Wiederherstellung. Isolierte Otolithenfunktionsstörungen oder eine Otolithenbeteiligung finden sich bei labyrinthären Störungen bei ca. 50\% der Fälle. Eine spezifische operative Therapie der selektiven Ausschaltung der Otolithenorgane wird derzeit erforscht. Gestörtes Gleichgewicht im Alter beeinträchtigt die Lebensqualität erheblich und wird häufig durch multimodale Störungen kompliziert. Antivertiginosa in Kombination mit einem Bewegungstraining führen zu einer signifikanten Besserung der Beschwerden. Zur Prophylaxe und Therapie von Kinetosen kann mit Antivertiginosa unterschiedlicher Wirkdauer (z.B. transdermale Scopolaminapplikation über ein Pflaster) sowie mittels Kinetosetraining erfolgen.

\section{Schlüsselwörter}

Neurootologie · Gleichgewichtsstörung · Labyrinth · Rehabilitation · Therapie · Otochirurgie · vestibuläre Kompensation

\section{$1 \quad$ Einführung}

Das Gleichgewichtsvermögen des Menschen wird durch die Funktionen des Labyrinths, des visuellen Systems und der zervikalen Tiefensensibilität erreicht. Diese genau aufeinander abgestimmten Sinnesmodalitäten steuern die Blickmotorik zur Orientierung im Raum in jeder Körperlage und während der Bewegung des Kopfes. Darüber hinaus werden durch die muskuläre Koordination Stehen, Gehen und simultane Kopfbewegungen möglich. Ist das Zusammenwirken dieser verschiedenen Sinnesfunktionen gestört, entsteht eine Wahrnehmung, die individuell unterschiedlich als Schwindelempfindung interpretiert wird. Dabei handelt es sich weder um eine Diagnose noch um einen Befund, sondern um ein vieldeutiges fachübergreifendes subjektives Symptom. Dieses tritt aber nicht nur bei Krankheiten des Gleichgewichtssystems auf, sondern auch bei nicht otologischen Erkrankungen. Unter Gleichgewichtsstörungen im engeren Sinne wird auch eine Störung der Haltungsregulation verstanden. Sie ist Folge von Läsionen im Bereich des vestibulären Systems. „Aus dem Gleichgewicht geraten“ kann man deshalb aus den unterschiedlichsten Gründen.

Der Umgang mit Schwindelbeschwerden und Gleichgewichtsstörungen wird im Allgemeinen als schwierig angesehen. Aufgrund des subjektiven Charakters, der Unschärfe und Ungenauigkeit des Begriffs „Schwindel“ ergeben sich nicht selten Probleme im klinischen Alltag. Das Wort „Schwindel“ lässt sich auf das althochdeutsche Verb „swintilon“ (für „In Ohnmacht fallen“, „Schwinden der Sinne“) (800 nach Chr.) zurückführen. Die Bedeutung beschrieb etwa den orthostatischen Schwindel. Erst im Mittelhochdeutschen entstand das Substantiv „swindel“ mit der innewohnenden Bedeutung des systematischen Schwindels und bedeutet heute im medizinischen aber auch juristischen Sinne, dass irgendetwas nicht zusammen stimmt [1,2]. In anderen Sprachen hingegen wird klar zwischen gerichteten Schwindelsensationen (engl. vertigo, frz. vertige) und unbestimmtem Unwohlsein (engl. dizziness, frz. malaise) unterschieden [3].

Schwindelbeschwerden und Gleichgewichtsstörungen gehören zu den häufigsten Beschwerden überhaupt und können deshalb als Volkskrankheit bezeichnet werden. Mehr als 300 verschiedene Ursachen können infrage kommen [4].

Akute oder dauerhaft vorhandene Schwindelzustände äußern sich in einer Störung, die Raumorientierung und Wahrnehmung (z.B. Drehschwindel), Blickstabilisierung (z.B. Nystagmus), Haltungsregulation (Ataxie, Fallneigung) und das vegetative Nervensystem betreffen kann [5]. Die Beeinträchtigung der Patienten durch diese Symptome ist teilweise erheblich. Aber nicht nur körperliche, sondern auch seelische Faktoren spielen eine bedeutende Rolle [6]. Nahezu immer ergeben sich dadurch für den Betroffenen Auswirkungen auf das alltägliche Leben und den Beruf.

Der vestibulookuläre Reflex (VOR) ist zentraler Bestandteil des sensomotorischen Systems. Er überträgt die Informationen vom Labyrinth über den Nervus vestibularis und seine Kerngebiete im Hirnstamm zu den Augenmuskeln (Abb.1). Vestibuläre Schwindelformen basieren auf Störungen im Bereich des VOR. Vor diesem Hintergrund erscheint die häufig gebräuchliche Unterscheidung peripherer und zentraler Störungen nicht mehr schlüssig. Sie ist didaktisch sinnvoll, eignet sich aber nicht für das Verständnis der Ursachen und zur Deutung funktionsdiagnostischer Befunde.

Zur Wiederherstellung des Gleichgewichts können eine medikamentöse Behandlung, physikalische Maßnahmen, funktionserhaltende operative Verfahren und Methoden der unilateralen Ausschaltung der Labyrinthfunktion zum Einsatz kommen. Grundlage hierfür ist die Kompetenz des Individuums zur vestibulären Kompensation, einen durch das Zentralnervensystem organisierten Vorgang bei einseitigen und beiderseitigen Funktionsstörungen im vestibulären System mit Neuorganisation des VOR.

In den letzten Jahren sind neue Impulse zur Aufklärung von Schwindelsyndromen seitens unseres Fachgebietes aber auch vom Fachgebiet der Neurologie ausgegangen. Gegenwärtig ist 
Tab. 1 Therapie bei Erkrankungen mit gestörtem Gleichgewicht (Vestibularisausfall, Morbus Menière, benigner paroxysmaler Lagerungsschwindel)

\begin{tabular}{|c|c|c|c|}
\hline Erkrankung & medikamentöse Therapie & physikalische Therapie & chirurgische Therapie \\
\hline $\begin{array}{l}\text { akuter einseitiger } \\
\text { Vestibularisausfall }\end{array}$ & z. B. Antivertiginosa, Glukokortikoide & vestibuläres Training & - \\
\hline Morbus Menière & $\begin{array}{l}\text { Anfallstherapie: Antivertiginosa } \\
\text { (z. B. Dimenhydrinat) } \\
\text { Anfallsprophylaxe: z. B. Cinnarizin und } \\
\text { Dimenhydrinat, Betahistin, Diuretika }\end{array}$ & vestibuläres Training & $\begin{array}{l}\text { funktionserhaltend: z. B. Saccotomie, } \\
\text { ablativ: z. B. Neurektomie des N. vestibularis; } \\
\text { medikamentös-chirurgisch: intratympanale } \\
\text { Gentamicin- oder Lidocaingaben }\end{array}$ \\
\hline $\begin{array}{l}\text { benigner paroxysmaler } \\
\text { Lagerungsschwindel }\end{array}$ & $\begin{array}{l}\text { als alleinige Therapie kontraindiziert, } \\
\text { im Einzelfall einmalige Gabe eines } \\
\text { Antivertiginosums nach physikalischer } \\
\text { Therapie }\end{array}$ & $\begin{array}{l}\text { nach Beteiligung des jeweiligen Bogen- } \\
\text { ganges: Befreiungsmanöver (z. B. nach } \\
\text { Semont) oder Repositionsmanöver } \\
\text { (z. B. nach Epley, Vannuchi) }\end{array}$ & $\begin{array}{l}\text { im Einzelfall: konventionell-chirurgische } \\
\text { Okklusion des jeweiligen Bogenganges } \\
\text { („Plugging“) oder laserchirurgische (Argon-, } \\
\mathrm{CO}_{2} \text {-Laser) Okklusion }\end{array}$ \\
\hline
\end{tabular}

Tab. 2 Prävention und Prophylaxe bei ausgewählten vestibulären Störungen

\begin{tabular}{ll}
\hline Erkrankung & Prävention/Prophylaxe \\
\hline bilaterale Vestibulopathie & $\begin{array}{l}\text { Kontrolle der Serumspiegel (Gentamicin), Vermeidung kumulativer Effekte (z. B. bei gleichzeitiger } \\
\text { Gabe von Schleifendiuretika) }\end{array}$ \\
\hline Gleichgewichtsstörungen nach Cochlea-Implantation & $\begin{array}{l}\text { Einbeziehung der Ergebnisse der thermischen Vestibularisprüfung sowie der Otolithenfunktionstests } \\
\text { in die Wahl der zu implantierenden Seite }\end{array}$ \\
\hline Borreliose & $\begin{array}{l}\text { Antibiotika (Einmalgabe), adäquate Behandlung eines Erythema chronicum migrans } \\
\text { reisespezifisches Kinetosentraining (wiederholte Reizexposition: Habituation), vorsichtiges Be- } \\
\text { schleunigen und Bremsen, Vermeidung zusätzlicher Beschleunigungskräfte (z. B. Kopfbewegungen } \\
\text { beim Autofahren), Vermeidung optisch-visueller Konfliktsituationen (z. B. Lesen beim Autofahren, } \\
\text { visuelle Kontrolle der Fahrt), Kopffixation während der Fahrt, Antivertiginosa vor Reiseantritt }\end{array}$ \\
\hline Höhenschwindel & $\begin{array}{l}\text { Vermeidung zu starker Kopfneigung, Hinsetzen oder Hinlegen, Festhalten oder Anlehnen, } \\
\text { Vermeidung von Bewegungen, nahe gelegene Kontraste sollten im Gesichtsfeld verbleiben }\end{array}$ \\
\hline Gleichgewichtsstörungen beim Tauchen & $\begin{array}{l}\text { Tauchtauglichkeitsuntersuchung, keine Tauchgänge bei Erkrankungen der oberen Luftwege mit } \\
\text { Tubenfunktionsstörungen } \\
\text { körperliches und Gleichgewichtstraining, Vermeidung von Stürzen durch sinnvolle Verordnung von } \\
\text { Medikamenten }\end{array}$ \\
\hline gestörtes Gleichgewicht im Alter &
\end{tabular}

eine Lösung diagnostischer und therapeutischer Fragestellungen bei Schwindelsyndromen kaum noch ohne die Zusammenarbeit mit anderen Fachrichtungen möglich.

Das folgende Referat widmet sich in erster Linie labyrinthären Erkrankungen mit gestörtem Gleichgewicht. Es werden historische und etablierte Behandlungsmethoden vorgestellt, kontroverse Ansichten gegenübergestellt und kritisch diskutiert. Die gewählte Darstellung wendet sich an den HNO-Arzt in der Arztpraxis und an den Kliniker.

So verfügbar, wurden zur Bewertung der Wirksamkeit einzelner therapeutischer Maßnahmen Quellen der evidenzbasierten Medizin herangezogen.

\section{$2 \quad$ Grundlagen}

\subsection{Entwicklung der Strukturen des Gleichgewichts- organs}

Die embryonale Entwicklung des Innenohres ist ein komplizierter Prozess mit einem Wachstum der Labyrinthstrukturen in drei Dimensionen. Der embryologische Ursprung ist das so genannte Ohrbläschen. Dieses unterteilt sich zunächst in einen ventralen
Anteil, bestehend aus Sacculus und Ductus cochlearis und eine dorsale Komponente, den Utriculus. Im Utriculus sind inzwischen Hinweise für adulte Stammzellen gefunden worden. Die Entwicklung des Innenohrs beginnt in der sechsten Woche. Alle drei Bogengänge entstehen gleichzeitig aus drei flachen Vorwölbungen des Utriculus. Die weitere Entwicklung der Bogengänge ist ein Prozess der Verschmelzung und des gleichzeitigen Wachstums. Der laterale Bogengang ist die letzte Struktur, die sich während der Embryogenese des Innenohres entwickelt. Eine Fehlbildung des lateralen Bogengangs kann als isolierte Anomalie vorkommen [7]. Ein Fehlen aller drei Bogengänge wird beim Goldenhar-Syndrom und der CHARGE-Assoziation beschrieben $[8,9]$.

\subsection{Anatomie, Physiologie und Pathophysiologie des vestibulären Systems}

Das knöcherne Labyrinth umscheidet das häutige (membranöse) Labyrinth. Letzteres stellt ein verzweigtes, in sich geschlossenes System dar. Die endolymphgefüllten Bogengänge münden mit fünf Öffnungen (ein Crus commune, nichtampulläres Ende des vorderen und hinteren Bogengangs) in den Utriculus. Von klinischer Bedeutung (Gleichgewichtsstörung nach Stapesoperationen) ist die unmittelbare Nachbarschaft der Otolithenorgane zur Fenestra vestibuli. Die Distanzen zum ovalen Fenster sind 


\section{Wahrnehmung<smiles>[131In][131I]</smiles> \\ z.B. Drehschwindel}
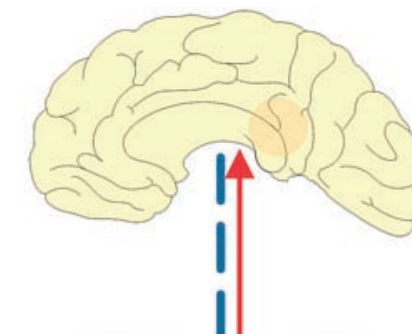

T

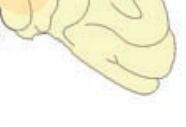

vestibulärer

Kortex

Thalamus

Augenmuskeln

Mittelhirn

Kerngebiete

der Augenmuskeln
Abb. 1 Der vestibulookuläre Reflex (VOR) vom Labyrinth bis zum Kortex. Der VOR ist zentraler Bestandteil des sensomotorischen Systems, das für die Raumorientierung und Wahrnehmung (vestibuläre Projektion im Kortex, perzeptiver Schenkel des VOR), Haltungsregulation (vestibulospinale Projektion, posturaler Schenkel) und Blickstabilisierung verantwortlich ist. Der VOR überträgt Informationen von den Bogengängen und Otolithenorganen über den Nervus vestibularis, die im Hirnstamm gelegenen Kerngebiete und vestibulären Projektionen an die Kerne der drei Augenmuskeln (Drei-Neuronen-Reflexbogen, okulomotorischer Schenkel). Die geringe Leitungszeit im VOR (ca. $20 \mathrm{~ms}$ ) garantiert ein scharfes retinales Abbild bei Kopfbewegungen $[5,15]$, (SVN; IVN; LVN; MVN: superiorer, inferiorer, lateraler, medialer Vestibulariskern).

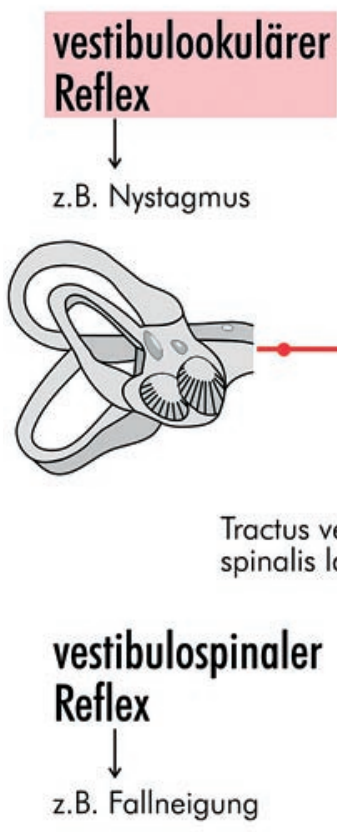

Hals- $u$. Rückenmark
Hirnstamm

Tractus vestibulospinalis medialis

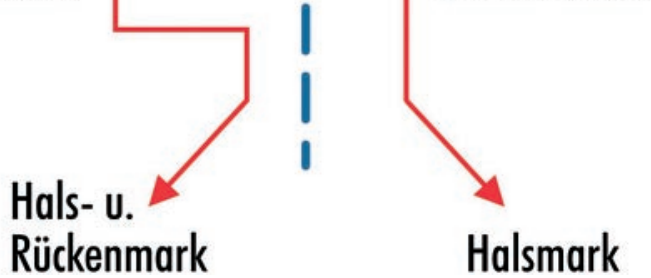

nach einer Zusammenstellung von Lang vom oberen Rand des ovalen Fensters zum Utriculus (medial und oben gelegen) am geringsten $(0,3 \mathrm{~mm})$. Vom hinteren Unterrand soll er durchschnittlich $1,4 \mathrm{~mm}$ betragen und von der unteren Wand 1,6 bis $2 \mathrm{~mm}$. Der Sacculus ist vom mittleren Anteil der Stapesfußplatte etwa $1 \mathrm{~mm}$ entfernt. Die geringste Distanz findet sich zur Vorderkante (etwa 0,75-1 mm) [10].

Die vaskuläre Versorgung des Gleichgewichtsorgans erfolgt über die Arteria labyrinthi. Sie gibt eine Arteria vestibularis anterior ab, deren Äste über den Ramus vestibularis mit der Arteria vestibulocochlearis anastomosieren. Variationen der Gefäßverläufe und Schlingenbildungen im Bereich des Hirnstammes (neurovaskuläre Kompression) können zu Schwindelbeschwerden im Rahmen einer Vestibularisparoxysmie führen.

Die Sinnesepithelien des vestibulären Labyrinths befinden sich im Otolithenapparat (Macula utriculi et sacculi) und in den Ampullen der drei Bogengänge (Cristae). Man unterscheidet zwei Typen von Haarzellen beim Menschen. Die flaschenförmigen Typ-I-Haarzellen und die zylindrisch geformten Typ-II-Haarzel- len. Beide funktionieren als mechano-sensorische Rezeptoren. Nach der Reizung durch Dreh- oder Linearbeschleunigungen erfolgt eine mechano-elektrische Transduktion. Diese ist einer aktuellen Studie zufolge in Typ-I-Haarzellen größer (500 pA) als in den Typ-II-Haarzellen [11]. Der Rezeptorpol beider Zellen enthält Stereozilien, die bei der Aufsicht hexagonal angeordnet sind. Die Stereozilien ragen in die mit Otolithen (Statolithen) besetzte, aufliegende gelatinöse, wabenartige Membran oder die gelatinöse Masse der Cupula hinein. Der adäquate Reiz ist eine Scherbewegung der Sinneshärchen. Entsprechend einer funktionellen Zellpolarisation befindet sich lateral des Stereozilienbündels eine Kinozilie (Verbiegung in Richtung der Kinozile = Depolarisation, entgegengesetzte Bewegung=Hyperpolarisation). Während die Polarisation der Sinneszellen in den Cristae einheitlich ist, sind die Verhältnisse in den Maculae funktionsbedingt komplizierter. Hier findet sich eine bogenförmig verlaufende Grenzlinie (Striola), die die Sinnesepithelien in zwei Hälften teilt. Die Sinneszellpolarisationen der Otolithenorgane verlaufen nicht parallel sondern ebenfalls bogenförmig und sind so in allen Richtungen einer Ebene vorhanden [12,13]. 
Die Informationen der in etwa rechtwinklig zueinander stehenden Otolithenorgane (Sacculus senkrecht) gelangen über die Nervenfasern des Nervus utricularis und saccularis zum oberen Anteil des Ganglion vestibulare (Scarpae). Ein weiterer Nerv zieht vom Sacculus zum Ganglion vestibulare inferior. Alle Cristae geben jeweils einen Nerven ab. Vorderer und lateraler Nervus ampullaris ziehen zum oberen Anteil des vestibulären Ganglions. Der hintere Bogengang entlässt den Nervus singularis und den Nervus ampullaris posterior zum Ganglion vestibulare inferior. Im Ganglion vestibulare liegen die Nervenzellen des zweiten Neurons. Die Faserbündel des Nervus vestibulocochlearis (Pars vestibularis superior, Pars vestibularis inferior, Pars cochlearis) rotieren auf dem Weg zum Eintritt in den Hirnstamm diskret. Die einzelnen Faserbündel lassen sich im Bereich der Fundus meatici acustici von einander abgrenzen. Einige der zahlreichen Anastomosen bestehen zwischen der Pars vestibularis superior und dem Nervus intermedius sowie dem oberen Anteil des Nervus saccularis und dem Nervus intermedius. Neben den afferenten Fasern verlaufen im Nervus vestibularis auch efferente Bahnen. Die Nervenendigungen verteilen sich im Gleichgewichtsorgan ohne Spezifität und steuern sowohl Typ-I- als auch Typ-IIZellen an. Feinabstimmungen des Gleichgewichtsorgans über die efferenten Bahnen werden angenommen $[10,14]$.

Die wichtigste Struktur des vestibulären Systems, der VOR, gibt die Informationen vom Labyrinth (Bogengänge und Otolithenorgane auf beiden Seiten) über den Nervus vestibularis, das Vestibulariskerngebiet, die vestibulären Projektionsgebiete im Hirnstamm (Fasciculus longitudinalis medialis, Brachium conjunctivum, aufsteigender Deiters Trakt) an die Kerngebiete der Augenmuskelnerven über einen so genannten „Drei-Neuronen-Reflexbogen “ (N. trochlearis, N. oculomotorius, N. abducens) weiter. Die paramediane Formatio reticularis der Pons (PPRF) als wesentliches Integrationszentrum für Augenbewegungen kontrolliert z. B. horizontale Sakkaden durch prämotorische Burst-Neuronen mit monosynaptischen Eingängen auf den N. abducens. Der VOR ist unter anderem verantwortlich für die Blickstabilisierung. Betrachtete Bilder werden bei allen Körperbewegungen simultan auf gleichen Orten der Netzhaut abgebildet. Andere Bahnen ziehen zum vestibulären Kortex (Raumorientierung und Wahrnehmung) und zu den vestibulospinalen Bahnen (Haltungsregulation) $[5,15]$.

In neueren Untersuchungen mit funktionellen kernspintomographischen Darstellungen und mittels Positronen-Emissions-Tomographie nach visueller und vestibulärer Stimulation von Hirnarealen konnte nachgewiesen werden, dass eine zentrale intersensorische Verarbeitung unterschiedlicher Stimuli erfolgt. Bei vestibulären Stimulationen (thermische Reizung) wurden Signale in parietoinsulären Zonen festgestellt (parietoinsulärer vestibulärer Kortex). Eine Aktivierung des visuellen Systems führte zu einer Minderung der Durchblutung im postinsulären Kortex. Wenn das vestibuläre System stimuliert wurde, war eine partielle Deaktivierung des visuellen Kortex die Folge. Diese so genannte reziproke inhibitorische Interaktion zwischen visuellem und vestibulärem System soll funktionelle Bedeutung in der Konfliktverarbeitung unterschiedlicher sensorischer Inputs haben [16-22]. So ist auch denkbar, dass solche Mechanismen auch bei der vestibulären Kompensation eine Rolle spielen könnten.

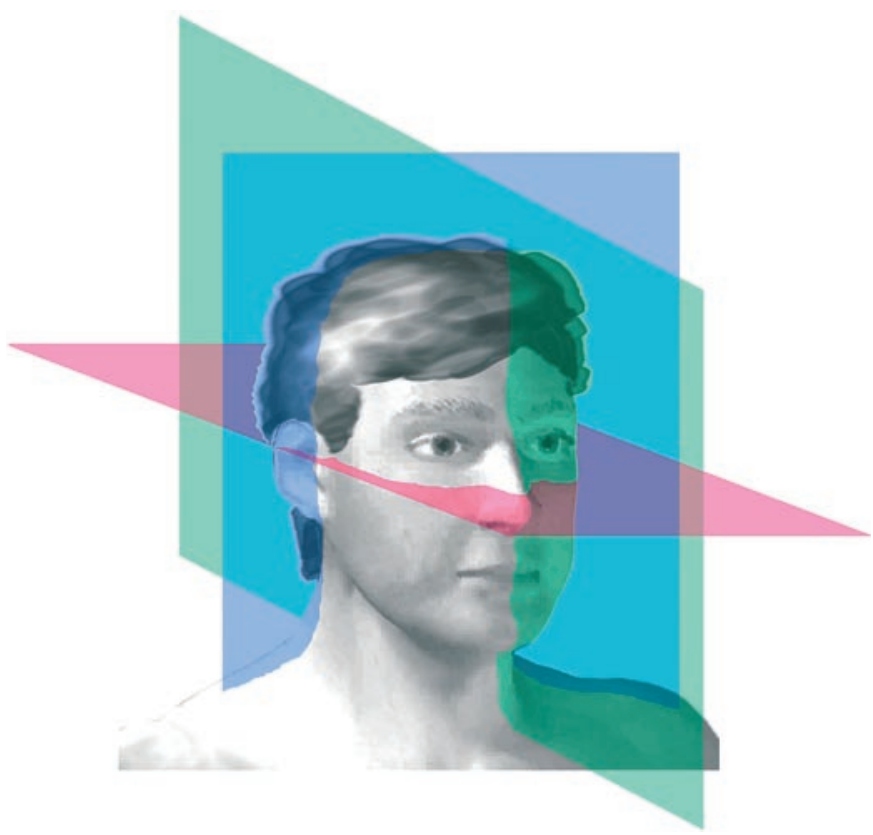

Abb 2 a Die drei Hauptarbeitsebenen des vestibulookulären Reflexes (VOR). Vertikale pitch-Ebene (grün), frontale roll-Ebene (grau), horizontale yaw-Ebene (grün) [23]. b Nystagmen bei definierten Schädigungen in den drei Hauptarbeitsebenen des VOR. Tonusimbalancen in der pitch-Ebene führen zu einem vertikalen Nystagmus (upbeat oder downbeat Nystagmus). Störungen in der roll-Ebene bewirken einen torsionellen Nystagmus und Schädigungen des VOR in der yaw-Ebene einen horizontalen Nystagmus.

Gestörtes Gleichgewicht kommt durch Läsionen an Strukturen des vestibulären Systems zustande und führt zu einem gestörten vestibulären Funktionsgleichgewicht. Der VOR besitzt drei Arbeitsebenen, eine sagittale (pitch), eine frontale (roll) und eine horizontale (yaw). Definierte topische Funktionsstörungen bedingen bisweilen definierte Nystagmusrichtungen. Diese klinische Zuordnung von Augenbewegungen und Schädigungsorten wurde vorwiegend für zentralnervöse Syndrome (Hirnstammläsionen) entwickelt und hilft bisweilen auch für die Einteilung von Störungen im labyrinthären Bereich (z.B. benigner paroxysmaler Lagerungsschwindel des lateralen Bogengangs) [5, 15 , 23] (Abb. 2a,b). Pathologische Augenbewegungen in der pitchEbene sind durch bilaterale pontomedulläre, pontomesenzephale und Flocculusschädigungen bedingt. Vestibuläre Syndrome in der roll-Ebene zeigen eine unilaterale Schädigung aufsteigender Bahnen (von den Bogengängen und Otolithenorganen) an. Gestörte Augenbewegungen in der yaw-Ebene werden durch einseitige Läsionen im Bereich der Eintrittszone des Nervus vestibularis in den Hirnstamm oder durch Schädigungen des mittleren und/oder oberen Vestibulariskern sowie der parapontinen Formatio reticularis hervorgerufen $[5,15,23]$.

Endo- und Perilymphe haben ein in etwa gleiches spezifisches Gewicht und stehen unter etwa gleichem Druck, der durch den Liquorraum beeinflusst wird. Dieser befindet sich in unmittelbarer Nähe des Labyrinths. Der Aquaeductus cochleae stellt eine bei der Ontogenese angelegte Verbindung zwischen Perilymph- und Subarachnoidalraum dar. Beim Erwachsenen ist sie verschlossen. Die Kommunikation der Perilymphe mit dem Liquorkompartiment über den Aquaeductus cochleae spielt beim Krankheitsbild 
der perilymphatischen Hypertension eine Rolle [24]. Auch eine interlabyrinthäre Verbindung zwischen den Perilymphräumen beider Ohren, die nach einer Hypothese über perineurale Lymphscheiden erfolgen soll, wird seit langem diskutiert („Schreiner-Effekt“, sympathetic cochleo-labyrinthitis) [25,26].

Der Aquaeductus vestibuli führt den Endolymphkanal (Ductus endolymphaticus). Dieser entsteht durch die Vereinigung der Gänge aus dem Utriculus und dem Sacculus. Der distale Saccus endolymphaticus ist unter der Dura der hinteren Schädelgrube an der Hinterkante der Felsenbeinpyramide zu finden. Er stellt eine ca. $10 \mathrm{~mm}$ große, intrakranielle Ausdehnung des häutigen Labyrinths dar. Charakteristische Epithelien mit funktioneller Bedeutung finden sich in drei Zonen: der Pars rugosa, der Pars intermedia und der Pars lateralis des Saccus endolymphaticus. Transportvorgänge zwischen dem Endo- und Perilymphraum verursachen Volumenverschiebungen und Flüssigkeitsströmungen. Dem Ductus und Saccus endolymphaticus werden verschiedene Funktionen zugeordnet, wie die Volumen- und Flussregulation (Klappensysteme), die Resorption von Endolymphe, sekretorische Aktivitäten und eine Rolle bei Immunprozessen des Innenohres (Pars rugosa) $[11,27,28]$. Ein ektatischer oder obliterierter Ductus endolymphaticus kann beispielsweise im Falle einer endolymphatischen Hypertension vorliegen.

\subsection{Vestibularisdiagnostik}

Labyrinthäre und neurogene Störungen des vestibulookulären Reflexes lassen sich heute mit modernen Methoden diagnostisch erfassen. Die Otolithenorgane sind bei einer Reihe von Funktionsstörungen aufgrund ihrer zentralen Lage früher und häufiger betroffen als die Cristae. Indikationen z.B. zur Einlage von Paukenröhrchen, explorativer Tympanotomie und Nischenabdeckung sowie endolymphatischer Shuntoperation können erst nach Ausschöpfung der gesamten neurootologischen Differenzialdiagnostik und Subklassifikation labyrinthärer Störungen gestellt werden.

Statische Kippung und exzentrische Rotation sowie thermische Prüfung in Pro- und Supinationslage mittels Videonystagmographie oder der Erfassung der subjektiven Vertikalen erlauben die seitengetrennte Beurteilung der Makulafunktion [29]. Mit modernen thermischen Reizmethoden (z. B. die Nahinfrarotreizung) wird eine gezielte, berührungsfreie, dosierte, geräuschlose und für den Patienten angenehmere Diagnostik ermöglicht. Zudem tritt hierbei das störende Phänomen der Verdunstungskälte nicht mehr auf [30-32].

Anhand von neueren rotatorischen Tests kann eine Aussage über den cristaabhängigen (frequenzselektive Drehpendelprüfung) und makulaabhängigen vestibulookulären Reflex (OVAR) gemacht werden. Vestibulär evozierte myogene Potenziale (VEMP) lassen sich durch gemittelte EMG-Ableitung gewinnen. Sie können der Funktion des Sacculus zugeordnet werden.

Zur Diagnostik von labyrinthären Anomalien und Neoplasien ist die hochauflösende Computertomographie geeignet. Fibrosierungen des endo- und perilymphatischen Raumes werden durch die Kernspintomogaphie und Maximum-Intensitäts-Pixel-Projektion dargestellt. Dreidimensionelle Visualisierungen erleichtern die räumliche Zuordnung von Befunden.
Da bei vielen Erkrankungen eine schrittweise Beeinträchtigung der labyrinthären Funktion (beginnend mit den Otolithenorganen und fortschreitend über eine Beeinträchtigung der Bogengangsfunktion) stattfindet, ist für eine Beurteilung bestimmter, vor allem druckbedingter Labyrinthfunktionsstörungen im Zeitverlauf eine Wiederholung von Untersuchungen und deren Vergleich sinnvoll [29]. Diagnostische Methoden mit Verlaufskontrollen sind außerdem erforderlich, um den Therapieerfolg im Einzelfall zu objektivieren und Therapiequalität zu sichern.

Die Untersuchung des vestibulookulären Reflexes ist innerhalb der letzten Dekade durch eine neue Generation der dreidimensionalen Videonystagmographie bereichert worden, die in Zunkunft zur Differenzialdiagnostik von vestibulären Störungen beitragen kann.

\section{$3 \quad$ Akute einseitige Vestibularisstörung}

\subsection{Diagnostik und Ursachen}

In der überwiegenden Zahl der Fälle handelt es sich bei einer plötzlich einsetzenden einseitigen Labyrinthstörung um einen idiopathischen „Vestibularisausfall“. Die Synonyme „akuter isolierter Vestibularisausfall“, „Neuritis vestibularis“ und „Neuropathia vestibularis" sind in der klinischen Praxis gebräuchliche Bezeichnungen für ein und dieselbe, jedoch meistens ätiologisch überwiegend unklare Erkrankung.

Die Diagnose eines „Vestibularisausfalls“ ist leicht zu stellen. In der Akutphase entwickelt sich intervallartig oder plötzlich eine ausgeprägte Schwindelsymptomatik mit vorwiegend horizontalschlagendem Spontannystagmus, eine Lateropulsion zur erkrankten Seite verbunden mit vegetativen Symptomen (Abb. 3). Der Halmagyi-Curthoys-Test eignet sich für ein Screening zur Klärung der Frage einer einseitigen labyrinthären Funktionsstörung (Prüfung des horizontalen VOR). Der Kopf wird mit beiden Händen des Untersuchers gehalten und dabei ein nahes Ziel fixiert. Dann erfolgen schnelle (3000 bis $4000 \%$ s) horizontale Kopfbewegungen nach rechts und links (10 bis $20 \mathrm{Grad}$ ). Ein ungestörter horizontaler VOR zeigt sich in schnellen kompensatorischen, ruckartigen Augenbewegungen entgegengesetzt zur Rotationsrichtung des Kopfes. Ein pathologischer horizontaler VOR (z.B. bei einer einseitigen Vestibularisstörung) zeigt sich in einem Zurückbleiben der Augen zur entgegengesetzten Seite (Korrektur der Blickrichtung durch Einstellsakkade) [33].

Bei den neurogenen Läsionen und Labyrintherkrankungen sind verschiedene Formen beschrieben. Ein kompletter „Ausfall“ des Gleichgewichtsorgans liegt in der überwiegenden Zahl der Fälle nicht vor. Vielmehr handelt es sich dabei um eine thermische Unerregbarkeit des lateralen Bogengangs, dessen thermische Reizantwort in der Praxis fälschlicherweise auf das gesamte Vestibularorgan extrapoliert wird. In solchen Fällen liegt vermutlich eine Form mit einer isolierten Schädigung der Pars superior des Nervus vestibularis vor, die den lateralen und vorderen Bogengang, den Utriculus sowie Teile des Sacculus versorgt. Auch eine alleinige Störung der Pars inferior des Nervus vestibularis mit selektivem Ausfall des hinteren Bogengangs [34] und eine kombinierte Funktionsstörung des hinteren Bogengangs und der Cochlea [15] werden als Formen einer labyrinthären vestibulären 


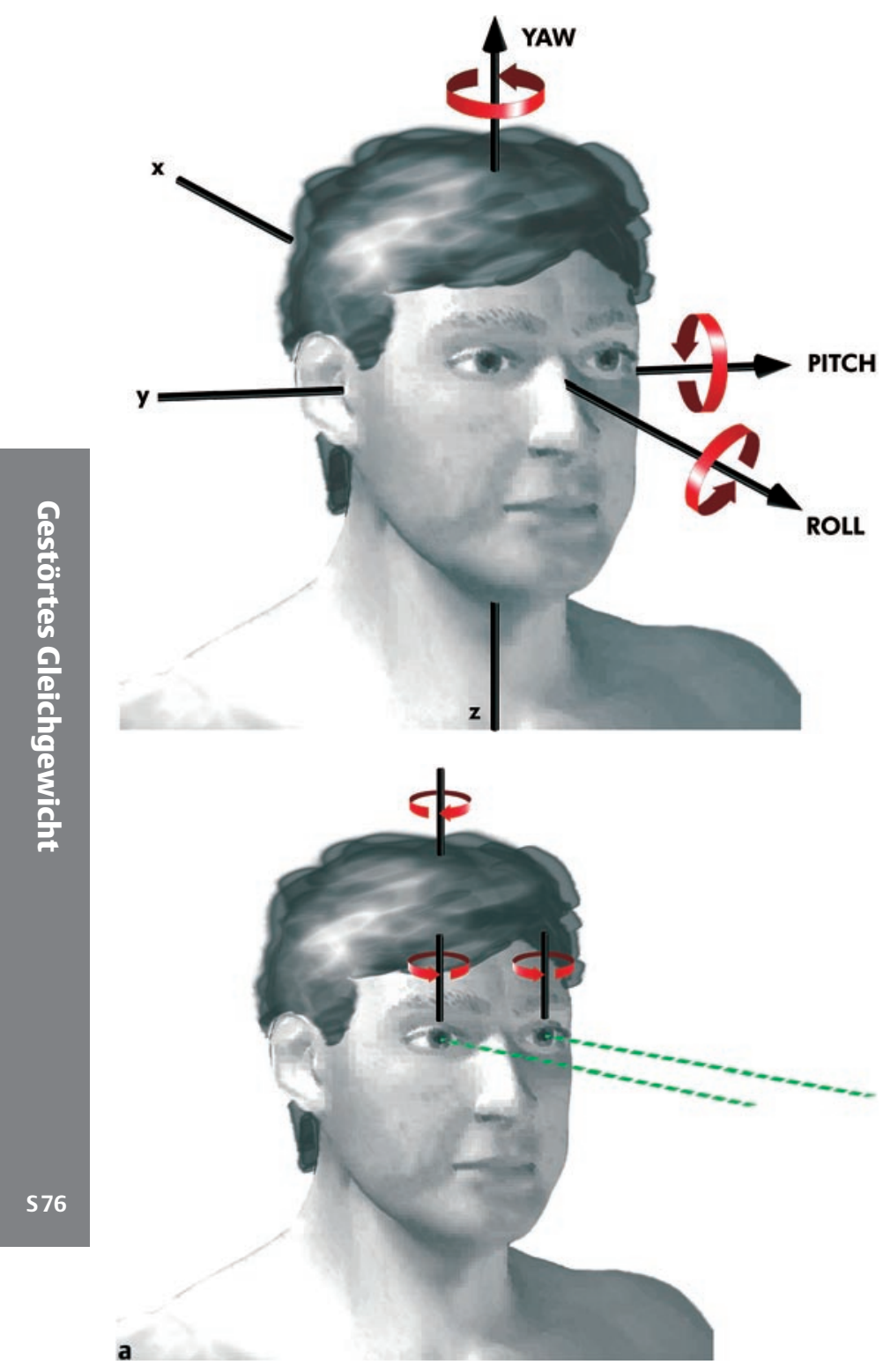

Funktionsstörung in der Literatur beschrieben. Neben Störungen der Bogengangsfunktion kommen auch Funktionsstörungen der Otolithenorgane im Rahmen eines Vestibularisausfalls vor [35].

Bei vertebrobasilären Gefäßprozessen können bei 60\% der Patienten isolierte Schwindelbeschwerden als Prodromalzeichen auftreten [36-41]. Gerade bei älteren Patienten mit episodischem Schwindel muss bei einem scheinbar klassischen Vestibularisausfall an vertebrobasiläre Gefäßprozesse als Ursache gedacht werden. Therapie der Wahl bei intrakraniellen Gefäßverschlüssen im vertebrobasilären Kreislauf ist die Antikoagulation. Stenosen der Abgänge der Arteria vertebralis können operativ saniert werden. Eine weitere Möglichkeit zur Behandlung extraund intrakranieller Stenosen der großen vertebrobasilären GefäBe stellt die perkutane transluminale Angioplastie dar [39].

Eine weitere bekannte Ursache für einen Vestibularisausfall ist das stumpfe Schädeltrauma mit Beteiligung des Innenohres (Contusio labyrinthi). Einblutungen oder Mikrofissuren des Labyrinths sind die Folge. In der Akutphase empfiehlt sich eine Cortisontherapie (150 mg über 3 Tage und dann abfallend oral) [42].
Abb. 3 a Bei einer gesunden Person ist die Richtung der Rotation beider Augen bei Kopfbewegungen entgegengesetzt zur Richtung der Kopfbewegung. Die Rotationsachsen von Kopf und Augen stehen zueinander parallel. Die Geschwindigkeit der Augenrotation entspricht der Geschwindigkeit der Kopfrotation (nach [68]). b Im Falle eines einseitigen Vestibularisausfalls ist die Geschwindigkeit der Augenrotation geringer als die Geschwindigkeit der Kopfbewegung. Die Rotationsachsen von Kopf und Augen unterscheiden sich. Beides führt zu einem unscharfen, verwischten retinalen Abbild (nach [68]).

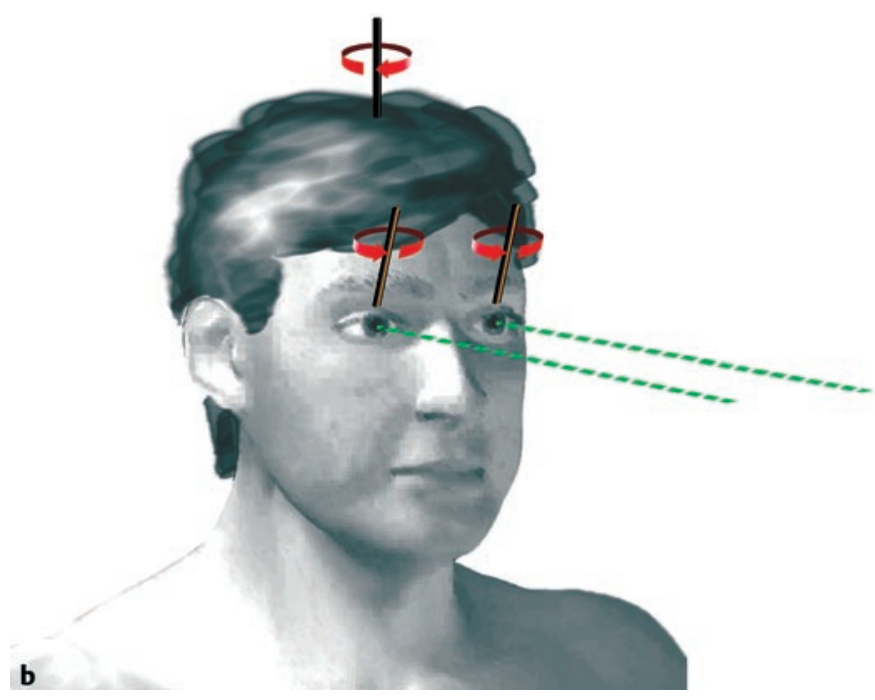

Isolierte Blutungen im Labyrinthbereich können nicht nur im Rahmen eines Traumas sondern auch spontan auftreten. Im Kernspintomogramm in den $\mathrm{T}_{1}$-gewichteten Sequenzen zeigt sich dann ein Signalenhancement des Labyrinths vor Kontrastmittelgabe $[43,44]$. Scherer und Helling vermuten als Substrat für einen Vestibularisausfall eine spontane Lösung der Cupula von der Ampullenwand. Da Unterschiede im Aufbau der Cupulae der drei Bogengänge nachgewiesen sind, wäre das auch eine Erklärung für unterschiedliche Verläufe. Tierexperimentell konnte das Bild eines Vestibularisausfalls durch eine Lösung der Cupula des lateralen Bogengangs bei der Taube erzeugt werden [45-47].

Weiterhin gibt es Anhaltspunkte dafür, dass es sich beim so genannten Vestibularisausfall um eine viral verursachte Erkrankung handelt (dann wäre der Terminus "Neuritis vestibularis“ gerechtfertigt). Vor allem Herpes simplex Viren Typ 1 (HSV 1), die sich latent im Ganglion des Nervus vestibularis aber auch im Labyrinth aufhalten sollen, wird im Rahmen einer Reaktivierung eine Rolle zuerkannt $[15,48,49]$. Auch eine Kontrastmittelanreicherung im Bereich des inneren Gehörgangs, die als Zeichen einer vermutlich viral induzierten Entzündung im Ganglion vesti- 
bulare (Ganglionitis, Neuritis) interpretiert werden kann, ist beschrieben [50]. In anderen Studien wiederum konnte ein entzündungsbedingtes Enhancement nicht bestätigt werden [51]. Auch die Ergebnisse serologischer Untersuchungen sind weder eindeutig noch einheitlich $[52,53]$. Hinweise für einen Zusammenhang mit dem Varicella zoster Virus (VZV) gibt es bei Rezidiven eines Vestibularisausfalls [53].

Neben Mikrozirkulationsstörungen und Virusinfektionen des Labyrinths werden auch Autoimmunerkrankungen als Ursache diskutiert [42].

Bei einer akuten einseitigen Vestibularisstörung findet in vielen Fällen eine Wiederkehr der thermischen Erregbarkeit statt. Die aus dem Schrifttum bekannt gewordenen Prozentsätze sind unterschiedlich. Haid und Mirsberger fanden bei 57\% $(n=47)$ eine Rückkehr der thermischen Erregbarkeit des Labyrinths [54]. 75\% bis $81 \%(\mathrm{n}=252)$ der Patienten zeigten bei Anwendung unterschiedlicher Therapiemethoden eine Erholung der thermischen Erregbarkeit nach vollständigem initialen Ausfall [55]. Herzog u. Mitarb. beobachteten bei $46 \%(n=79)$ eine Normalisierung der vestibulären Funktion nach akuter labyrinthärer Funktionsstörung bis zu vier Monate nach dem Akutereignis [56].

\subsection{Medikamentöse Therapie}

In der Akutphase eines akuten Vestibularisausfalls sind eine Elektrolytsubstitution und die Therapie mit Antiemetika, Antivertiginosa (z.B. Dimenhydrinat i.v. oder als Suppositorium für höchstens drei Tage) und Glukokortikoide (100 mg Methylprednisolon in abfallender Dosierung über ein bis zwei Wochen) unabhängig von den oben geschilderten Ursachen indiziert [15]. Wir führen in der Akutphase zudem eine Behandlung mit durchblutungsfördernden Medikamenten durch [42]. Diese Therapie wird zum Teil von anderen Autoren als unwirksam angesehen [15].

Virostatika in Kombination mit Glukokortikoiden stellen einen kausalen Behandlungsansatz dar, wenn es sich um eine viral verursachte Erkrankung handelt. Die für die Behandlung infrage kommenden und auf dem Markt verfügbaren antiviralen, virostatisch wirksamen Medikamente sind nur effektiv, wenn das Virus im Rahmen einer Reaktivierung und Vermehrung den extrazellulären Raum erreicht hat. Im Ergebnis einer aktuellen Studie zeigte sich, dass Methylprednisolon die Erholung der vestibulären Funktion beim Vestibularisausfall signifikant verbesserte, nicht jedoch die Verabreichung eines antiviralen Medikamentes (Valaciclovir) [57]. Lokale Medikamentenapplikationen (z. B. Ganciclovir) über ein spezielles Paukenröhrchen (MicroWick ${ }^{\circledR}$ ) werden als mögliche zukünftige Therapieansätze bei eindeutig als viral identifizierten einseitigen Vestibularisstörungen im Schrifttum diskutiert [58].

Die Verabreichung einer fixen Kombination von Cinnarizin $(20 \mathrm{mg}$ ) und Dimenhydrinat $(40 \mathrm{mg}$ ) hat bereits nach einer Woche zu einer besseren Reduktion von akuten vestibulären Schwindelbeschwerden geführt als die Monotherapie mit diesen Medikamenten [59]. Cinnarizin und Dimenhydrinat aber auch Betahistin beeinträchtigen einer neueren Studie zufolge die Vigilanz nur geringfügig [60]. Eine signifikante Verbesserung von akuten Schwindelbeschwerden konnte in einer randomisierten
Doppelblindstudie auch mit einem homöopathischen Arzneimittel erzielt werden [61].

\subsection{Vestibuläre Kompensation}

Bei allen Labyrinthschädigungen erfolgen vestibuläre Kompensationsmechanismen, wenn das Zentralnervensystem zu einer entsprechenden Funktion in der Lage ist. Bei der vestibulären Kompensation handelt sich um einen zeit- und altersabhängigen plastischen neuronalen, zentralen Prozess, an dem mehrere Sinnesmodalitäten beteiligt sind. Eine Beeinflussung durch eine Veränderung der Empfindlichkeit der primären vestibulären Sinneszellen im Innenohr über die nach ipsi- und kontralateral verlaufenden efferenten Fasern des Nervus vestibularis soll dabei eine wesentliche Rolle spielen [14]. Der Prozess der vestibulären Kompensation wird durch ein spezielles vestibuläres Training gefördert, was in tierexperimentellen Studien belegt werden konnte, so dass ein gestörtes Tonusgleichgewicht bei einer einseitigen Läsion des Gleichgewichtsorganes wiederhergestellt werden kann $[14,15,62,63]$.

Gramowski hat bereits 1964 auf die Bedeutung der Habituation für die Rehabilitation von Vestibularisstörungen hingewiesen. Er sah im Phänomen der Habituation eine Veränderung des Regelbereiches auf eine andere Empfindlichkeitsstufe. Eine wiederholte Reizung in kurzen Intervallen führt in einem „zentralen Vorgang“, der eine Reduzierung der Reizantwort zur Folge hat, zu einer Reaktionsabnahme (Habituation). Reaktionsabnahme bedeutet bei Patienten mit einseitiger vestibulärer Läsion eine Leistungssteigerung im Hinblick auf Anforderungen an das Gleichgewichtssystem [64].

Die in Phasen ablaufende vestibuläre Kompensation erstreckt sich bei bleibendem Verlust der thermischen Erregbarkeit des lateralen Bogengangs über mehrere Wochen. Um die zentralen vestibulären Kompensationsvorgänge zu trainieren, ist das allmähliche, systematische, individuelle Aufsuchen von Situationen, die schließlich das gesamte vestibuläre System einbeziehen (Konfliktsuche), die wirkungsvollste physikalische Therapiemethode [65]. Früh nach Labyrinthfunktionsstörung sind Antivertiginosa kontraindiziert, da sie den vestibulären Kompensationsvorgang verzögern $[15,66]$. Curthoys und Halmagyi haben diesen Zeitabschnitt auch sehr treffend als „kritische Phase“ bezeichnet $[67,68]$. Anschließend können aktive Kopfbewegungen zur Förderung der vestibulären Kompensation durchgeführt werden. In einer weiteren Phase erfolgt zusätzlich die Aktivierung vestibulospinaler und vestibulozerebellärer Verbindungen, indem Ziel- und Haltemotorik trainiert werden.

Ziel dieser speziellen physikalischen Therapie ist eine Beschleunigung der Neueinstellung des vestibulookulären Reflexes. Die Neuorganisation des vestibulookulären Reflexes wird nur aufgrund der Plastizität des Zentralnervensystems möglich [69].

In Anlehnung an Cawthorne, Cooksey und Sterkers hat Hamann in den 1980er-Jahren ein Trainingsprogramm entwickelt, mit dem Schwindelbeschwerden in etwa 90\% der Fälle gebessert werden können. In der Literatur findet sich eine Vielzahl weiterer komplexer physikalischer Trainingsprogramme [70-76]. 
Die vestibuläre Kompensation bei Patienten ohne thermisch nachweisbare Erholung der Labyrinthfunktion erfolgt bei Anwendung von Trainingsprogrammen mit allmählicher Steigerung der Anforderungen an das Körpergleichgewicht signifikant schneller als ohne diese $[77,78]$.

Ein positiver Einfluss von Glukokortikoiden auf die Kompensation konnte im Tierexperiment nachgewiesen werden [79]. Glukokortikoide fördern nach bisherigen Erkenntnissen wahrscheinlich auch die Kompensation nach einseitiger Labyrinthläsion beim Menschen [15,57]. Auch Koffein und Amphetamine sollen ihn fördern $[66,78]$. Tierexperimentell ist eine negative Einwirkung von Alkohol, Diazepam und Phenobarbital gesichert [15].

Scherer unterscheidet fünf Kompensationsstadien nach akuter einseitiger vestibulärer Läsion [14]. Der Prozess der Kompensation kann sehr schnell erfolgen und schon nach mehreren Wochen abgeschlossen sein, unter Umständen jedoch auch Monate bis Jahre in Anspruch nehmen und auf der Stufe einer inkompletten Kompensation (Teilkompensation) verharren. Die Ursachen für eine inkomplette Kompensation im erwarteten Zeitumfang sind bisher nicht vollständig geklärt. So ist bei Patienten mit kombinierten Erkrankungen des Gleichgewichtssystems, beispielsweise simultanen labyrinthären, zentralnervösen und okulären Funktionsstörungen aber auch unter dem Einfluss von Alkohol, eine verzögerte und unvollständige Kompensation zu beobachten [80,81]. Auch die Halswirbelsäule muss als „Störfaktor“ in Betracht gezogen werden. Einflüsse dieser Art werden in einem weiteren Referat dieses Bandes behandelt. Beim Vorliegen einer unvollständigen Kompensation und dem Verdacht auf multitope Störungen muss eine interdisziplinäre Schwindeldiagnostik erfolgen, um Reserven für weitere Therapieformen zu ergründen. Sonst ist gegebenenfalls über die von Stoll entwickelten Kriterien zur Begutachtung eine weitere Rehabilitation, z. B. eine berufliche Umorientierung, erforderlich [82 - 84]. Für die Abschätzung der vestibulären Kompensationsleistung, z.B. nach unilateralen Vestibularisstörungen gibt es eine Reihe diagnostischer Möglichkeiten. Wir benutzen die frequenzselektive Drehpendelprüfung mit Frequenzen von 0,01 bis $0,16 \mathrm{~Hz}$ [85]. Diese ermöglicht eine Objektivierung von Beeinträchtigungen des vestibulookulären Reflexes, da der Test eine starke Ähnlichkeit zu täglichen Bewegungsmustern aufweist [86]. Posturographische und stabilometrische Verfahren werden hierfür ebenfalls empfohlen.

\section{$4 \quad$ Benigner paroxysmaler Lagerungsschwindel}

\subsection{Ursachen}

Otolithen bestehen aus Kalziumkarbonatkristallen, die in eine Proteinmatrix eingebettet sind. Sie haben eine charakteristische Form und Größe. Die Faktoren, welche diesen Partikeln ihre Form geben und ihre Größe kontrollieren, waren bisher nicht bekannt. Kürzlich konnte ein neues Gen im Zebrafisch entdeckt und charakterisiert werden, das für die Bildung der Otolithen bei Fischen nötig ist. Das Genprodukt Starmaker wurde als Bestandteil der organischen Proteinmatrix der Otolithen identifiziert. Es konnte nachgewiesen werden, dass Gestaltveränderungen der Otolithen durch das schrittweise Herunterregulieren der Aktivität des Starmaker-Gens zustande kommen. Diese morphologischen Veränderungen der Otolithen (von der Kugel- zur
Sternform) werden durch eine Veränderung der Gitterstruktur der Otolithen hervorgerufen. Eine Verringerung der StarmakerKonzentration führte auch zu einem verstärkt unkontrollierten Wachstum von Kalziumkarbonatkristallen [87].

Anderen tierexperimentellen Studien zufolge sollen Wachstum und Anzahl der Otokonien etwa zur Geburt abgeschlossen sein. Danach werden offenbar keine neuen Otolithen gebildet [88]. Im Laufe der Zeit, vor allem im mittleren und höheren Alter, soll deren Zahl insbesondere im Sacculus abnehmen [89]. Die vestibulären dunklen Zellen, die auch für die Endolymphproduktion verantwortlich sind, können offenbar frei werdende Kalziumionen aufnehmen. Daher wird vermutet, dass diese in die Resorption degenerierter Otolithen eingebunden sind [90]. Der Nachweis eines Kalziumturnover lässt einen dynamischen Prozess vermuten, der für die Regeneration der Otolithen jedoch auch deren Degeneration eine Rolle spielen könnte. Die Fähigkeit der Otolithen zur Aufnahme von Kalziumionen nimmt mit zunehmendem Alter ab [91,92]. Eine Spontanheilung beim benignen paroxysmalen Lagerungsschwindel ist wohl häufiger als vermutet, was wir aufgrund eigener Beobachtungen bestätigen können [93]. Etwa ein Drittel aller Personen über 70 Jahre haben eine solche Symptomatik einmal oder mehrfach erlebt [15]. Die Fähigkeit der Endolymphe, degenerierte Otokonien auflösen zu können, ist möglicherweise als Erklärung geeignet [94]. Gegenwärtig kann man pharmakologisch noch nicht in diese unvollständig aufgeklärten Stoffwechselprozesse der Otolithen eingreifen.

Lindsay und Hemenway berichten über mehrere Patienten, bei denen die Symptomatik eines gutartigen Lagerungsschwindels meistens auf der Seite der primären Läsion in einem unmittelbaren zeitlichen Zusammenhang von mehreren Tagen bis mehreren Monaten nach einem akuten isolierten Vestibularisausfall aufgetreten ist. Die Erkrankung wird heutzutage auch als Lindsay-Hemenway-Syndrom bezeichnet $[95,96]$. Wir beobachten die spontan reversible und daher meist nicht behandlungsbedürftige Symptomatik eines gutartigen Lagerungsschwindels manchmal etwa zehn Tage nach dem Akutereignis eines akuten Vestibularisausfalls. Ob es sich dabei um eine entzündlich, gar viral verursachte Symptomatik handelt, bleibt bisher ungeklärt.

Die intraoperative Beobachtung von Partikeln im hinteren Bogengang („free-floting particles“) gelang Parnes und McClure sowie Welling während Okklusionsoperationen des hinteren Bogengangs („canal plugging“), was die bis dahin existierenden Vorstellungen über die Pathogenese des Krankheitsbildes erweiterte und bestätigte $[97,98]$. Eine kernspintomographische Visualisierung im Endolymphschlauch oder auf der Cupula während einer Schwindelattacke gelang jedoch bisher noch nicht.

\subsection{Symptomatik und Varianten}

Pathophysiologische Grundlage der Erkrankung ist das dystope Vorkommen von Otolithen in einem oder mehreren Bogengängen. Die Otolithenpartikel können durch Anpralltraumen des Kopfes, eine Degeneration oder auch im Rahmen von Innenohrerkrankungen in die Bogengänge gelangen. Patienten mit einem gutartigen Lagerungsschwindel erleben die Schwindelattacken häufig in der Nacht beim Drehen und Umlagern im Bett, nach schnellem Hinlegen oder Aufstehen mit Kopfbewegungen [99]. Sie berichten über einen ausgeprägten, „bedrohlichen“ Dreh- 
schwindel, mit an- und abschwellendem Charakter, der in der Regel nicht länger als eine Minute anhält.

Es werden mehrere Varianten des gutartigen Lagerungsschwindels unterschieden, je nachdem, welcher Bogengang frei flottierende Otolithenfragmente auf welcher Seite enthält. Am weitaus häufigsten ist in der klinischen Praxis die isolierte Beteiligung des hinteren Bogengangs anzutreffen (ca.90\%), da dieser mit seinem kaudalen Schenkel den tiefsten Punkt aller Bogengänge markiert. Entsprechend der Schwerkraft können die Partikel aus dem Utriculus sehr leicht dort hineingelangen.

Seltener ist die Beteiligung des lateralen Bogengangs (5-10\%) $[93,100]$. Obwohl einige Autoren die Existenz eines Lagerungsschwindels des vorderen Bogengangs als nicht überzeugend beschrieben ansehen [101], gibt es Fallbeschreibungen in der Literatur. In einer Untersuchung von 122 Patienten mit einem gutartigen Lagerungsschwindel wurden bei 110 der hintere Bogengang, bei zehn Patienten der horizontale als Ort der Otokonienablagerung und bei nur zwei Erkrankten die Variante des vorderen Bogengangs diagnostiziert [102,103].

Neben einseitigen kommen aber auch beiderseitige Varianten des Lagerungsschwindels eines Bogengangs (besonders nach Kopfanpralltraumen) vor. Auch kombinierte Formen zweier unterschiedlicher Bogengänge (nach Behandlung, bei der Otolithen auf einer Seite vom hinteren in den lateralen Bogengang oder umgekehrt bewegt wurden) sind in der Praxis möglich, jedoch selten $[93,104]$. Die Diagnostik bereitet dann oft Schwierigkeiten. Man sollte jedoch daran denken. Ist die Nystagmusreaktion nicht typisch, liegen atypische Varianten eines Lagerungsschwindels vor, die mit dem benignen paroxysmalen Lagerungsschwindel verwechselt werden können [99,105 -107].

\subsection{Diagnostik}

Zur genauen Überprüfung und Lokalisation des klassischen gutartigen Lagerungsschwindels des hinteren Bogengangs ist eine Lagerungsprüfung nach Hallpike mit Verwendung einer FrenzelBrille (abgedunkelter Raum) erforderlich. Bei der einseitigen Variante des hinteren Bogengangs ist typischerweise nach einer Latenz von wenigen Sekunden ein zum unten liegenden Ohr (geotroper) bzw. zur betroffenen Seite schlagender, torsionaler Nystagmus zu sehen, der nicht länger als eine Minute andauert. Die begleitende Schwindelempfindung weist ein crescendo-decrescendo auf. Die Richtung des Nystagmus kehrt sich nach dem Wiederaufrichten um (ageotroper Nystagmus). Der Lagerungswechsel sollte sehr zügig erfolgen. Ein abruptes Abbremsen des Kopfes erhöht die Wahrscheinlichkeit, einen Nystagmus zu sichern, aber auch die Intensität des Schwindels. Ein falsches Hallpike-Lagerungsmanöver (fehlende oder mangelnde Kopfdrehung vor der Lagerung) kann eine beiderseitige Variante der hinteren Bogengänge vortäuschen [108]. Die Auslösbarkeit eines Lagerungsnystagmus ist bei der Variante des hinteren Bogengangs nach wiederholter Provokation erschöpflich (Habituation) und erst nach mehreren Stunden wieder reproduzierbar. Aus diesem Grund muss bei einer positiven Anamnese auch bei zunächst fehlendem Nachweis eines Lagerungsnystagmus der Verdacht bestehen bleiben. Die Ermüdung des Nystagmus kann dazu führen, dass beispielsweise bei kurz zuvor erlittenen, mehrfachen Schwindelattacken bei der Diagnostik kein Nystagmus mehr nachweisbar ist [99]. Die Diagnostik des benignen paroxysmalen Lagerungsschwindels muss vor allen anderen diagnostischen Methoden der Vestibularisprüfung durchgeführt werden. Dadurch werden Habituationseffekte vermieden [99,108]. Da die Beschwerden auf der betroffenen Seite meist ausgeprägter sind, lässt sich diese nicht selten auch explorativ ermitteln. Auf der vermuteten Seite sollte dann auch die erste Hallpike-Lagerungsprüfung durchgeführt werden [99].

Auch der gutartige Lagerungsschwindel bei Beteiligung des vorderen Bogengangs kann mit dem Hallpike-Lagerungsmanöver diagnostiziert werden. Es zeigt sich im Vergleich zum hinteren Bogengang eine inverse Symptomatik. Die vertikale Komponente des Nystagmus schlägt nicht geotrop sondern entgegengesetzt (ageotrop). Das oben liegende Ohr ist dann betroffen.

Der seltene gutartige Lagerungsschwindel mit Beteiligung des lateralen Bogengangs weist einige Besonderheiten auf. Die Beschwerden werden durch Kopfdrehung um die Körperlängsachse im Liegen provoziert. Er wird beim auf dem Rücken liegenden Patienten diagnostiziert, indem eine schnelle Drehung von Kopf und Körper um die Längsachse des Körpers (ca. 90 Grad) in Richtung der vermuteten Seite der Läsion erfolgt. Befinden sich die Partikel im Endolymphkanal des lateralen Bogengangs (Kanalolithiasis), so zeigt sich ein rein horizontaler Nystagmus, der in Richtung des betroffenen Ohres schlägt. Die Intensität der Attacken ist ausgeprägter und die Latenz kürzer als bei der Variante des hinteren Bogengangs. Zudem zeigt sich eine fehlende oder eingeschränkte Tendenz zur Ermüdung. Besteht der Verdacht auf eine Variante des hinteren Bogengangs, sollten diese immer vor den lateralen Bogengängen geprüft werden [93,99,100,108]. Befinden sich die Otokonien direkt auf der Cupula (Kupulolithiasis) und nicht frei im Endolymphschlauch, dann präsentiert sich dem Untersucher ein ageotroper Nystagmus auf der geprüften Seite der Läsion. Richtungsweisend ist immer die größte Intensität des Nystagmus (und des Schwindels) auf der Seite der Schädigung. Eine rechte Kupulolithiasis (geotroper Nystagmus) und eine linke Kanalolithiasis (ageotroper Nystagmus) im lateralen Bogengang würden also zu einer maximalen Nystagmusintensität auf der linken Seite führen. Offenbar handelt es sich dabei um Teilchenkonglomerate (Canalith jam). Kleine Partikel sollen den Bogengang bereits bei Kopfbewegungen verlassen. Die größere Intensität des Nystagmus bei dieser Form ist am ehesten auf die größere Empfindlichkeit und Verstärkung des horizontalen vestibulookulären Reflexes zurückzuführen [108,109].

In der Praxis sollen neben Kanalolithiasis und Kupulolithiasis auch der so genannte „Otolithenstau“ bzw. die Blockade des Kanals oder der Cupula (canalith jam) vorkommen (Abb. 4). Diagnostik und Therapie sind von Epley detailliert beschrieben worden [110].

\subsection{Physikalische Therapie}

Für alle Varianten des benignen paroxysmalen Lagerungsschwindels wurden physikalische Therapieverfahren, so genannte „Manöver“ entwickelt. Ziel aller Behandlungsmethoden ist eine Rückführung der „verloren gegangenen“ Teilchen aus den Bogengängen in den Utriculus. Dabei werden Beschleunigungskräfte angewendet und die Gravitation ausgenutzt. 


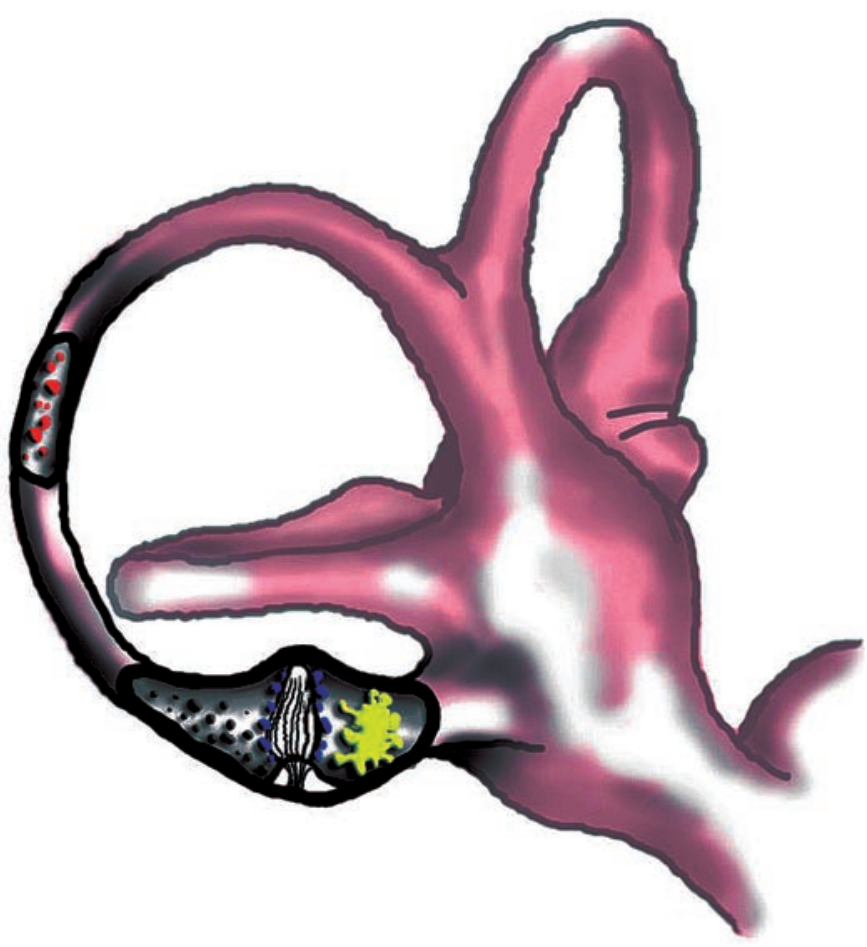

Abb. 4 Kanalolithiasis (rot und grau dargestellte Partikel), Kupulolithiasis (blaue Partikel) und „Canalith jam“ (gelbe Partikelmasse) im Bereich des hinteren Bogenganges.

Ist der hintere Bogengang betroffen, kann das Semont- oder Epley-Manöver angewendet werden [111,112]. Beim Semont-Manöver („Befreiungsmanöver“) bedient man sich vorwiegend Beschleunigungskräften (schnelle, abrupte passive Kopf- und Körperbewegungen) als auch der Schwerkraft („Befreiungsmanöver“). Das Epley-Manöver ist ein „Repositionsmanöver“, bei dem die Otolithenpartikel vorwiegend unter dem Einfluss der Schwerkraft aus den Bogengängen „ausgeschüttet“ werden. Beschleunigungskräfte werden bei dieser Methode nur bedingt angewendet. In der überwiegenden Mehrzahl der Fälle ist mit beiden Techniken eine schnelle und für den Patienten eindrucksvolle Therapie möglich. Ausgeprägte vegetative Reaktionen können die Diagnostik und das therapeutische Vorgehen in Einzelfällen erschweren und verzögern. Wir bevorzugen das Epley-Manöver (Abb. 5).

Das Semont-Manöver wird in folgenden Schritten durchgeführt:

1. Schritt: Patient sitzt aufrecht vor dem Arzt auf einer Untersuchungsliege, Kopfdrehung um ca. 45 Grad zur gesunden Seite, das betroffene (erkrankte) Ohr zeigt zum Untersucher. Der Kopf wird vom Therapeuten gehalten.

2. Schritt: abrupte Seitwärtslagerung zur erkrankten Seite. Der Kopf des Patienten, der immer noch in den Händen des Arztes liegt, sollte okzipital aufliegen, optimalerweise über das Ende einer Untersuchungsliege (105 Grad) reichen. Nach einer Latenz tritt ein Nystagmus (wie beim Hallpike-Lagerungstest) auf, die zum untenliegenden Ohr schlägt. Verweildauer ca. 3 Minuten

3. Schritt: Zügige Seitwärtslagerung (195 Grad) zur anderen Seite. Der Nystagmus schlägt entgegengesetzt (zum oben liegenden Ohr). Verweildauer ca. 3 Minuten.

4. Schritt: Schnelles Aufsetzen in die Ausgangslage, Verweildauer bis zum Abklingen von Schwindel.
Die Erfolgsrate dieser Behandlungsmethoden ist sehr hoch. Nur wenige Patienten müssen mehr als zweimal behandelt werden. Rezidive kommen vor. In der Praxis trifft man extrem selten auch auf therapieresistente Fälle, bei denen dann eine chirurgische Behandlung erfolgen kann. Kontroverse Ansichten gibt es darüber, ob ein Kopfschütteln oder Oszillationen, die Epley in seiner Erstbeschreibung benutzte, die Erfolgsquote verbessern helfen $[113,114]$. Der Therapieerfolg sollte nach einigen Tagen mittels Hallpike-Manöver geprüft werden.

Als Ersttherapie ist das Brandt-Daroff-Manöver ideal [115]. Die Autoren erzielten damit nach 14-tägiger Therapie bei über $90 \%$ der Patienten eine Heilung.

Für die physikalische Behandlung des gutartigen Lagerungsschwindels des vorderen Bogengangs kann das Semont- oder Epley-Manöver modifiziert angewendet werden.

Die Behandlung der Kanalo- oder Kupulolithiasis des lateralen Bogengangs kann mit unterschiedlichen Lagerungstechniken erfolgen [116,117]. Etwas umständlich durchzuführen ist das so genannte prolongierte Lagerungsmanöver nach Vannucchi. Der Patient liegt dabei 12 Stunden auf dem gesunden Ohr. In mehr als 90\% konnte damit ein Behandlungserfolg verzeichnet werden. Allerdings ist in Einzelfällen auch eine Konversion in eine Variante mit Beteiligung des hinteren Bogengangs beschrieben [116]. Eine weitere Prozedur ist die von Epley erwähnte walzenartige Drehung um die Körperlängsachse (360 Grad). Der Patient wird dabei in 90 Grad-Schritten vom beeinträchtigten $\mathrm{Ohr}$,weggerollt" [110]. Auch diese Methoden bedienen sich der Einwirkung der Schwerkraft („Repositionsmanöver“).

Bemerkenswert ist, dass viele Patienten nach erfolgreichem Lagerungsmanöver für mehrere Stunden oder Tage eine Schwindelempfindung wahrnehmen, die einem Otolithenschwindel ähnelt und von dem beim Lagerungsschwindel empfundenen deutlich unterschieden werden kann. Eine antivertiginöse Therapie lindert die Beschwerden aus empirischer Sicht [99].

Die Behandlung eines gutartigen Lagerungsschwindels mit den Repositions- und Befreiungs- Manövern kann ausschließlich ambulant durchgeführt werden. Es handelt sich um eine sehr effiziente neurootologische Therapieform. Nach dem Therapieerfolg ist die Veranlassung einer weiteren Diagnostik nicht sinnvoll. Instruktionen, wie das Schlafen mit erhöhtem Kopf nach der Behandlung beeinflussen den Behandlungserfolg nicht [118].

\subsection{Chirurgische Therapie}

Die operative Therapie des gutartigen Lagerungsschwindels ist sehr selten indiziert und therapieresistenten Fällen vorbehalten $[99,119]$. Sie sollte erst durchgeführt werden, wenn die physiotherapeutische Rehabilitation erfolglos war, wenn andere, seltene Formen eines gutartigen Lagerungsschwindels ausgeschlossen worden sind und differenzialdiagnostisch keine andere Erkrankung infrage kommt. Eine bildgebende Diagnostik ist im Vorfeld ggf. erforderlich, um zentrale Störungen (Tumoren) auszuschließen [99,120]. Zu den seltenen Differenzialdiagnosen zählt z.B. auch die Vestibularisparoxysmie. 

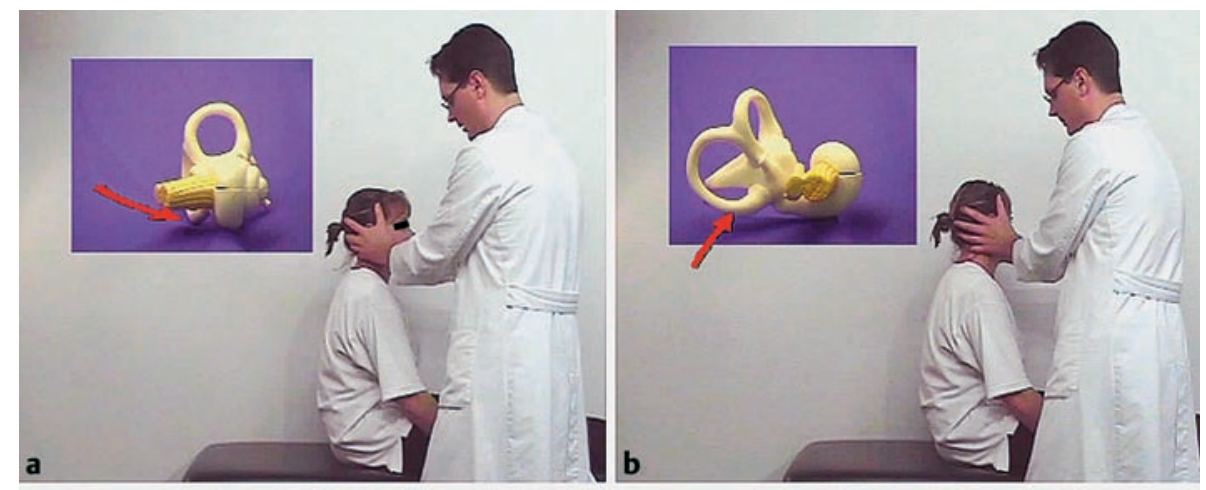

Abb. 5 Epley-Repositionsmanöver. Sequenzen der physikalischen Therapie für den linken hinteren Bogengang (roter Pfeil).
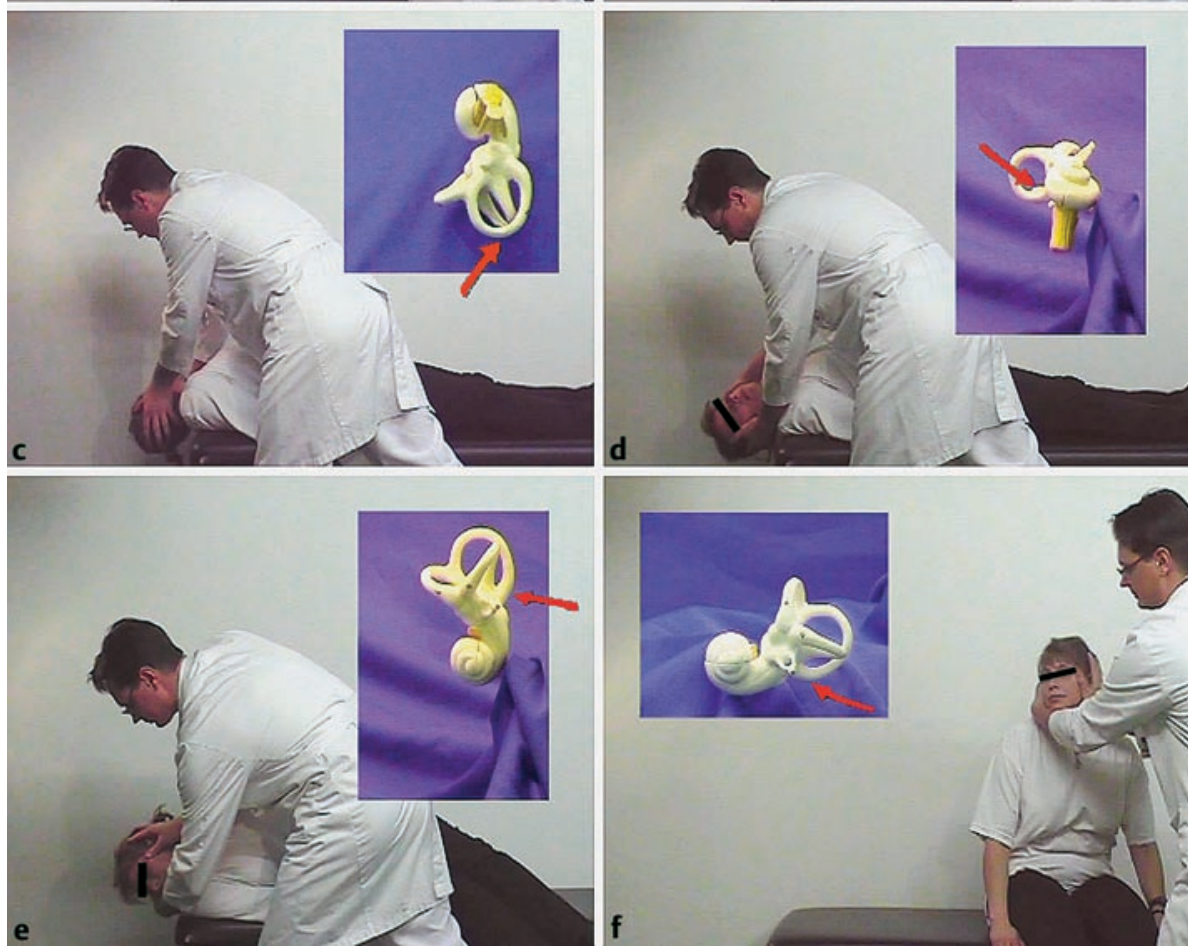

Die Neurektomie des Nervus singularis soll ein effektives chirurgisches Therapieverfahren zur selektiven Ausschaltung der Funktion des hinteren Bogengangs darstellen [121,122]. Der aus dem Nervus vestibularis inferior hervorgehende Nerv kann transtympanal am Unterrand der runden Fensternische dargestellt und durchtrennt werden [119]. Anatomischen Beschreibungen zufolge ist der Nervus singularis ein von der Crista ampullaris posterior entspringender akzessorischer Nerv, der durch einen eigenen Knochenkanal zieht und sich ein bis zwei Millimeter nach der Vereinigung des Nervus saccularis inferior mit dem Nervus ampullaris posterior dem Nervus sacculoampullaris anschließt. Die Nervenzellen liegen im Ganglion vestibulare inferior $[24,120]$. Eine vollständige sensorische Ausschaltung würde auch eine Durchschneidung des Nervus ampullaris posterior erfordern. Untersuchungen an Felsenbeinpräparaten zeigten, dass der Nervus singularis, wenn er transtympanal für eine Neurektomie aufgesucht wird, aber nur in einem Fünftel der Fälle im Bereich des Unterrandes des runden Fensters gut erreichbar ist [124]. Daher ist ein Aufbohren der runden Fensternische hin und wieder erforderlich. Das Verfahren kann auch laserchirurgisch (Argon-Laser) durchgeführt werden, indem der Nerv koaguliert wird [125]. Bis heute hat es jedoch keine weite Verbreitung erlangt. Ein entscheidender Nachteil dieser Methode ist, dass eine Verschlechterung des Hörvermögens eintreten kann
[126]. Daher sind dieser Methode Okklusionsoperationen vorgezogen worden. Eine Okklusion des hinteren Bogengangs kann ebenfalls sowohl konventionell chirurgisch als auch laserchirurgisch durchgeführt werden $[93,127,128]$. Das Konzept der Okklusionsoperation des hinteren Bogengangs wurde von Parnes und McClure entwickelt [128 - 130]. Danach wird der hintere Bogengang nach Durchführung einer Mastoidektomie gefenstert und das Lumen mit Knochenmehl und Fibrinkleber verschlossen. So wird eine Obliteration des Endolymphschlauches und eine „Fixierung“ der Cupula erreicht. Strutz und Menke haben tierexperimentell unterschiedliche Materialien für den Bogengangsverschluss untersucht. Teflon und Titan erwiesen sich als optimal und führten zu einer starken Induktion von Bindegewebe und Knochengewebe innerhalb des Bogengangs [131]. Eine temporäre, vier- bis sechswöchige Periode mit Schwindelbeschwerden soll bei allen operierten Patienten vorkommen. Daher ist auch in diesen Fällen eine Trainingstherapie zur Förderung der Kompensation hilfreich. Mögliche Komplikationen sind die Entwicklung einer temporären oder permanenten Hörminderung, einer Perilymphfistel sowie einer Labyrinthitis [127,132]. Die geringe Komplikationsrate und hohe Erfolgsrate dieser unseres Erachtens selten indizierten Operationsmethode wird in anderen Studien bestätigt [132]. Sie ist demzufolge einer Neurektomie des Nervus singularis vorzuziehen. Auch eine beiderseitige Ok- 
klusion der hinteren Bogengänge und ein Plugging des vorderen Bogengangs sind im Schrifttum erwähnt [127,133].

Die Methode der laserchirurgischen Okklusion des hinteren Bogengangs schnitt in einer Studie beim Vergleich mit den Ergebnissen der konventionell-chirurgischen Okklusion des hinteren Bogengangs sogar besser ab [134]. Das Verfahren geht auf Studien von Wilpizeski und Anthony zurück $[135,136]$. Sowohl Argon- und $\mathrm{CO}_{2}$-Lasersysteme sind für die Koagulation des Endolymphschlauches geeignet $[137,138]$. Nach der Argon-Laserkoagulation des Endolymphschlauches ist eine Fibrosierung und spätere Verknöcherung des Lumens des Bogengangs histologisch gesichert worden [137]. Auch die Makulaektomie des Utriculus (selektive Laser-Labyrinthektomie) wird in der Literatur für die Behandlung des gutartigen Lagerungsschwindels erwähnt [138].

Die Erkrankung des benignen paroxysmalen Lagerungsschwindels kann selten auch im Kindesalter zwischen dem ersten und vierten Lebensjahr vorkommen [139]. Als Ursache wird auch eine Form der Migräne (ohne Kopfschmerzen) diskutiert [140 - 142]. Hamann beobachtete Schwindelzustände im Kindesalter, die er aber eindeutig als benignen paroxysmalen Lagerungsschwindel von migräneassoziierten Schwindelbeschwerden abgrenzen konnte [143].

\subsection{Fakten der evidenzbasierten Medizin}

Eine Recherche in den Quellen der evidenzbasierten Medizin ergab für den gutartigen Lagerungsschwindel wenige, jedoch interessante Fakten.

Die Diagnose „benigner paroxysmaler Lagerungsschwindel“ ist heutzutage eine exakt definierte Erkrankung mit klar definierten klinischen Testmethoden und einfachen, schnellen Behandlungsverfahren, die in einer Zeit von weniger als fünf Minuten durchführbar sind. Die Diagnosestellung ist nur in Ausnahmefällen schwierig und anspruchsvoll. Die Bezeichnung „gutartig“ ist prinzipiell gerechtfertigt und impliziert einige wenige Ausnahmen, die sich sekundär nach der Diagnostik ergeben (so genannter maligner paroxysmaler Lagerungsschwindels bei zentralen Schädigungen, „pseudo-benigner paroxysmalen Lagerungsnystagmus“ bei Kleinhirnstörungen, Unterscheidung: in der Regel keine Habituation) [144-147]. Traumatische oder durch eine Labyrinthitis induzierte gutartige Varianten des Lagerungsschwindels haben eine schlechtere Prognose als die, welche im Zusammenhang mit einem Morbus Menière entstanden sind [148].

Nach einer Analyse aller Studien bis einschließlich Januar 2004 stellt das Epley-Manöver nach evidenzbasierten Kriterien eine sichere Behandlungsmethode dar [149]. Im Zeitraum bis zu drei Monaten nach Durchführung der Therapie, führte ein Repositionsmanöver bei Patienten, verglichen mit solchen, die nicht behandelt worden sind, zu einem signifikant besserem Befinden [150]. Unbehandelte Patienten zeigen im Vergleich zu bereits behandelten eine Symptomverbesserung, die jedoch auf der Vermeidung provokativer Körperpositionen beruhen soll. Bei vielen der unbehandelten Patienten zeigte sich aber auch noch nach Wochen ein positives Hallpike-Manöver [151].

Eine alleinige, schwindeldämpfende medikamentöse Behandlung des gutartigen Lagerungsschwindels wird als uneffektiv eingeschätzt und ist unserers Erachtens auch kontraindiziert. Die Selbstbehandlung (z.B. Brandt-Daroff-Manöver) wird von evidenzbasierten Quellen empfohlen [152]. Fehldiagnosen und falsche Therapiestrategien sowie eine uneffektive Behandlung des benignen paroxysmalen Lagerungsschwindels verursachten unnötige, hohe Kosten (entsprechend einer Studie in den USA im Jahre 2000 über \$2000) [153].

\section{$5 \quad$ Morbus Menière}

\subsection{Differenzialdiagnostik und Therapieansätze}

Die Auffassung, welche Erkrankung sich hinter der Bedeutung des Wortes „Morbus Menière“ verbirgt, hat sich in den letzten Jahrzehnten entscheidend gewandelt. Die Bezeichnungen „Morbus Menière“ oder „menièriforme Erkrankung“ stellten noch vor etwa 100 Jahren eine Sammelbezeichnung für Krankheiten mit der Symptomtrias Schwindelbeschwerden-Tinnitus-Hörstörung dar, die ätiologisch nicht eindeutig zuzuordnen waren. Im Laufe der Zeit trennte man mehrere Differenzialdiagnosen ab, die heute klar vom Morbus Menière abgegrenzt werden können. Auch heutzutage noch treten differenzialdiagnostische Schwierigkeiten auf, wenn anfallsartige Schwindelbeschwerden, Hörstörungen und Ohrgeräusche simultan vorkommen.

Anfallsweise auftretende Schwindelattacken sind Leitsymptom des Morbus Menière und stellen für den Patienten die größte Beeinträchtigung dar. Stoll beobachtete 15 Patienten über einen Zeitraum von 10 bis 15 Jahren und konnte anhand der Schwindelanfälle vier Verlaufsarten herausarbeiten:

- den regressiven Verlauf: Im Verlauf der Erkrankung werden Intensitäten und Häufigkeiten der Anfälle geringer (20\%),

- den wechselhaften Verlauf: Anfallshäufigkeit und Intensität wechseln in Intervallen (13\%),

- den progressiven Verlauf: monosymptomatischer Beginn, Zunahme der Anfallshäufigkeit, danach Übergang zu schnellem oder langsamem Typ 1 (27\%) und

- den pausenreichen Verlauf mit anfallsfreien Intervallen (40\%) [126].

Die klassische Trias war bei nur einem Fünftel der Fälle zu beobachten. Entsprechend der unterschiedlichen Verläufe wurde auf hohe Variabilität des Krankheitsbildes hingewiesen. Das stellt die nosologische Einheit der Erkrankung infrage. Es wurde deshalb vorgeschlagen, den Begriff „Morbus Menière“ durch die Bezeichnung „Menière-Syndrom“ zu ersetzen [154].

Problematisch für eine Therapieentscheidung ist der phasenhafte Verlauf und die Tatsache, dass eine prognostische Aussage über die weitere Entwicklung gerade im Frühstadium der Erkrankung schwer gemacht werden kann [155]. Prinzipiell besteht bei einer einseitigen Lokalisation auch die Gefahr der späteren Entwicklung einer bilateralen Erkrankung. Die Häufigkeit wird in der Literatur sehr variabel zwischen $2 \%$ und $47 \%$ [119] bzw. mit $15 \%$ bis $50 \%$ [156] angegeben.

Rezidivierende Tieftonhörverluste sind nur in wenigen Fällen (3,7\%, n= 27; fünf Jahre Nachbeobachtungszeit) erstes Zeichen eines Morbus Menière [157]. 
Immunologische Hypothesen über die Genese des Morbus Menière stellen einen Ansatz für eine Therapie mit Glukokortikoiden dar $[158,159]$. Der Saccus endolymphaticus ist als Bestandteil des MALT-Systems zu einer immunologischen Reaktion befähigt („Innenohrtonsille“) [159-161]. Auch vaskuläre Ursachen [162], eine virale Genese (Herpes simplex virus Typ 1) $[163,164]$ und hereditäre Faktoren werden diskutiert [165].

Kürzlich konnte ein drucksensitiver kalziumabhängiger Kaliumkanal in vestibulären Haarzellen nachgewiesen werden. Eine Änderung des hydrostatischen Drucks der Endolymphe, wie beim endolymphatischen Hydrops, soll zu einer Erhöhung des Kaliumausstroms und damit auch zu einer Erhöhung der Spikefrequenz des Nervus vestibularis der betroffenen Seite führen, was auch den Reiznystagmus im akuten Anfall erklärt. Durch die Modulation vorgeschalteter Kalziumeinwärtsströme wird die Stromdichte des drucksensitiven Kanals beeinflusst [166,167]. Möglichkeiten im Sinne einer Anfallstherapie ergeben sich ggf. zukünftig mit Kalziumkanalantagonisten, die für die Therapie von Schwindelbeschwerden und Gleichgewichtsstörungen zugelassen sind (z. B. Flunarizin, Cinnarizin) [168].

Die Differenzialdiagnostik des Morbus Menière wird gegenwärtig durch neue radiologische Methoden bereichert. Diese beeinflussen therapeutische Entscheidungen wesentlich $[169,170]$. So können heute seltene Störungen, wie beispielsweise eine neurovaskuläre Kompression im Kleinhirnbrückenwinkelbereich (Vestibularisparoxysmie) diagnostiziert werden [171].

Richtlinie für eine Diagnosestellung und Beurteilung im Rahmen von Studienergebnissen sollten die aktuellen Kriterien der American Academy of Otolaryngology - Head and Neck Surgery (AAO-HNS) sein [172].

\subsection{Medikamentöse Therapie}

Die medikamentöse Therapie des Morbus Menière umfasst die Therapie des Anfalls und die Anfallsprophylaxe [173,174]. Eine kausale Therapie wird derzeit noch erforscht.

Die Anfallstherapie kann mit einem Antivertiginosum (z.B. Dimenhydrinat, oral oder auch als Suppositorium) erfolgen. Falls anfallsartige Schwindelbeschwerden mit einer Aura vorliegen, besteht die Möglichkeit einer Selbstbehandlung.

Kalziumantagonisten blockieren den spannungsabhängigen Kalziumeinwärtskanal der vestibulären Haarzelle und verhindern damit wahrscheinlich den erhöhten Kaliumausstrom bei Repolarisation im akuten Anfall [175]. In der Praxis hat sich ein Kombinationspräparat (Cinnarizin $20 \mathrm{mg}$ mit Dimenhydrinat $40 \mathrm{mg}$ ) zur Behandlung eines Anfalls bewährt. Die fixe Kombination von Cinnarizin und Dimenhydrinat stellt nach evidenzbasierten Kriterien eine sichere und effektive Behandlungsform bei akuten Episoden des Morbus Menière dar [176].

Die Wirksamkeit des Betahistins (H1-Antihistaminikum) in der Prophylaxe weiterer Anfälle beruht auf dessen H1-Agonismus und einem H3-Antagonismus. H2-Rezeptoren gegenüber ist es nahezu inaktiv. Die Wirkung beruht auf einer Steigerung der Mikrozirkulation im Innenohr [177]. Auch Einflüsse auf zentrale vestibuläre Neuronen sind beschrieben [178]. Der positive Effekt von Betahistin auf die Frequenz der Schwindelanfälle und die Intensität des Schwindels beim Morbus Menière ist belegt. Allerdings wird die Qualität vieler Studien zu Recht kritisiert [179]. Von Vorteil ist die Tatsache, dass Betahistin ein geringes Nebenwirkungspotential hat und die vestibuläre Kompensation sogar fördern soll [180]. Für die Dauermedikation kann Betahistin in der von den Herstellern angegebenen Dosis $(3 \times 8 \mathrm{mg}$ bis $3 \times 16 \mathrm{mg}$ ) verordnet werden. Die Dosierung kann in begründeten Einzelfällen nach unseren Erfahrungen bei unbefriedigendem Therapieerfolg erhöht werden (Aufklärung des Patienten erforderlich, off label use, cave: Kontraindikation Asthma bronchiale). Brandt et al. empfehlen $3 \times 12 \mathrm{mg}$ bis $3 \times 24 \mathrm{mg}$ Betahistin über einen Zeitraum von 4 bis 12 Monaten. Beim Versagen dieser Maßnahmen kann ein Therapieversuch mit Diuretika (Hydrochlorothiazid und Triamteren) indiziert sein [15,181,182]. Hydrochlorothiazid und Triamteren haben allerdings nur einen nachgewiesenen positiven Einfluss auf das Symptom „Schwindel“, nicht aber auf die Hörminderung [181]. Tieftonschwerhörigkeiten mit einem erhöhten SP/AP-Quotienten sprechen nach Vollrath besser auf eine Dehydratationstherapie (Mannitol und Acetacolamid) an, als auf eine rheologische Behandlung. Unter Umständen ist auch nach erfolgloser vasoaktiver Therapie mit der Dehydratation noch eine Hörschwellenverbesserung zu erreichen [183].

Der dehydrierende Effekt, der beim Klockhoff-Test mit Glycerol eintritt, zeigt vor allem eine positive Auswirkung auf das Hörvermögen. Acetacolamid kann als Monopräparat verabreicht werden $(20-25 \mathrm{mg} / \mathrm{d})$ [182]. Kortikosteroide werden mit dem Hintergrund der immunologischen Genese des Morbus Menière angewendet. Unterschiedliche Schemata der Verabreichung in absteigender Dosierung, meist in Kombination mit anderen Medikamenten, stehen zur Verfügung $[184,185]$. Niedermeyer et al. empfehlen im Ergebnis einer Analyse des Kortisolspiegels in der Perilymphe die intravenöse Applikation von $250 \mathrm{mg}$ Prednisolon bei Innenohrstörungen, so auch beim Morbus Menière [186].

Vasoaktive Substanzen sollen zur Verbesserung der cochleären Mikrozirkulation beitragen [182]. Diätetische Maßnahmen (Salzrestriktion, Meidung von Koffein) können im Einzelfall zu einer Besserung führen.

\subsection{Intratympanale Applikation von Medikamenten 5.3.1 Aminoglykosidtherapie}

Schwindelbeschwerden und vor allem auch Hörstörungen wurden unmittelbar nach der Entwicklung des Streptomycins im Jahre 1944 als sehr störende und unerwünschte Nebenwirkungen bei der Tuberkulosebehandlung beschrieben [187]. Die Idee, die unerwünschten Nebenwirkungen diese Aminoglykosidtherapie therapeutisch nutzbar zu machen, reifte nach dem objektiven Nachweis, dass dieses Antibiotikum in der Lage ist, eine strukturelle Labyrinthfunktionsstörung zu verursachen [188, 189]. Fowler benutzte 1948 erstmals Streptomycin, das er systemisch verabreichte, um Schwindelbeschwerden und Gleichgewichtsstörungen zu behandeln [190]. Im Jahre 1956 verwendete es Schuknecht zur Behandlung des Morbus Menière. Er applizierte das Antibiotikum aber nicht intravenös sondern zweimal täglich intramuskulär. Ein Jahr später beschrieb Schuknecht dann erstmals die intratympanale Anwendung von Streptomycinsulfat [191,192]. Beide, die intravenöse und die intratympanale Anwen- 
dung führten jedoch nicht zu einer gewünschten selektiven Vestibulotoxizität. Erst das 1963 entwickelte Gentamicin erwies sich als weniger cochleotoxisch [193]. Auch die folgenden Aminoglykoside Amicain und Netilmicin hatten ein geringeres ototoxisches Potenzial [194]. Holz et al. konnten 1966 tierexperimentell nachweisen, dass bei der Streptomycingabe mit der simultanen Gabe von Ozothin ein Schutz der cochleären Haarzellen möglich ist [195]. Lange hat zwei Jahre später über eine selektive medikamentöse Ausschaltung des Gleichgewichtsorganes mit Streptomycin in Kombination mit Ozothin berichtet [196]. Die intratympanale Gabe von Gentamicin wurde 1976 erstmals von Lange publiziert, von ihm weiterentwickelt und von mehreren Autoren modifiziert [197-202]. Gentamicin kann durch unterschiedliche Techniken in die Pauke appliziert werden. Katzke (1982) verwendete ein Paukenröhrchen und drückte das Gentamicin mit einem Politzerballon langsam vom Gehörgang aus in die Pauke [203]. Auch die Einlage von Schläuchen in das Mittelohr und die Applikation mit Hilfe von Infusionspumpen ist beschrieben [202,204,205]. Die Dauer des Kontaktes des Medikamentes mit den semipermeablen Mittelohrmembranen ist bei dieser Art der transtympanalen Verabreichung unbekannt. Daher wird auch über den Verschluss der runden Nische mit einem Bindegewebspfropf vor Gentamicingabe berichtet [206,207]. Damit wird die Diffusion in die Innenohrflüssigkeiten verzögert. In letzter Zeit ist über assistierte Mikrodosierungen mit Mikrokathetern publiziert worden, die direkt in die Rundfensternische platziert werden können [208]. Jede Kathetereinlage oder andere Manipulation kann aber auch zu einer Schwellung der Mittelohrschleimhaut und zur Bildung von Granulationsgewebe im Mittelohr führen. Vor allem der zusätzliche Eingriff einer Tympanotomie soll nachteilig sein. Damit wird der Übertritt des Antibiotikums in das Innenohr nicht mehr berechenbar. Lange bevorzugt daher für die Applikation die auf Tjell zurückgehende Technik einer atraumatischen einfachen Paukenpunktion im vorderen oberen Quadranten des Trommelfells. Während der Behandlung (in Rückenlage) wird der Kopf um 45 Grad zur gesunden Seite gedreht, umso eine maximale Anreicherung im Bereich der Innenohrfenster zu erreichen [209-211].

Gentamicin gelangt durch Diffusion über die Membranen der Pauke in die Innenohrflüssigkeiten, hauptsächlich über das runde Fenster. Vermutlich spielen beim Transport auch Gefäßverbindungen zwischen Mittelohrschleimhaut und Labyrinth eine Rolle. Da Aminoglykoside sehr gut wasserlöslich sind, reichern sie sich in den Innenohrflüssigkeiten an und verteilen sich dort. Ein weiterer Vorteil ist, dass sie die Blut-Hirn-Schranke nicht passieren können. Ort der Schädigung sind die dunklen vestibulären Zellen, welche vermutlich für die Endolymphproduktion verantwortlich sind [212-215].

Das zum Innenohrschutz verabreichte Ozothinöl wurde in der Regel ca. 30 Minuten vor der Aminoglykosidgabe verabreicht. Zusätzlich sollen neurotrope Vitamine, vasoaktive Substanzen und Spurenelemente (Magnesium und Zink) einem cochleären Haarzellschaden vorbeugen. Neben Magnesium zählt auch Kalzium zu den effektiven Kompetitoren der Aminoglykoside [194, 209].

Akute Cochleaschäden können in Gegenwart von Kalzium in geringen Dosierungen zu Beginn der Applikation durch elektrostatische Bindung der Aminoglykoside an die äußere Haarzelle re- versibel sein [212 - 214]. Bei höheren, toxischen Dosen treten irreversible Schädigungen der äußeren Haarzelle auf. Diese beruhen auf einer selektiven hohen Bindungsaffinität des Gentamicin für PIP2 (Phosphatidylinositbiphosphat) [216]. Entscheidend ist es daher, in welcher zeitlichen Abfolge die Applikation des Gentamicin zur Rehabilitation des Anfallschwindels erfolgt. Weiterhin sind der Ort und die applizierte Dosis von Bedeutung, um eine irreversible Cochleaschädigung durch Kumulation oder Überdosierung des Medikaments zu vermeiden. Dabei muss auch beachtet werden, dass das Medikament renal eliminiert wird [194]. Bis heute lassen sich fünf Arten der intratympanalen Verabreichung unterscheiden [217]:

- die mehrfache tägliche Applikation (drei Dosen täglich für 4 Tage oder mehr) [218],

- eine wöchentliche Applikation (maximal vier Dosen wöchentlich) $[219,220]$,

- die niedrig dosierte Verabreichung (eine bis zwei Gaben, nur bei Anfällen erneut) [221],

- eine kontinuierliche, mikrokatheterassistierte Verabreichung $[208,222,223]$ und

- die titrierte Applikation (tägliche oder wöchentlichen Gabe bis zum Einsetzen von Spontannystagmus bzw. Schwindelbeschwerden oder Hörstörungen) [224].

Magnusson et al. konnten 1991 nachweisen, dass der ototoxische Effekt um Monate verspätet einsetzt. Sie applizierten an zwei aufeinanderfolgenden Tagen und setzten die Behandlung dann aus. Alle Patienten entwickelten Schwindelbeschwerden innerhalb von drei bis fünf Tagen, ohne dass Hörstörungen auftraten [225]. Ödkvist u. Mitarb. empfehlen eine Stufentherapie. Nach zwei Dosen an zwei aufeinander folgenden Tagen wurde vier Wochen pausiert, wenn die ototoxischen Effekte innerhalb von zehn bis vierzehn Tagen eintraten. Eine weitere Applikation wurde erst dann und nur bei persistierenden Schwindelbeschwerden empfohlen, auch wenn die thermische Erregbarkeit noch vorhanden war [226]. Lange et al. berichteten kürzlich über eine intratympanale Intervalltherapie, bei der unter Verwendung niedriger Gentamicindosen nicht mehr mit Hörverlusten gerechnet werden muss (titrierte Gabe). Am ersten Tag wurden 0,3 ml Gentamicinsulfat intratympanal appliziert. Am achten Tag wurde die Injektion wiederholt, wenn noch keine Reaktionen (Nystagmus oder Schwindelbeschwerden) auftraten. Bei subjektiven („Heilschwindel“) und objektiven vestibulären Symptomen (Nystagmus) ist nicht weiter behandelt worden. Waren am 15. Tag noch keine Innenohrsymptome vorhanden (etwa ein Viertel der Patienten), ist letztmalig behandelt und anschließend für mindestens zwei bis drei Monate bis zu einer erneuten Therapie abgewartet worden. Nach Lange kann die Indikation beim Morbus Menière heute großzügiger gestellt werden. Eine Behandlung in frühen Stadien der Erkrankung ist möglich [227,228]. Die Autoren würden nicht zögern, nach erfolgreicher einseitiger Therapie auch die Gegenseite zu behandeln [227,228]. Es stellt sich allerdings die Frage, ob mit der Induktion einer bilateralen Vestibulopathie für den betroffenen Patienten eine Verbesserung der Lebensqualität verbunden ist.

Es ist ratsam, bei Unsicherheiten über den Intoxikationsgrad des Innenohres eine Therapiepause einzulegen und eine entsprechende audiologische und Vestibularisdiagnostik vorzunehmen. Die Therapie muss am Erhalt eines rehabilitationsfähigen Gehörs 
ausgerichtet sein $[227,228]$. Der Verlust der thermischen Erregbarkeit ist für den Therapieerfolg nicht notwendig. Anfallsfreiheit kann durchaus auch bei noch nachweisbarer thermischer Erregbarkeit eintreten [227-231].

Beim Vorliegen eines beiderseitigen Morbus Menière befürworten Jahnke und Arweiler die intravenöse Gabe dann, wenn episodische Schwindelbeschwerden mit einem pancochleären Hörverlust von mehr als 40-50 dB einhergeht, eine konservative Therapie nicht effektiv ist und eine Saccotomie nicht mehr in Betracht kommt. Eine weitere Indikation kann mit Einschränkungen bei einseitiger Erkrankung des letzthörenden Ohres indiziert sein. Die verwendete tägliche intravenöse Dosis betrug $2 \times 120 \mathrm{mg}$ Gentamicin, gelöst in $500 \mathrm{ml}$ Ringer-Lösung, titriert über zwei bis drei Stunden, über einen Zeitraum von fünf bis sechs Tagen. Die Erfolgsquote war hoch. Fünf von sechs Patienten (Nachbeobachtungzeitraum nach Therapieende ca. fünf Jahre) waren beschwerdefrei. Auch bei dieser Methode war eine thermische Erregbarkeit nach Beendigung der Behandlung noch nachweisbar. Signifikante Hörschäden konnten vermieden werden [206,207]. Auch bei thermisch nachweisbarer Restfunktion ist nach der Behandlung ein Training zur Förderung der zentralen Kompensation erforderlich [226-228].

Die Erfolgsraten der intratympanalen Gentamicinapplikation sind hoch. Von Küppers werden $89 \%$ berichtet $(n=28)$. Bei über der Hälfte blieb eine thermisch nachweisbare Erregbarkeit erhalten $[204,205]$. Lange et al. konnten mit der Intervalltherapie in über $95 \%(n=57)$ einen Therapieerfolg erzielen $[227,228]$. In einer 2004 publizierten Metaanalyse der intratympanalen Gentamicintherapie (1978-2002, 27 Studien, $n=980)$ wurde eine durchschnittliche Erfolgsrate von 90,2\% ermittelt [217]. Mit einer titrierten Gabe wurde das beste Rehabilitationsergebnis erreicht (96,3\%). Die Ergebnisse der anderen Therapiemethoden einschließlich der Prozentsätze der Hörstörungen finden sich in Tab. 3.

Blakley ermittelte in einer retrospektiven Analyse der intratympanalen Behandlung des Morbus Menière eine Erfolgsrate zwischen $78 \%$ und 100\% (13 Studien). Eine spezielle Methode konnte im Ergebnis der Analyse nicht empfohlen werden. Sowohl über die Dosierung als auch über die Applikationsmethodik besteht derzeit kein Konsens [230].

Auch andere Techniken in Kombination mit einer Aminoglykosidgabe finden im Schrifttum Erwähnung. So führten Shea und Norris eine Fensterungsoperation des lateralen Bogengangs (Labyrinthotomie) auf mastoidalem Wege durch und leiteten Streptomycin in die Perilymphe. In einer Multizenterstudie konnten mit dieser Technik etwa 80\% der Patienten von Schwindelbeschwerden geheilt werden. Bei $20 \%$ war jedoch noch ein weiteres Verfahren erforderlich. Immerhin 57\% verloren ihr Hörvermögen auf der behandelten Seite [200,201,232-233].

Wenige Untersuchungen gibt es über den Langzeitverlauf der Cristafunktion und Maculafunktion anhand der thermischen Erregbarkeit und anderer Testmethoden nach Verabreichung von Gentamicin. Tierexperimentelle Studien zeigten, dass eine Regeneration von vestibulären Haarzellen bereits 24 Wochen nach Gentamicinapplikation eintreten kann [234]. Forge und Nevill
Tab. 3 Erfolgsraten (Schwindelbeschwerden) mit unterschiedlichen Methoden der intratympanalen Gentamicintherapie und Hörstörungen nach Therapie. Nach Chia et al. 2004 [217]

\begin{tabular}{|lll|}
\hline Art der Applikation & $\begin{array}{l}\text { durchschnittliche } \\
\text { Erfolgsrate (Schwindel- } \\
\text { beschwerden) (\%) }\end{array}$ & $\begin{array}{l}\text { durchschnittliche Rate } \\
\text { an Hörstörungen nach } \\
\text { Behandlung (\%) }\end{array}$ \\
\hline mehrfach täglich & 91,1 & 34,7 \\
\hline wöchentlich & 89,3 & 13,1 \\
\hline niedrig dosiert & 86,8 & 23,7 \\
\hline kontinuierlich & 88,3 & 24,4 \\
\hline titriert & 96,3 & 24,2 \\
\hline
\end{tabular}

bestätigten diese Ergebnisse anhand eigener Untersuchungen. Eine Regeneration der cochleären Haarzellen konnte jedoch nicht gefunden werden [235].

De Waele et al. haben 22 Patienten mit einer intratympanalen Gentamicintherapie behandelt. Bei etwa einem Drittel der Patienten wurde innerhalb von zwei Jahren eine Funktionswiederkehr festgestellt. Schwindelbeschwerden traten nicht auf, wenn ein kompletter Verlust der Bogengangsfunktion nach der Therapie verzeichnet worden ist [236]. Westhofen beobachtete mehrere Jahre nach einer Gentamicintherapie in mehreren Fällen eine Wiederkehr der Otolithenfunktion [35]. Andere Autoren sind der Meinung, dass die Otolithenfunktion bei der Gentamicinbehandlung vor der Cristafunktion erlischt [226].

Eine noch vorhandene Otolithenfunktion könnte eine Ursache für Therapieversager der intratympanalen Therapie sein. Eine weitere mögliche Erklärung für mangelnde Erfolge oder Misserfolge der Methode ist eine partielle oder vollständige Obstruktion der runden Fensternische bei einem Teil der Patienten mit einem Morbus Menière [237]. Trotz dieser Argumente stellt die transtympanale Gentamicintherapie entsprechend einem systematischem Review von Diamond et al. eine effektive Methode dar, um die Symptomatik eines Morbus Menière zu beherrschen [238].

\subsubsection{Labyrinthanästhesie}

Die Labyrinthanästhesie stellt ein weiteres Therapieverfahren des Morbus Menière dar. Sie beruht auf der Instillation von Lokalanästhetika (z.B. Lidocain, Xylocain) in das Mittelohr [239]. Nach der Diffusion in das Innenohr sollen sich Lokalanästhetika in den Melanozyten der Stria vascularis anreichern und zu einer Ausschaltung des Gleichgewichtsorganes führen [240]. Das erklärt auch zeitweilige Schwindelzustände nach Eingriffen am Ohr in Lokalanästhesie und mahnt zur Vorsicht beim Vorliegen von Trommelfelldefekten. Ristow berichtete 1968 über eine Erfolgsquote von $83,3 \%(n=12)$. Bei seinen Patienten wurde intratympanal ein Gemisch von $0,7 \mathrm{~cm}^{3}$ zweiprozentiger Tetracaincain- oder 4\%iger Xylocainlösung mit Furfuryladenin (Kinetin) instilliert. In 33\% der Fälle ist eine Verschlechterung oder wesentliche Verschlechterung des Hörvermögens zwei Jahre nach der Behandlung registriert worden [241]. Fradis et al. konnten in ihrer Studie bei $82 \%$ eine schnelle Besserung des anfallsartigen Schwindels feststellen [242]. 
Im Jahre 2003 publizierten Adunka et al. eine retrospektive Analyse über Patienten $(n=24)$ mit unilateraler Menière-Erkrankung, die mit 4\% Lidocain und Kinetin behandelt worden sind. Bei 87,5\% der Patienten konnte eine Besserung der Schwindelsymptomatik erreicht werden. 66\% waren frei von Attackenschwindel [243]. Auch Sakata u. Mitarb. empfahlen die Labyrinthanästhesie mit Lidocain aufgrund der positiven Auswirkungen auf Schwindelbeschwerden [244].

\subsubsection{Glukokortikoidtherapie}

Der Entwicklung lokal wirksamer Medikamentenapplikationen gehört möglicherweise die Zukunft bei der Behandlung des Morbus Menière aber auch anderer Erkrankungen des Labyrinths. Hohe Erwartungen werden gegenwärtig in Glukokortikoide gesetzt. Eine exakte Dosierung bereitet derzeit jedoch noch Probleme und ist Gegenstand intensiver Bemühungen [245,246]. Für die Applikation stehen spezielle Paukenröhrchen $\left(\right.$ MikroWick $\left.^{\circledR}\right)$ [247] oder auch Mikrokatheter $\left(\mathrm{RW} \mu \mathrm{Cath}^{\circledR}\right)$ zur Verfügung $[208,222,223,248,249]$. Ein Katheter kann in Lokalanästhesie im Rahmen einer Tympanotomie unter mikroskopischer Sicht in die Region der Nische des runden Fensters platziert werden (cave: Kettenluxtion). Mit einem Mikroendoskop lässt sich die runde Nische gut darstellen und die Beschaffenheit der Membran beurteilen. Des Weiteren wird in der Literatur beschrieben, dass die transtympanale Endoskopie eine korrekte Platzierung von Medikamentensystemen gestattet [250]. Mit Hilfe einer externen Pumpe kann eine exakte Dosierung vorgenommen werden.

Die Rundfenstermembran ist für unterschiedliche Substanzen durchlässig: Antibiotika, Toxin, Albumin, Sauerstoff oder Glukokortikoide [251]. Die Glukokortikoide Dexamethason, Methylprednisolon und Hydrocortison entfalten ihre Wirkung wahrscheinlich über im Innenohr nachgewiesene Rezeptoren [252]. Die Wirksamkeit von Glukokortikoiden bei einzelnen Schwindelerkrankungen („Neuritis vestibularis“, Morbus Menière) ist belegt [57,253-255]. Für eine optimale Wirkstoffkonzentration in den Innenohrflüssigkeiten sind jedoch hohe Dosen erforderlich, die nur über eine transtympanale Applikation erreicht werden können [246]. Tierexperimentelle Untersuchungen haben gezeigt, dass die lokale Verabreichung hoher Glukokortikoiddosen über das runde Fenster tatsächlich zu einer hohen Konzentration in der Perilymphe führt [256]. Bachmann konnte nach einer einmaligen Applikation ein Anfluten über drei Stunden bis zu einer Konzentration von $1 \mathrm{~g} / \mathrm{l}$ Perilymphe mit einer Wirkdauer von ca. $16 \mathrm{~h}$ nachweisen [246]. Dodson et al. erreichten bei 54,2\% ihrer Patienten mit Morbus Menière mit intratympanal appliziertem Methylprednisolon und Dexamethason in kurzer Zeit eine Besserung des Schwindels [257]. Auch Barss et al. berichten über die erfolgreiche Anwendung von Dexamethason $(4 \mathrm{mg} / \mathrm{ml}$ über vier Wochen) [258]. Plontke und Salt simulierten die Kortikoidsteroid-Pharmakokinetik und konnten nachweisen, dass die im Innenohr nachweisbaren Medikamentenspiegel durch eine definierte Kontaktzeit im Mittelohr kontrolliert werden könnten. Bereits geringe Unterschiede der virtuell verabreichten Dosen verursachten große Differenzen der nachweisbaren Medikamentenspiegel im Innenohr [259]. Unterschiede im anatomischen Bau der Mittelohrfenster spielen eine entscheidende Rolle. So sollen Variationen im Aufbau der runden Nische bei etwa einem Drittel der Patienten vorkommen [260].

\subsection{4 „Osmotische Induktion“}

Arslan forderte 1971 eine therapeutische Methode, die einfach durchführbar ist und bei der größere operative Risiken vermieden werden. Die Wahl der Therapie sollte sich nach dem Hörvermögen richten. Er berichtete über 95 Fälle, bei denen er die Nische des runden Fensters nach einer Tympanotomie mit Natriumchloridkristallen auffüllte. Er vermutete, dass dadurch ein osmotisches Ungleichgewicht zwischen Endo- und Perilymphe induziert werden würde, was sich gleichsam auf den endolymphatischen Hydrops auswirke. Wenige Sekunden nach der Applikation konnte ein Nystagmus in das behandelte Ohr festgestellt werden. Nach 12 - 16 Stunden kehrte sich der Nystagmus um. Ein bis zwei Tage nach der Operation waren keine Schwindelsensationen mehr vorhanden. Bei über $90 \%$ der Patienten konnte so eine Besserung der Schwindelsymptomatik erzielt werden [261]. Obwohl offenbar effektiv, ist die Methode heute nicht mehr in der klinischen Routine gebräuchlich.

\subsection{Beeinflussung von Mittelohrdruck, -mechanik und Hydrodynamik des Innenohres}

Änderungen des Luftdruckes wirken sich unter normalen atmosphärischen Bedingungen nicht auf das Innenohr aus, da die Ossikelgelenke einen Schutzmechanismus darstellen. Handelt es sich aber um Entzündungen oder arthrotische Veränderungen der Ossikelgelenke, kann ein behinderter Gleitmechanismus die Folge sein, so dass ein Schutzmechanismus nicht mehr in vollem Umfang wirksam ist [262]. Im Experiment konnten unter solchen Bedingungen unphysiologische, verstärkte Bewegungen der Steigbügelfußplatte induziert werden. Bei Änderungen des Umgebungsluftdruckes waren an einem artefiziell versteiften Hammer-Amboss-Gelenk Änderungen der physiologischen, normalen Ein- und Auswärtsbewegungen des Stapes (5 - $30 \mu \mathrm{m}$ ) auf ein Mehrfaches (100 $\mu \mathrm{m})$ möglich [262]. Bei Patienten mit einer Pistonprothese nach Stapesplastik konnten tympanometrisch Nystagmen registriert werden. Bei Erkrankten mit einem einseitigen Morbus Menière waren bei schnellen Druckschwankungen (Wechseldrucke) signifikante vestibulospinale Änderungen nachweisbar. So führen Veränderungen der Mittelohrmechanik auch druckabhängig zu Schwindelbeschwerden [262 -265].

Paukenröhrchen haben hinsichtlich ihrer Belüftungsfunktion eine Auswirkung auf den Mittelohrdruck. In einer Reihe von Studien wird beschrieben, dass sich das Symptom „Schwindel“ beim Morbus Menière nach Einlage einer Paukendrainage gebessert hat [266-268]. Über Erfolgsraten bis zu $82 \%$ wird berichtet $[269,270]$. Eine Tubenfunktionsstörung soll allerdings auch bei ca. einem Drittel aller Patienten mit Morbus Menière vorkommen [271].

Die Tenotomie der Sehne des Musculus tensor tympani und des Musculus stapedius hatte sowohl einen positiven Einfluss auf das Hörvermögen als auch auf die Schwindelattacken bei Patienten mit einem Morbus Menière $(n=45)$. Bei vielen Patienten war intraoperativ eine Entzündungsreaktion der Pauke zu beobachten [272].

Variierende Veränderungen des Luftdruckes (Wechseldruckapplikation) haben eine positive Auswirkung auf die Hydrodynamik des Labyrinths bei Patienten mit einem endolymphatischen Hydrops. Schwindelsymptome aber auch Hörstörungen im Rah- 
men der Erkrankung konnten durch kontrollierte Luftdruckveränderungen gebessert werden. In Schweden wurde kürzlich eine Methode entwickelt, bei der Druckpulse mit maximal $12 \mathrm{~cm}$ Wassersäule in Kombination mit einem zuvor applizierten Paukenröhrchen im äußeren Gehörgang appliziert wurden. Es wurde nachgewiesen, dass die Therapie zu einer deutlichen Verminderung von Schwindelbeschwerden führt [273 - 279].

Auch die Behandlung von Patienten mit Morbus Menière in einer Unterdruckkammer zeigte, dass die Schwindelbeschwerden druckabhängig beeinflusst werden konnten. Sie besserten sich in ca. 30\% der Fälle [279].

\subsection{Chirurgische Therapie \\ 5.5.1 Funktionserhaltende Labyrinthchirurgie \\ 5.5.1.1 Saccotomie}

Die operative Therapie des Morbus Menière umfasst funktionserhaltende und destruierende Eingriffe. Die Saccotomie gehört zu den funktionserhaltenden Verfahren der operativen Behandlung des Morbus Menière. In der erstmals von Gruber 1895 postulierten Hydropstheorie des Morbus Menière wird davon ausgegangen, dass Abflussstörungen der Endolymphe in den Saccus endolymphaticus zu einer Endolymphüberproduktion führen [281]. Zuvor sprach man auch vom „Glaukom des Innenohres“ [282]. Portmann nahm an, dass der Saccus endolymphaticus in die Druckregulation der Endolymphe eingebunden ist. Nach erfolgreichen tierexperimentellen Untersuchungen Anfang der 1920er-Jahre führte er wenige Jahre später die erste Saccotomie erfolgreich beim Menschen durch [283 - 285]. Ziel dieser Methode ist eine endolymphatische Dekompression. Diese gelingt entweder durch eine Dekompression ohne Inzision, durch die Ableitung der Endolymphe nach mastoidal oder die Eröffnung des Saccus nach subarachnoidal (Einlage von Shuntventilen). Des Weiteren soll nach der Eröffnung und Einlage eines Silikonstreifens eine größere Resorptionsfläche geschaffen werden (Bildung eines Neosaccus) [286-289] (Abb.6). House und hierzulande Plester haben die Saccotomie und Saccusdekompression modifiziert und ihr zum praktischen Durchbruch verholfen [290,291].

Auf transmastoidalem Wege gelangt man zum Saccus, indem man die Kontur des lateralen Bogengangs, den Sinus sigmoideus und den hinteren Bogengang identifiziert und darstellt. Der Saccus endolymphaticus findet sich medial und dorsal des hinteren Bogengangs als Duraduplikatur der hinteren Schädelgrube. Vor der Inzision des Endolymphsackes sind die Gabe eines Antibiotikums und eine einmalige Kortikosteroidapplikation empfehlenswert [292].

Bei den Diskussionen um das Für und Wider unterschiedlicher chirurgischer Methoden zur Behandlung des Morbus Menière ist in den 1980er-Jahren ein heftiger und zum Teil emotional geführter Streit um diese Methode entbrannt. In der initialen Analyse, einer plazebokontrollierten Doppelblindstudie, wurde eine Patientengruppe untersucht, von denen sich je 15 einer Saccotomie sowie einer Mastoidektomie unterzogen. Etwa 70\% der Patienten in beiden Gruppen gaben hinsichtlich des Schwindels eine Besserung an. Der Operationserfolg wurde als unspezifisch gewertet und von den Verfassern als „Plazeboeffekt“ bezeichnet. Als Methode der Wahl für die operative Therapie beim Morbus Menière wurde die Neurektomie des Nervus vestibularis vorge-

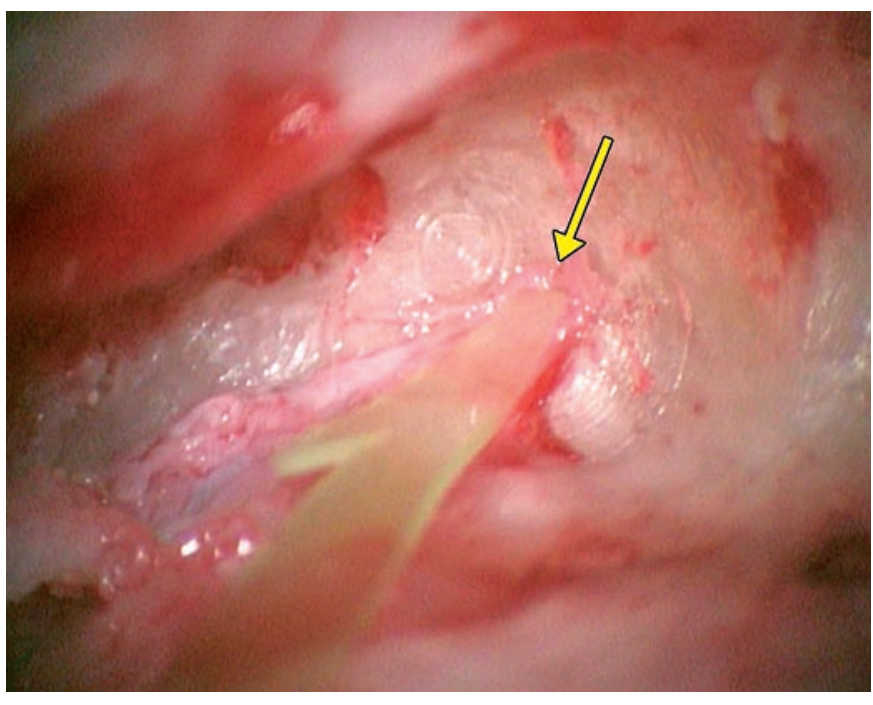

Abb. 6 Einlage einer Silikonfolie in den Saccus endolymphaticus (gelber Pfeil) im Rahmen einer Saccotomie. Intraoperativer Situs.

schlagen [293-296]. Heftige Diskussionen reichen bis in die heutige Zeit [297-300]. Brandt et al. schätzen derzeit ein, dass für eine operative Therapie gegenwärtig nur noch eins bis drei Prozent der Patienten in Betracht kommen würden [15]. Kerr et al. führten vor der Durchführung einer Neurektomie eine einfache Mastoidektomie durch und erreichten bei nur $57 \%$ aller Fälle Beschwerdefreiheit [301]. Silverstein et al. verglichen Patienten nach endolymphatischer Shuntoperation (subarachnoidale Shuntanlage) und nach Neurektomie mit dem natürlichen Verlauf eines Morbus Menière $(\mathrm{n}=83)$. Zwei Jahre nach Saccusoperation waren $40 \%$ und nach 8,7 Jahren $70 \%$ beschwerdefrei. In der Gruppe ohne Operation ( $n=50)$ zeigten $57 \%$ nach 2 Jahren und $71 \%$ nach 8,3 Jahren keine Schwindelbeschwerden mehr. 4,4 Jahre nach Neurektomie waren demgegenüber sogar $93 \%$ beschwerdefrei. Der Langzeitverlauf der Erkrankung wird nach Meinung der Autoren durch endolymphatische Shuntoperation nicht beeinflusst [302].

Fibrotische Umwandlungen im Bereich des Saccus endolymphaticus (Saccusfibrose) beim Morbus Menière sind im Zusammenhang mit unterschiedlichen Erfolgsquoten beschrieben [303, 304]. Ußmüller et al. haben die Frage aufgegriffen, ob entwicklungsbedingte Anomalien des Saccus nachzuweisen sind und 46 Felsenbeinpräparate der Hamburger Wittmaack-Sammlung untersucht. Sie konnten feststellen, dass sich im Bereich des Saccus endolymphaticus im Verlaufe des Lebens ein Alterungsprozess mit zunehmender Stenosierung des Lumens auch bei ohrgesunden Personen vollzieht. Die Autoren fordern deshalb eine kritische Indikationsstellung für die Operation nach Vollendung des fünften Dezenniums. Der Therapieerfolg der Saccotomie ist vom Vorhandensein eines weiten, normal konfigurierten Saccus endolymphaticus abhängig [305].

Eine Reevaluierung der Effektivität der Methode der Saccotomie erfolgte im Jahre 2000 von Welling und Nagaraja [306] anhand der seinerzeit von Bretlau und Thomsen [293-296] veröffentlichten Daten. Sie konnten daraufhin die Vorstellung der Plazebo-Operation „Saccotomie“ widerlegen. Auch in einer nach den Kriterien der evidenzbasierten Medizin durchgeführten Analyse 
von 96 Saccotomien zeigte sich eine Besserung der Schwindelbeschwerden in $68 \%$ bis $92 \%$ der Fälle [307].

Kato et al. konnten in einer retrospektiven Analyse von mittels endolymphatischer Shuntoperation operierten Patienten mit einem Morbus Menière $(n=159)$, bei denen eine medikamentöse Therapie nicht erfolgreich war, feststellen, dass sich die Lebensqualität bei $87 \%$ der Befragten nach Saccotomie besserte, bei $9 \%$ schlechter war und nur bei $3 \%$ unveränderte Beschwerden bestanden [308]. Huang schätzt die Methode nach seiner Erfahrung mit über 3000 Saccotomien für den in dieser Technik geübten Mikrochirurgen als risikoarm, hocheffektiv und sicher ein [309]. Die Saccotomie soll in einem frühen Stadium der Erkrankung auf längere Sicht einen besseren Erfolg hinsichtlich des Symptoms „Schwindel“ erzielen als in einem späteren Stadium [301,311]. Ein intraoperatives Elektrocochleographie-Monitoring während einer Saccusdekompression vermag die Dekompression eines Endolymphhydrops und damit den Erfolg der Operation intraoperativ zu bestätigen [312]. Reserven für höhere Erfolgsraten der Methode werden unter anderem in einer Vermeidung einer intraoperativen Traumatisierung des Saccus endolymphaticus gesehen [313]. Die Methode der Saccotomie hat nach Yin et al. in Bezug auf Schwindelbeschwerden einen Langzeiteffekt ( $n=6$, endolymphatische Dekompression und mastoidale Shuntanlage, Follow-up durchschnittlich 10 Jahre) [314].

Auch eine kombinierte Therapie mit Medikamentengaben wurde beschrieben. So ist z. B. zusätzlich im Rahmen einer Saccotomie eine Steroidinstillation in den Saccus durchgeführt worden [315]. Andere Autoren benutzten Mitomycin C und ein Antibiotikum (Cephalosporin). Die guten Kurzzeitresultate ( $<3$ Jahre, $\mathrm{n}=103$ ) sprachen für die Methode. Rezidive konnten nicht beobachtet werden [316].

Welling beschrieb 1996 ein Verfahren, bei dem der extraossäre Saccus endolymphaticus entfernt wurde. Im Vergleich zur Mastoid-Shunt-Operation wurden keine Unterschiede gesehen [316].

In der überwiegenden Mehrzahl der Fälle nach Saccotomie kommt es durch Ausbleiben von Anfällen zur Ausbildung einer stabilen vestibulären Kompensation. Zur Beschleunigung und Unterstützung von Kompensationsmechanismen ist auch hier eine Trainingstherapie indiziert [318].

Häufig kann es infolge einer Saccotomie zu einer Normalisierung der Labyrinthfunktion kommen (Erhaltung der Funktion). Die Schwindelbeschwerden der Patienten allein, die als Kriterium für eine Bewertung in anderen Studien benutzt werden, erlauben kein hinreichendes Urteil über den Operationserfolg. Die Dokumentation der vestibulären Funktionen, insbesondere die Prüfung der thermischen Erregbarkeit ist für die Einschätzung des Operationserfolges hinsichtlich des Schwindels notwendig [318].

Schwager et al. untersuchten retrospektiv 29 Patienten nach Revisionssaccotomie. Nach 20 Monaten waren $62 \%$ beschwerdefrei. $14 \%$ gaben eine Besserung der Symptome an. 7\% waren nur temporär für 18 Monate schwindelfrei. 17\% gaben keine Besserung an. Die Autoren fanden Knochenneubildungen im Bereich der Shuntoperation als eine Ursache für das Versagen der Thera- pie. Sie empfehlen aber die Revisions-Saccotomie als eine Methode der Wahl, bevor andere Therapieverfahren, wie die Neurektomie, indiziert werden [319].

Bei einem bilateralen Morbus Menière kann die Saccotomie die chirurgische Methode der ersten Wahl sein [320].

\subsubsection{Cochleosacculotomie}

Die Cochleosacculotomie ist auf dem amerikanischen Kontinent verbreiteter als in Europa. Ziel dieser Methode ist die Herstellung eines persistierenden endo-perilymphatischen Shunts zur Vermeidung eines endolymphatischen Hydrops [323]. Das Verfahren kann in Lokalanästhesie durchgeführt werden. Ein scharfes, rechteckig gebogenes Häkchen $(2-3 \mathrm{~mm})$ wird dabei so in die Rundfenstermembran eingeführt, dass die Spitze in die Mitte der Fußplatte zeigt. Der Haken wird anschließend etwas nach rechts und nach links bewegt. Dadurch wird eine Fraktur der Lamina spiralis ossea und des Ductus cochlearis provoziert. Danach wird die Prozedur wiederholt und das Fenster bindegewebig verschlossen. Einige Patienten nehmen intraoperativ ein clickartiges Geräusch wahr, wenn der Haken in das runde Fenster eingeführt wird, jedoch keine Schwindelsensationen [321,322]. Die Langzeiterfolge liegen zwischen $82 \%$ und 89\% [322]. Jedoch sind die Auswirkungen auf das Hörvermögen nicht unbedeutend. Schuknecht berichtet bei 60 Patienten über eine Rate von immerhin 25\% Hörverschlechterungen [323]. Viele Autoren sehen daher eine Indikation im fortgeschrittenen Alter oder bei fehlender Narkosefähigkeit [324-327]. Wegen des hohen Prozentsatzes an nachfolgenden Hörminderungen ist die Methode aus eigener Anschauung ausschließlich bei Patienten mit hochgradiger Hörstörung oder Hörverlust indiziert.

\subsubsection{Ausschaltung der Labyrinthfunktion \\ 5.5.2.1 Neurektomie des Nervus vestibularis}

Die unilaterale, selektive Durchtrennung des Nervus vestibularis (Vestibularisneurektomie) zählt zu den destruierenden und sehr effektiven Verfahren bei der chirurgischen Behandlung des Morbus Menière. Die Durchschneidung des Nerven kann auf unterschiedlichem Wege erfolgen. Die Neurektomie, speziell beim Morbus Menière, geht zurück auf Dandy [328]. Er berichtete über Erfolgsraten von über 90\%. Dandy wählte den Zugang über die hintere Schädelgrube [329]. McKenzie entwickelte die Vestibularisneurektomie über einen subokzipitalen Zugang [330]. House und Fisch modifizierten die Methode weiter. Sie erreichten den Nervus vestibularis über die mittlere Schädelgrube transtemporal [331,332]. Bei funktionellem Restgehör wird nach Fehlschlagen funktionserhaltender Verfahren der erweiterte transtemporale oder subokzipitale Zugang empfohlen [277,333]. Besteht eine funktionelle Ertaubung, ist eine Neurektomie auch auf transmeatalem bzw. translabyrinthärem Wege möglich [334,335].

Die hohe Effizienz der Methode der Neurektomie wird in mehreren Studien belegt: Molony $(95 \%, \mathrm{n}=27)$, Thomsen et al. $(88 \%$, $\mathrm{n}=42)$, Hillman $(95 \%, \mathrm{n}=39)$ [336-338]. Damit ist die Neurektomie des Nervus vestibularis das Therapieverfahren mit der höchsten Erfolgsrate beim Morbus Menière.

Rosenberg et al. fanden bei neurektomierten Patienten einen niedrigeren Prozentsatz der Entwicklung eines bilateralen Mor- 
bus Menière, als bei ausschließlich medikamentös behandelten Erkrankten (17\% versus 0\%, 6,3 Jahre Nachbeobachtung) [339].

Weniger als $10 \%$ der Patienten sollen nicht von einer Neurektomie profitieren. Die Methode hat keinen Einfluss auf den Pathomechanismus des Morbus Menière, „schützt“ also nicht vor fluktuierenden Hörstörungen infolge eines weiterhin bestehenden endolymphatischen Hydrops („cochleäre Menière-Anfälle“). In der amerikanischen Literatur wird derzeit diskutiert, inwieweit die Saccotomie als erster Schritt der Stufentherapie beim Morbus Menière geeignet ist, der bei Versagen durch die Neurektomie ergänzt wird. In einer Studie führten 36\% der Otochirurgen die endolymphatische Shuntoperation zuerst durch, 24\% hingegen wählen die Neurektomie als ersten Schritt [340,341]. Der postoperative Zustand nach Neurektomie entspricht dem eines einseitigen Vestibularisausfalls. Daher müssen die dort erwähnten medikamentösen und physikalischen Therapiemethoden bis zur optimalen vestibulären Kompensation auch nach Vestibularisneurektomie angewendet werden. Die postoperativen Beschwerden sind bei geringer Restfunktion des Labyrinths vor der Operation für den Patienten kaum spürbar.

\subsubsection{Labyrinthektomie}

Die Methode des Labyrinthektomie wurde von Schuknecht und Cawthorne erstmals auf transmeatalem Wege durchgeführt. Hierbei erfolgt eine vollständige Destruktion des Labyrinths und Entfernung des Neuroepithels der Maculae und Cristae $[342,343]$. Die Indikationen zur Labyrinthektomie bei Gleichgewichtsstörungen kann gestellt werden, wenn das Labyrinth weitestgehend ausgefallen ist, die Lebensqualität durch wiederkehrende oder permanente Schwindelzustände wesentlich eingeschränkt ist und dem Patienten eine Allgemeinnarkose für eine Neurektomie des Nervus vestibularis nicht zugemutet werden kann [344].

Eine inkomplette Entfernung der membranösen sensorischen Strukturen kann zu einem Persistieren von Schwindelbeschwerden führen. Häufig lässt sich das Ergebnis einer inkompletten Labyrinthektomie dann postoperativ nicht von einer unvollständigen vestibulären Kompensation unterscheiden [345]. Silverstein hat die Labyrinthektomie mit einer transmeatalen cochleovestibulären Neurektomie kombiniert und gute Resultate (89\%) erzielt [334]. Modifikationen der Labyrinthdestruktion durch eine Kombination von Operation mit Entfernung des Neuroepithels und mit zusätzlicher Alkoholinstillation oder Elektrokoagulation wurden aufgrund der negativen Auswirkungen auf den Nervus facialis wieder verlassen [346 - 348]. Die chirurgische Labyrinthektomie, auch in Kombination mit ototoxischen Medikamenten schaltet das Labyrinth nicht so zuverlässig aus, wie die Neurektomie [344].

\subsection{Zusammenfassende Bemerkungen}

Die vollständige Klärung der Ätiologie des Morbus Menière steht bis heute aus. Für die Behandlung des Schwindels beim Morbus Menière sind eine Vielzahl an konservativen, funktionserhaltenden und destruktiven operativen Therapiemethoden entwickelt worden. Vor Beginn der Behandlung des Morbus Menière ist eine subtile Differenzialdiagnostik erforderlich.
Die praktische Erfahrung zeigt, dass bei der Erkrankung bereits frühzeitig psychische Folgen entstehen können. Der Morbus Menière wird heute zu oft diagnostiziert und zu selten in seiner oft wechselseitigen Bedingtheit der organischen und seelischen Faktoren beachtet. Die Angst vor den Schwindelbeschwerden kann so groß werden, dass sie selbst als Unsicherheit und „Schwindel“ empfunden wird. Psychogene Schwindelbeschwerden können sich auch dann manifestieren, wenn das Gleichgewichtsorgan seine Funktion längst verloren hat $[4,6]$.

Besteht die Erkrankung mit einer hohen Anfallsfrequenz längere Zeit fort, ist eine länger dauernde Arbeitsunfähigkeit nicht selten oder es drohen Berufsunfähigkeit oder gar Invalidität. Ziel muss es sein, den Patienten frühzeitig, funktionserhaltend, effektiv und möglichst ohne die potenzielle Gefahr gravierender Komplikationen (wie eine Ertaubung) von seinen Beschwerden zu befreien. Der unregelmäßige Verlauf, die hohe Variabilität und die Schwierigkeit der Abschätzung einer Prognose tragen dazu bei, dass derzeit keine Methode in der Lage ist, allen Forderungen gerecht zu werden.

Wesentliche Faktoren für die Wahl der Therapie sind der Zustand des Patienten, die Dauer der Erkrankung, die Erfolge einer konservativen (medikamentösen) Therapie, das Hörvermögen und die Seitenlokalisation sowie der Grad der Otolithenfunktionsstörung.

Wir führen an der Aachener HNO-Universitätsklinik ein abgestuftes otomikrochirurgisches Therapiekonzept durch. Indikationen für eine chirurgische Therapie beim Morbus Menière sind dabei gegeben, wenn

- Patienten nicht oder nicht ausreichend auf konservative Therapie (ca. 6-12 Monate) ansprechen,

- eine Beeinträchtigung durch eine progrediente Verschlechterung der cochleären Funktion vorliegt,

- die Lebensqualität und/oder die berufliche Aktivität durch eine erhöhte Anfallsfrequenz ( $<2$ pro Woche) stark beeinträchtigt sind (relative Indikation).

Die ein- oder beiderseitige Einlage eines Paukenröhrchens erfolgt bei Patienten mit nachgewiesener temporärer Störung der Otolithenfunktion, wenn sich in der Impedanzaudiometrie reproduzierbar (zu mindestens zwei Untersuchungszeitpunkten) eine Verschiebung der maximalen Compliance von mehr als 50 daPa oder Einschränkungen der Tubenfunktion nachweisbar und objektivierbar sind. Sowohl bei der endo- als auch bei der perilymphatischen Hypertension werden die Otolithenorgane aufgrund ihrer zentralen Lage bevorzugt erreicht und in Mitleidenschaft gezogen. Dagegen sehen wir keine Operationsindikation für eine Paukendrainage bei alleinigen Bogengangsfunktionsstörungen. Durch die Belüftung der Pauke kann ggf. in Ergänzung weiterer Therapiemaßnahmen eine deutliche Verbesserung der Beschwerden erzielt werden. Im Falle eines therapierefraktären endolymphatischen Hydrops empfehlen wir eine funktionserhaltende endolymphatische Shuntoperation. Dafür ist zumindest eine Restfunktion der Makula und/oder Crista Voraussetzung. Die Druckentlastung erfolgt nach Schlitzung des Saccus auf transmastoidalem Wege. Die Einlage eines dünnen, keilförmigen, tannenbaumartig zugeschnittenen Silikonstreifens in den Saccus bietet nach unserer Auffassung eine höhere Sicherheit im Ver- 
gleich zur einfachen Saccusdekompression. Sie führt nach unseren Beobachtungen zur Bildung eines Neosaccus. Während Saccusrevisionen fand sich eine um die Silikonfolie reichende, extrem vergrößerte Pars lateralis des Saccus endolymphaticus.

Eine Ausschaltung der Labyrinthfunktion ist indiziert, wenn konservative Rehabilitation und funktionserhaltende Maßnahmen nicht zu einem gewünschten Rehabilitationsergebnis führen. Die Indikation zur Neurektomie des Nervus vestibularis wird bei erhaltenem sozialen Gehör gestellt. Dabei stellt auch eine bilaterale Erkrankung keine Kontraindikation dar. Liegt primär kein verwertbares Hörvermögen vor, sind labyrinthdestruierende Eingriffe als operative Primärtherapie indiziert. Eine Cochleosacculotomie empfehlen wir bei normalem kontralateralem aber nicht mehr vorhandenem sozialen Hörvermögen ipsilateral [35].

Ein physiotherapeutisches Training zur Förderung der Kompensation ist in Analogie zum akuten isolierten Vestibularisausfall bei akuten einseitigen Funktionsstörungen mit Verminderung der thermischen Erregbarkeit die Methode der Wahl beim Morbus Menière.

\section{6}

\section{Funktionsstörungen der Otolithenorgane}

Isolierte Otolithenfunktionsstörungen oder eine Otolithenbeteiligung liegen bei etwa 50\% der Patienten mit labyrinthären Schwindelbeschwerden vor. Erkrankungen der Otolithenorgane kommen sowohl als alleinige Ursache für Schwindelbeschwerden vor, können jedoch auch in Kombination mit Funktionsstörungen der Cochlea und/oder der Bogengänge auftreten [35]. Allein ein Viertel aller Patienten, die sich wegen Schwindelbeschwerden in unserer Klinik vorstellen, beklagen Beschwerden, wie Liftschwindel oder ein Kippen bei bestimmten Körperlagen oder unspezifische Beschwerden, die sich als Otolithenfunktionsstörungen herausstellen. Maculafunktionsstörungen können heute mit Screening-Verfahren qualitativ erfasst oder mit zeitaufwändigeren apparativen Methoden quantifiziert werden $[35,366]$. Eine noch nicht vollständig erforschte Möglichkeit der Otolithendiagnostik (Utriculus) ist die thermische Prüfung in Pro- und Supinationslage. Die vestibulär evozierten myogenen Potenziale (VEMP) stellen Antworten auf eine Sacculusreizung dar [369].

Eine spezifische operative Therapie der selektiven Ausschaltung der Otolithenorgane befindet sich derzeit auf der Stufe tierexperimenteller Studien [349,350]. Für die Therapie isolierter Störungen des Otolithenapparates bietet sich die Laserchirurgie an. Mit einem Argon-Laser ist eine Destruktion der Otolithenorgane bei Meerschweinchen nach Applikation durch die intakte Fußplatte nachgewiesen worden, ohne dass Hörschäden nachweisbar waren [349]. Auch eine Laserbestrahlung im Tierexperiment mit temporärer Entfernung der Fußplatte wird beschrieben [350]. Dieses als „selektive Labyrinthektomie“ bezeichnete Verfahren ist bisher nur einmal erfolgreich bei einer Patientin angewendet worden [351,352]. Ähnlich wie beim Ausfall eines Bogengangs kommt es bei isolierten einseitigen Otolithenstörungen zu einer Kompensation. Das Kompensationszeitintervall beträgt aber etwa nur drei Tage [349]. Artefizielle Ausschaltungen der Otolithenorgane auf einer Seite führen gleichzeitig zu einer Redukti- on der Bogengangsantwort, da die Otolithenorgane in der Lage sind, die Quantität der Bogengangsantwort zu modulieren $[353,354]$.

\section{$7 \quad$ Bilaterale Vestibulopathie}

Neben beiderseitigen labyrinthären Ursachen (Fehlbildungen, Schädelbasisfrakturen mit Einbeziehung des Labyrinths, Labyrinthitis, Morbus Menière) kommen für das relativ seltene Krankheitsbild der beiderseitigen Vestibularisstörung auch zentralnervöse Störungen (Meningitis) oder Stoffwechselerkrankungen (Vitamin-B6- und -B12-Mangel) infrage [355]. In einer eigenen Untersuchung bei 64 Patienten fanden wir als häufigste bekannte Ursachen eine vestibulotoxische Medikation (12\%) und eine Meningitis ( $8 \%$ ). In den meisten Fällen (62\%) blieb die Ätiologie jedoch unklar. Rinne et al. konnten bei $39 \%$ eine zentralnervöse Ursache, bei $17 \%$ eine ototoxische Antibiotikagabe und bei $9 \%$ eine Autoimmunerkrankung ermitteln $(n=53)$. In etwa einem Fünftel (21\%) fand sich keine Ursache [356]. Die Schädigung beider Labyrinthe kann akut eintreten oder sich langsam fortschreitend manifestieren. Beide Vestibularorgane können simultan oder sequenziell befallen werden. Bei langsam fortschreitenden, wechselseitigen vestibulären Funktionsverlusten mit zwischenzeitlicher vestibulärer Kompensation kann das Bechterew-Phänomen beobachtet werden $[355,357,358]$. Bei erworbenen Störungen besteht eine Gangunsicherheit (Ataxie) mit visuellen Wahrnehmungsstörungen (Oszillopsien). Dieses von Dandy beschriebene Symptom wurde erstmals nach doppelseitiger Durchtrennung des Nervus vestibularis beobachtet [359].

Die thermische Erregbarkeit des lateralen Bogengangs muss nicht vollständig „erloschen“ sein. Auch eine Resterregbarkeit führt zur typischen Symptomatik einer bilateralen Vestibulopathie [360]. Bei einem von uns in zwei Fällen zufällig entdeckten beiderseitigen Verlust der thermischen Erregbarkeit waren die Patienten erstaunlicherweise völlig symptomlos (angeborene Form einer bilateralen Vestibulopathie).

Während der Gabe von ototoxischen Arzneimitteln, vor allem Aminoglykosiden, muss heute ein Monitoring (Plasmaspiegelkontrolle) gefordert werden. Risikofaktoren stellen ein hohes Alter, eine Niereninsuffizienz und die zusätzliche Gabe von Diuretika (Furosemid) oder Salizylaten (Kumulation) dar [361].

Beim Cogan-Syndrom werden hohe Kortisongaben (1 g Urbason über fünf Tage) und unter bestimmten Voraussetzungen von wenigen Autoren Azathioprin oder Cyclophosphamid empfohlen $[15,355,362]$.

Bei einem nachgewiesenen partiellen oder kompletten Verlust der thermischen Erregbarkeit ist eine physikalische Therapie sinnvoll. Eine vestibuläre Trainingstherapie erleichtert die Anpassung an die Funktionsstörung. Brandt spricht von visueller und somatosensorischer Substitution [15]. Nach Herdmann soll sich die Balanceleistung trainierter im Vergleich zu nicht behandelten Probanden aber nicht signifikant unterscheiden [363]. Der Begriff der „Gewöhnung“ ersetzt im Fall des kompletten Verlustes der Funktion beider Gleichgewichtsorgane den Begriff der Kompensation. 
Tab. 4 Medikamente zur Prophylaxe und Therapie der Reisekrankheit (Quelle: Rote Liste 2004)

\begin{tabular}{|c|c|c|c|c|c|}
\hline Stoffgruppe & Medikament & Beispiel & Dosierung & $\begin{array}{l}\text { Zeitdauer der Gabe vor } \\
\text { Reisebeginn (in Stunden) }\end{array}$ & $\begin{array}{l}\text { Wirkdauer in } \\
\text { Stunden }\end{array}$ \\
\hline \multirow[t]{3}{*}{ H1-Antihistaminika } & Dimenhydrinat & Reisetabletten ratiopharm ${ }^{\circledR}$ & $50 \mathrm{mg}$ per os & 0,5 & 8 \\
\hline & Meclozin & Peremesin ${ }^{\circledR} \mathrm{N}$ & $25 \mathrm{mg}$ per os & 0,5 & 12 \\
\hline & Scopolamin & Scopoderm TTS ${ }^{\circledR}$ & $\begin{array}{l}1,5 \text { mg transdermal } \\
\text { retroaurikulär }\end{array}$ & 6 & 72 \\
\hline Serotonin-(5-HT3)-Antagonisten & Tropisetron & Navoban $^{\circledR}$ & 5 mg per os & direkt vor Exposition & 24 \\
\hline pflanzliche Antiemetika & Ingwerwurzelstock & Citona $^{\circledR}$ & $500 \mathrm{mg}$ per os & 0,5 & 4 \\
\hline Homöopathika & Cocculus & Hervertigon SL Tabletten ${ }^{\circledR}$ & $250 \mathrm{mg}$ per os & 0,2 & $0,25-6$ \\
\hline $\begin{array}{l}\text { Neuroleptika (nur als } \\
\text { Kombinationspräparat) }\end{array}$ & Promethazin & Atosil $^{\circledR}$ & 25 mg per os & direkt vor Exposition & $6-8$ \\
\hline
\end{tabular}

8

\section{Gestörtes Gleichgewicht im Alter}

Schwindelartige Beschwerden nehmen im Alter eine besondere Stellung ein. In der Altersgruppe über 65 Jahre sind Schwindelbeschwerden und Gleichgewichtsstörungen mit deutlichem $\mathrm{Ab}$ stand der häufigste Grund für einen Arztbesuch. Mehr als die Hälfte von über 75-jährigen Krankenhauspatienten beklagen Schwindelbeschwerden. Kürzliche Untersuchungen haben gezeigt, dass die Lebensqualität dadurch erheblich eingeschränkt ist. In einer Anwendungsbeobachtung wurden acht Wochen lang eine bis zwei Retardtabletten Dimenhydrinat pro Tag verabreicht. Ein Teil der Patienten erhielt zusätzlich eine Krankengymnastik. Die Ergebnisse zeigten, dass sich das Wohlbefinden der medikamentös behandelten Patienten in verschiedenen Lebenssituationen deutlich verbesserte. Die Verträglichkeit des Medikaments wurde in $95 \%$ der Fälle als sehr gut eingeschätzt. Eine zusätzliche Krankengymnastik vermochte einen noch besseren Lebensqualitätsscore herbeizuführen [364].

Mit körperlichem Training im Alter kann man nicht nur kardiovaskulären Risikofaktoren vorbeugen. Kontinuierliche Gleichgewichtsübungen tragen auch zur Verbesserung von neuromuskulären Leistungskomponenten, wie Koordination und Beweglichkeit, bei. Die Auffassung, dass das Zentralnervensystem ein statisches Organ ist, musste revidiert werden. Es ist heute bekannt, dass es auch im Alter über eine ungeahnte Plastizität verfügt, die durch Training genutzt werden kann $[365,366]$.

Taumeligkeit und Gangunsicherheit bei älteren Patienten bedingen nicht selten auch Stürze. Patienten mit Schwindelbeschwerden stürzen zehnmal häufiger als Patienten ohne diese. Durch ein regelmäßiges Gleichgewichtstraining lassen sich etwa 50\% der Stürze im Alter vermeiden, was mit erheblichen Kosteneinsparungen verbunden ist.

Die sinnvolle Verordnung von Medikamenten, die Schwindelbeschwerden verursachen, trägt zur Prävention von Stürzen bei [367]. Gleichgewichtsprothesen könnten in Zukunft bei unvollständiger Kompensation Stürze verhindern helfen („Cochlea Implant für das Gleichgewichtsorgan“) [368].

\section{$9 \quad$ Kinetosen}

Kinetosen entstehen durch optisch-vestibuläre Diskrepanzen z.B. bei Auto-, Bahn- und Flugreisen, die „Seekrankheit“ bei Schiffsreisen durch Linear- und Winkelbeschleunigungen einer niedrigen Frequenz $(<1 \mathrm{~Hz})$. Für die Entstehung der so genannten Simulatorkrankheit sind optokinetische Reizeinflüsse verantwortlich [14,15].

Die Kinetosesyndrome lassen sich in zwei Schweregrade unterteilen. Beim „Sopite-Syndrom“ kommt es zu zwanghaftem Gähnen, Unlust, Abgeschlagenheit und Müdigkeit, das „Nausea-Syndrom" umfasst Übelkeit und Erbrechen.

Prinzipiell kann jeder Mensch eine Kinetose entwickeln (Coriolis Effekt) $[14,369]$. Die interindividuelle Empfindlichkeit ist jedoch unterschiedlich. Seitendifferente Otolithenmassen, vor allem des Utriculus, sollen eine Rolle spielen [370,371]. In der Schwerelosigkeit nennt man die Kinetose space-motion-sickness oder space-adaption-syndrome $[369,372]$.

Die Therapie kann medikamentös erfolgen. Eine sehr praktische und einfache Behandlungsform ist die Verwendung von transdermal applizierten Parasympatholytica (Scopolamin). An der Stelle der besten Hautpermeabilität hinter dem Ohr beträgt die Wirkdauer ca. 72 Stunden. Für die optimale Wirkung ist ein Beginn der Applikation ca. sechs Stunden vor dem Reiseantritt erforderlich. Eine Vielzahl weiterer Medikamente findet sich in (Tab.4). Bei den meisten Antivertiginosa tritt der Effekt aber schon eher ein (ca. 30 Minuten nach Verabreichung).

Vor dem Antritt von Reisen ist die Einnahme von leichten, geringen Speisemengen empfehlenswert. Milchprodukte sollten gemieden werden. Während der Reise ist es ratsam, den Horizont oder ein Objekt zu fixieren und in Fahrtrichtung zu blicken (visuelle Kontrolle). Möglicherweise klagen die Personen, welche ein Fahrzeug steuern, deshalb weitaus seltener über Kinetosen $[369,372]$. Kinetosebeschwerden klingen bis zu 24 Stunden nach Beendigung der Reizexposition ab [15].

Mit einem kinetoseinduzierendem Training (wiederholte Reizexposition) kann die Schwelle der Entstehung einer Kinetose verschoben werden [15]. 


\section{Literatur}

${ }^{1}$ Ilgner J, Loske A. Zur Etymologie des Wortes „Schwindel“. HNO aktuell 1997; 12: $339-340$

${ }^{2}$ Reker U, Frese KA. Objektive Kriterien für die Begutachtung des vestibulären Schwindels. Laryngo Rhino Otol 1998; 77: 179-184

${ }^{3}$ Probst R. Schwindel aus neurootologischer Sicht. Therapeutische Umschau 1995; 52: 724-731

${ }^{4}$ Schaaf H, Nelting M, Hesse G. Schwindel - psychosomatisch gesehen. München: Profil, 1999

${ }^{5}$ Dieterich M, Eckardt-Henn A. Neurologische und somatoforme Schwindelsyndrome. Nervenarzt 2004; 75: 281 - 302

${ }^{6}$ Schaaf H. Psychogener Schwindel in der HNO-Heilkunde. HNO 2001; 49: $307-315$

${ }^{7}$ Langman J. Medizinische Embryologie. Stuttgart: Thieme, 1977

${ }^{8}$ Murofushi T, Ouvrier RA, Parker GD, Graham RI, da Silva M, Halmagyi GM. Vestibular abnormalities in charge association. Ann Otol Rhinol Laryngol 1997; 106: 129-134

${ }^{9}$ Lemmerling MM, Vanzieleghem BD, Mortier GR, Dhooge IJ, Kunnen MF. Unilateral semicircular canal aplasia in Goldenhar's syndrome. Am J Neuroradiol 2000; 21: 1334-1336

${ }^{10}$ Lang J. Anatomie des vestibulären Systems. In: Haid CT (Hrsg). Schwindel aus interdisziplinärer Sicht. Stuttgart: Thieme, 2003: $4-16$

${ }^{11}$ Rennie KJ, Manning KC, Ricci AJ. Mechano-electrical transduction in the turtle utricle. Biomed Sci Instrum 2004; 40: 441 - 444

${ }^{12}$ Spoendlin H. Strukturelle Organisation des Innenohres. In: Helms J, Herberhold C, Kastenbauer E (Hrsg). Oto-Rhino-Laryngologie in Klinik und Praxis. Bd 1. Stuttgart: Thieme, 1994: $32-74$

${ }^{13}$ Reiss G, Wolkowiak W, Zenner HP, Plinkert PK, Lehnhardt E. Das stato-akustische Organ. Hannover: Duphar Pharma, 1989

${ }^{14}$ Scherer H. Das Gleichgewicht. Berlin: Springer, 1997

${ }^{15}$ Brandt T, Dieterich M, Strupp M. Vertigo. Darmstadt: Steinkopff, 2004

${ }^{16}$ Brandt T, Bartenstein P, Janek A, Dieterich M. Reciprocal inhibitory visual-vestibular interaction. Visual motion stimulation deactivates the parieto-insular vestibular cortex. Brain 1998; 121: 1749-1758

${ }^{17}$ Dieterich M, Brandt T. Brain activation studies on visual-vestibular and ocular motor interaction. Curr Opin Neurol 2000; 13: $13-18$

18 Dieterich M, Brandt T. Vestibular system: anatomy and functional magnetic resonance imaging. Neuroimaging Clin N Am 2001; 11: $263-273$

${ }^{19}$ Brandt T, Glasauer S, Stephan T, Bense S, Yousry TA, Deutschlander A, Dieterich M. Visual-vestibular and visuovisual cortical interaction: new insights from fMRI and pet. Ann N Y Acad Sci 2002; 956: $230-241$

${ }^{20}$ Kleinschmidt A, Thilo KV, Büchel C, Gresty MA, Bronstein AM, Frackowiak RS. Neural correlates of visual-motion perception as object- or self-motion. Neuroimage 2002; 16: 873-882

${ }^{21}$ Dieterich M, Bense S, Stephan T, Yousry TA, Brandt T. fMRI signal increases and decreases in cortical areas during small-field optokinetic stimulation and central fixation. Exp Brain Re 2003; 148: 117- 127

${ }^{22}$ Naidich TP, Kang E, Fatterpekar GM, Delman BN, Gultekin SH, Wolfe D, Ortiz O, Yousry I, Weismann M, Yousry TA. The insula: anatomic study and MR imaging display at 1.5 T. AJNR Am J Neuroradiol 2004; 25: $222-232$

${ }^{23}$ Brandt T, Dieterich M. Central vestibular syndromes in roll, pitch and yaw planes. Topographic diagnosis of brainstem disorders. Neuroophthalmology 1995; 15: $291-303$

${ }^{24}$ Leblanc A. Atlas of hearing and balance organs. Paris: Springer, 1999

${ }^{25}$ Schreiner L. Neuere experimentelle und klinische Erkenntnisse zur Frage einer interlabyrinthären Verbindung. Laryngo Rhino Otol 1999; 78: $387-393$

${ }^{26}$ Harris JP, Low NC, House WF. Contralateral hearing loss following inner ear injury: sympathetic cochleolabyrinthitis? Am J Otol 1985; 6: $371-377$

${ }^{27}$ Salt AN, Rask-Andersen H. Responses of the endolymphatic sac to perilymphatic injections and withdrawals: evidence for the presence of a one-way valve. Hear Res 2004; 191: 90 - 100

28 Schuknecht HF, Ruther A. Blockage of longitudinal flow in endolymphatic hydrops. Eur Arch Otorhinolaryngol 1991; 248: 209-217

${ }^{29}$ Westhofen M. Vestibulärer Schwindel. Neue Entwicklungen zwischen Otologie, Neurologie und Otochirurgie. Laryngo Rhino Otol 2001; 80: 651
${ }^{30}$ Walther LE, Schmidt WD, Gudziol H, Scheibe A, Scheiding B, Rössler B, Fassler D, Beleites E. Nahinfrarotreizung des Gleichgewichtsorgans - erste klinische Erfahrungen. Laryngo Rhino Otol 2003; 82: 687-692

${ }^{31}$ Walther LE, Gudziol H, Beleites E. Gezielte Strahlungskalorisation des Gleichgewichtsorgans mittels Nahinfrarot. Laryngo Rhino Otol 2004; 83: $88-95$

32 Walther LE, Scheibe A, Schmidt WD, Römhild D, Fassler D, Gudziol H, Beleites E. Untersuchungen zur thermischen Reizung des Gleichgewichtsorgans mittels Wärmestrahlung (NIR). HNO 2004; 52: 525-532

${ }^{33}$ Halmagyi GM, Curthoys IS. A clinical sign of canal paresis. Arch Neurol 1988; 45: 737-739

${ }^{34}$ Halmagyi GM, Aw ST, Karlberg M, Curthoys IS, Todd MJ. Inferior vestibular neuritis. Ann N Y Acad Sci 2002; 956: 306-313

${ }^{35}$ Westhofen M. Aktueller Stand der Diagnostik und der operativen Therapie von Otolithenerkrankungen. In: Stoll W (Hrsg). Vestibuläre Erkrankungen - eine interdisziplinäre Herausforderung. Stuttgart: Thieme, 2001: 83-97

${ }^{36}$ Kömpf D. Der pseudovestibuläre Kleinhirninsult. Nervenarzt 1986; 57: $163-166$

${ }^{37}$ Grad A, Baloh RW. Vertigo of vascular origin. Clinical and electronystagmographic features in 84 cases. Arch Neurol 1989; 46: 281 - 284

${ }^{38}$ Gomez CR, Cruz-Flores S, Malkoff MD, Sauer CM, Burch CM. Isolated vertigo as a manifestation of vertebrobasilar ischemia. Neurology 1996; 47: $94-97$

${ }^{39}$ Berlit P. Isolierter Schwindel bei vertebrobasilärer Ischämie - gibt es das? HNO 1998; 46: 296-300

40 Walther LE, Beleites E. Schwindeldiagnostik. Ärztebl Thüring 1999; 10: $549-554$

${ }^{41}$ Schmiz A, Haibt-Lüttke G, Albrecht G, Hagen R, Gustorf-Aeckerle R. Die Thrombose der Arteria basilaris - eine seltene Differenzialdiagnose des Hörsturzes und des Vestibularisausfalls. Laryngo Rhino Otol 2000; 79: 253-259

42 Westhofen M. Hals-Nasen-Ohrenheilkunde systematisch. Bremen: Uni-Med, 2001

43 Whitehead RE, MacDonald CB, Melhem ER, McMahon L. Spontaneous labyrinthine hemorrhage in sickle cell disease. AJNR Am J Neuroradiol 1998; 19: $1437-1440$

${ }^{44}$ Stange T. Hämorrhagische Labyrinthitis: Ursache für akuten Innenohrausfall. Vortrag XIX. Neusser HNO-Kolloquium 2004

${ }^{45}$ Helling K, Clarke AH, Watanabe N, Scherer H. Morphologische Untersuchungen zur Form der Cupula in der Bogengangsampulle. HNO 2000; 48: $822-827$

${ }^{46}$ Scherer H, Helling K, Watanabe S. Zur Pathogenese der so genannten Neuropathia vestibularis - Experimente an der Ampulle. In: Stoll W (Hrsg). Vestibuläre Erkrankungen - eine interdisziplinäre Herausforderung. Stuttgart: Thieme, 2001: 16-22

${ }^{47}$ Helling K, Watanabe N, Jijiwa H, Mizuno Y, Watanabe S, Scherer H. Altered cupular mechanics: a cause of peripheral vestibular disorders? Acta Otolaryngol 2002; 122: 386-391

48 Arbusow V, Theil D, Strupp M, Mascolo A, Brandt T. HSV-1 not only in human vestibular ganglia but also in the vestibular labyrinth. Audiol Neurootol 2001; 6: 259-262

${ }^{49}$ Gacek RR, Gacek MR. Vestibular neuronitis: a viral neuropathy. In: Arnold W (Hrsg). Viral neuropathies in the temporal bone. Adv Otorhinolaryngol 2002; 60: 54-66

${ }^{50}$ Fenton JE, Shirazi A, Turner J, Fagan PA. Atypical vestibular neuritis: a case report. Otolaryngol Head Neck Surg 1995; 112: 738 - 741

${ }^{51}$ Strupp M, Jager L, Müller-Lisse U, Arbusow V, Reiser M, Brandt T. High resolution Gd-DTPA MR imaging of the inner ear in 60 patients with idiopathic vestibular neuritis: no evidence for contrast enhancement of the labyrinth or vestibular nerve. J Vestib Res.1998; 8: 427-433

52 Shimizu T, Sekitani T, Hirata T, Hara H. Serum viral antibody titer in vestibular neuronitis. Acta Otolaryngol Suppl 1993; 503: $74-78$

53 Walther LE, Hentschel H, Oehme A, Gudziol H, Beleites E. Herpesviren bei akuter Innenohrschwerhörigkeit und „Vestibularisausfall“: klinische und serologische Befunde. Otorhinolaryngol Nova 2002; 12: $124-131$

${ }^{54}$ Haid T, Mirsberger J. Die periphere Neuropathia vestibularis und ein zentral-vestibuläres Äquivalent. HNO 1985; 33: $262-270$

55 Ellies M, Politycki C, Laskawi R. Therapie des isolierten einseitigen Vestibularisausfalls. Otorhinolaryngol Nova 1996; 6: 264-270 
${ }^{56}$ Herzog N, Allum JHJ, Probst R. Verlauf der kalorischen Erregbarkeit nach akuter peripherer vestibulärer Funktionsstörung. HNO 1997; 45: $123-127$

${ }^{57}$ Strupp M, Zingler VC, Arbusow V, Niklas D, Maag KP, Dieterich M, Bense S, Theil D, Jahn K, Brandt T. Methylprednisolone, valacyclovir or the combination for vestibular neuritis. N Engl J Med. 2004; 351: $354-361$

${ }^{58}$ Gacek RR, Gacek MR. Antiviral therapy of vestibular ganglionitis. In: Arnold W (Hrsg). Viral neuropathies in the temporal bone. Adv Otorhinolaryngol 2002; 60: 124-126

${ }^{59}$ Scholtz AW, Schwarz M, Baumann W, Kleinfeldt D, Scholtz HJ. Treatment of vertigo due to acute unilateral vestibular loss with a fixed combination of cinnarizine and dimenhydrinate: a double-blind, randomized, parallel-group clinical study. Clin Ther 2004; 26: 866-877

${ }^{60}$ Schneider D, Kiessling B, Wieczorek M, Bognar-Steinberg I, Schneider $\mathrm{L}$, Claussen CF. Influence of 3 antivertiginous medications on the vigilance of healthy volunteers. Int J Clin Pharmacol Ther 2003; 41: $171-181$

${ }^{61}$ Weiser M, Strosser W, Klein P. Homeopathic vs conventional treatment of vertigo: a randomized double-blind controlled clinical study. Arch Otolaryngol Head Neck Surg.1998; 124: 879-885

62 Westhofen M. Verlauf der kalorischen Erregbarkeiten nach akuter peripherer Funktionsstörung. HNO 1997; 45: 112 - 113

${ }^{63}$ Igarashi M. Compensation for peripheral vestibular disturbances animal studies. In: Bles W, Brandt T (Hrsg). Disorders of posture and gait. Amsterdam: Elsevier, 1986: 337-351

${ }^{64}$ Gramowski KH. Das trainierte Labyrinth. HNO (Berl) 1964; 12: 105

${ }^{65}$ Ehrenberger K. Prinzipien einer konservativen Therapie peripherer und zentraler Gleichgewichtsstörungen. HNO 1988; 36: 301 - 304

${ }^{66}$ Zee DS. Perspectives on the pharmacotherapy of vertigo. Arch Otolaryngol 1985; 111: 609-612

${ }^{67}$ Curthoys IS, Halmagyi GM. Vestibular compensation: a review of the oculomotor, neural, and clinical consequences of unilateral vestibular loss. J Vestib Res 1995; 5: 67-107

${ }^{68}$ Lacour M. Restoration of nerve function: Models and concepts. In: Lacour M, Toupet M, Denise P, Christen Y (Hrsg). Vestibular compensation: Facts, theories and clinical perspectives. Paris: Elsevier, 1989: $11-34$

${ }^{69}$ Curthoys IS, Halmagyi GM. Vestibular compensation. In: Büttner U. Vestibular dysfunction and its therapy. Adv Otorhinolaryngol 1999; 55: $82-110$

${ }^{70}$ Cawthorne T. Vestibular injuries. Proc R Soc Med 1946; 39: 270-273

${ }^{71}$ Cooksey FS. Rehabilitation in vestibular injuries. Proc R Soc Med 1946; 39: $273-275$

72 Sterkers JM. La méthode du point de mire pur la rééducation anti-vertigineuse. Rev Laryngol (Paris) 1977; 98: 535-539

${ }^{73}$ Hamann KF. Training gegen Schwindel. Berlin: Springer, 1987

${ }^{74}$ Hamann KF. Rehabilitation von Patienten mit vestibulären Störungen. HNO 1988; 36: 305-307

75 Gans RE. Vestibular Rehabilitation: Protocols and programs. San Diego: Singular Publishing Group, 1996

${ }^{76}$ Cesarini A, Alpini D. Vertigo and diziness rehabilitation. Berlin: Springer, 1999

${ }^{77}$ Strupp M, Arbusow V, Brandt T. Exercise and drug therapy alter recovery from labyrinth lesion in humans. Ann N Y Acad Sci 2001; 942: 79-94

78 Strupp M, Arbusow V, Maag KP, Gall C, Brandt T. Vestibular exercises improve central vestibulospinal compensation after vestibular neuritis. Neurology 1998; 51: $838-844$

${ }^{79}$ Jerram AH, Darlington CL, Smith PF. Methylprednisolone reduces spontaneous nystagmus following unilateral labyrinthectomy in guinea pig. Eur J Pharmacol 1995; 275: 291 -293

80 Pfaltz CR, Meran A. Sudden unilateral loss of vestibular function. Adv Oto Rhino Laryng 1981; 27: 159-167

81 Pfaltz CR. Vestibular compensation. Acta Otolaryngol 1983; 95: 402-406

${ }^{82}$ Stoll W. Die Begutachtung vestibulärer Störungen. Laryng Rhinol 1979; 58: 509- 515

${ }^{83}$ Stoll W. Untersuchungsmethoden zur Objektivierung und Begutachtung vestibulärer Störungen. Akt Neurol 1982; 9: 121 - 125

${ }^{84}$ Stoll W. Das neurootologische Gutachten: Konsensusbericht und Fazit. In: Stoll W (Hrsg). Das neurootologische Gutachten. Stuttgart: Thieme, 2002: 146 - 155
${ }^{85}$ Krückels G, Dujardin H, Westhofen M. Verfahren zur Abschätzung der vestibulären Kompensationsleistung - Klinische Beobachtung/quantitative Neurootometrie? Laryngo Rhino Otol 1999; 78: 204-209

${ }^{86}$ Kley W, Reinecken R. Drehpendelprüfung (Eine Drehschwachreizprüfmethode des Vestibularapparates). Z Laryngol Rhinol Otol 1961; 40: $68-77$

${ }^{87}$ Söllner C, Burghammer M, Busch-Nentwich E, Berger J, Schwarz H, Riekel C, Nicolson T. Control of crystal size and lattice formation by starmaker in otolith biomineralization. Science 2003; 302: 282-286

${ }^{88}$ Kawamata S, Igarashi Y. Growth and turnover of rat otoconia as revealed by labeling with tetracycline. Anat Rec 1995; 242: 259-266

${ }^{89}$ Ross MD, Johnsson LG, Peacor D, Allard LF. Observation on normal and degenerating human otoconia. Ann Otol 1976; 85: 310-326

${ }^{90} \mathrm{Lim}$ DJ. Formation and fate of the otoconia. Ann Otol 1973; 82: $23-35$

91 Takumida M, Zhang DM, Yajin K. In vitro calcium ion turnover in otoconia of the guinea pig. Auris Nasus Larynx 1997; 24: 119-124

92 Takumida M, Zhang DM, Yajin K, Harada Y. Polychromatic labeling of otoconia for the investigation of calcium turnover. ORL J Otorhinolaryngol Relat Spec 1997; 59: 4-9

93 Parnes LS, Agrawal SK, Atlas J. Diagnosis and management of benign paroxysmal positional vertigo (BPPV). CMAJ 2003; 169: 681 - 693

94 Zucca G, Valli S, Valli P, Mira E. Why do benign paroxysmal positional vertigo episodes recover spontaneously? J Vestibul Res 1998; 8: 325-329

${ }^{95}$ Lindsay JR, Hemenway WG. Postural vertigo due to unilateral sudden partial loss of vestibular function. Ann Otol Rhinol Laryngol 1956; 65: $692-706$

${ }^{96}$ Lindsay JR. Paroxysmal postural vertigo and vestibular neuronitis. Arch Otolaryngol 1967; 85: 544-547

${ }^{97}$ Parnes LS, McClure JA. Free floating endolymph particles: A new operative finding during posterior semicircular canal occlusion. Laryngoscope 1992; 102: 988 - 992

98 Welling DB, Parnes LS, O’Brien B, Bakaletz LO, Brackmann DE, Hinojosa R. Particulate matter in the posterior semicircular canal. Laryngoscope 1997; 107: $90-94$

${ }^{99}$ Walther LE. Benigner paroxysmaler Lagerungsschwindel. Forum HNO 2002; 5: $165-170$

${ }^{100}$ Schmäl F, Stoll W. Diagnostik und Therapie des benignen paroxysmalen Lagerungsschwindels. Laryngo Rhino Otol 2002; 81: 368 - 380

101 von Brevern M, Lempert T. Benigner paroxysmaler Lagerungsschwindel. HNO 2002; 50: 671-681

102 Korres S, Balatsouras DG, Kaberos A, Economou C, Kandiloros D, Ferekidis E. Occurrence of semicircular canal involvement in benign paroxysmal positional vertigo. Otol Neurotol 2002; 23: 926-932

${ }^{103}$ Bertholon P, Bronstein AM, Davies RA, Rudge P, Thilo KV. Positional down beating nystagmus in 50 patients: cerebellar disorders and possible anterior semicircular canalithiasis. J Neurol Neurosurg Psychiatry 2002; 72: 366-372

104 Steddin S, Brandt T. Unilateral mimicking bilateral benign paroxysmal positioning vertigo. Arch Otolaryngol Head Neck Surg. 1994; 120: $1339-1341$

105 Sakata E, Uchida Y, Nakano Y, Takahashi K. Pathophysiology of positional vertigo of the malignant paroxysmal type. Auris Nasus Larynx 1984; 11: 79-90

${ }^{106}$ Sakata E, Ohtsu K, Shimura H, Skai S. Positional nystagmus of benign paroxysmal type (BPPV) due to cerebellar vermis lesions: pseudoBPPV. Auris Nasus Larynx 1987; 14: 17-21

107 Califano L, Montanaro SC, Capparuccia PG, di Maria D, Villari G. Case report: ipsilateral association of posterior and anterior canalolithiasis. Acta Otorhinolaryngol Ital 2002; 22: $376-379$

108 Steddin S, Brandt T. Benigner paroxysmaler Lagerungsschwindel. Nervenarzt 1994; 65: $505-510$

109 Bertholon P, Faye MB, Tringali S, Martin C. Benign paroxysmal positional vertigo of the horizontal canal. Clinical features in 25 patients. Ann Otolaryngol Chir Cervicofac 2002; 119: 73 - 80

110 Epley JM. Human experience with canalith repositioning maneuvers. Ann N Y Acad Sci 2001; 942: 179-191

111 Semont A, Freyss G, Vitte E. Curing the BPPV with a liberatory maneuver. Adv Otorhinolaryngol 1988; 42: 290-293

112 Epley JM. The canalith repositioning procedure: for treatment of benign paroxysmal positioning vertigo. Otolaryngol Head Neck Surg 1992; 107: 399-404

113 Hain TC, Helminski JO, Reis IL, Uddin MK. Vibration does not improve results of the canalith repositioning procedure. Arch Otolaryngol Head Neck Surg 2000; 126: 617-622 
114 Li JC. Mastoid oscillation: a critical factor for success in canalith repositioning procedure. Otolaryngol Head Neck Surg 1995; 112: 670-675

115 Brandt T, Daroff RB. Physical therapy for benign paroxysmal positional vertigo. Arch Otolaryngol 1980; 106: 484-485

116 Lempert T, Thiel-Wilck K. A positional maneuver for treatment of horizontal-canal benign positional vertigo. Laryngoscope 1996; 106: $476-478$

117 Vannucchi P, Giannoni B, Pagnini P. Treatment of horizontal semicircular canal benign paroxysmal positional vertigo. J Vestib Res 1997; 7: $1-6$

118 Cohen HS, Kimball KT. Treatment variations on the Epley maneuver for benign paroxysmal positional vertigo. Am J Otolaryngol 2004; 25: $33-37$

119 Iro H, Waldfahrer F, Wolf SR, Gjuric M, Haid CT, Wigand ME. Chirurgische Therapieoptionen bei Schwindel. In: Stoll W (Hrsg). Vestibuläre Erkrankungen - eine interdisziplinäre Herausforderung. Stuttgart: Thieme, 2001: 77-82

${ }^{120}$ Haid CT. Leitsymptome beim Akustikusneurinom. In: Stoll W. Differenzialdiagnose Schwindel. Berlin, Heidelberg: Springer, 1998: $29-37$

${ }^{121}$ Silverstein H. Surgery for vertigo (you don't have to live with it). J Otolaryngol 1981; 10: $343-358$

${ }^{122}$ Gacek RR. Further observations on posterior ampullary nerve transection for positional vertigo. Ann Otol Rhinol Laryngol 1978; 87: $300-305$

${ }^{123}$ Bergström B. Morphology of the vestibular nerve. I. Anatomical studies of the vestibular nerve in man. Acta Otolaryngol 1973; 76: $162-172$

${ }^{124}$ Leuwer RM, Westhofen M. Surgical anatomy of the singular nerve. Acta Otolaryngol 1996; 116: 576-580

${ }^{125}$ Nomura Y, Ooki S, Kukita N, Young YH. Laser labyrinthectomy. Acta Otolaryngol 1995; 115: $158-161$

${ }^{126}$ Gacek RR. Technique and results of singular neurectomy for the management of benign paroxysmal positional vertigo. Acta Otolaryngol 1995; 115: $154-157$

127 Agrawal SK, Parnes LS. Human experience with canal plugging. Ann N Y Acad Sci 2001; 942: 300-305

128 Parnes LS, McClure JA. Posterior semicircular canal occlusion for intractable benign paroxysmal positional vertigo. Ann Otol Rhinol Laryngol 1990; 99: 330-334

129 Parnes LS, McClure JA. Posterior semicircular canal occlusion in the normal hearing ear. Otolaryngol Head Neck Surg 1991; 104: 52 - 57

130 Parnes LS. Update on posterior canal occlusion for benign paroxysmal positional vertigo. Otolaryngol Clin North Am 1996; 29: 333 - 342

131 Strutz J, Menke K. Die Chirurgie des benignen paroxysmalen Lagerungsschwindels. (Abstract) HNO 1998; 46: 417

132 Walsh RM, Bath AP, Cullen JR, Rutka JA. Long-term results of posterior semicircular canal occlusion for intractable benign paroxysmal positional vertigo. Clin Otolaryngol 1999; 24: 316 - 323

${ }^{133}$ Brantberg K, Bergenius J. Treatment of anterior benign paroxysmal positional vertigo by canal plugging: a case report. Acta Otolaryngol 2002; 122: $28-30$

${ }^{134}$ Antonelli PJ, Lundy LB, Kartush JM, Burgio DL, Graham MD. Mechanical versus $\mathrm{CO}_{2}$ laser occlusion of the posterior semicircular canal in humans. Am J Otol 1996; 17: 416-420

135 Wilpizeski C. Experimental labyrinthotomy in monkeys by argon and carbon dioxide lasers. Otolaryngol Head Neck Surg 1981; 89: 197-203

${ }^{136}$ Anthony PF. Partitioning of the labyrinth: application in benign paroxysmal positional vertigo. Am J Otol 1991; 12: 388-393

${ }^{137}$ Nomura Y. Argon laser irradiation of the semicircular canal in two patients with benign paroxysmal positional vertigo. J Laryngol Otol 2002; 116: $723-725$

138 Anthony PF. Utricular macular ablation for benign paroxysmal positional vertigo. Ear Nose Throat J 1996; 75: 416-421

139 Basser LS. Benign paroxysmal vertigo of childhood (a variety of vestibular neuronitis). Brain 1964; 87: 141 - 152

${ }^{140}$ Herraiz C, Calvin FJ, Tapia MC, de Lucas P, Arroyo R. The migraine: benign paroxysmal vertigo of childhood complex. Int Tinnitus J 1999; 5: $50-52$

141 Drigo P, Carli G, Laverda AM. Benign paroxysmal vertigo of childhood. Brain Dev 2001; 23: $38-41$

142 Uneri A, Turkdogan D. Evaluation of vestibular functions in children with vertigo attacks. Arch Dis Child 2003; 88: 510-551
${ }^{143}$ Hamann KF, von Czettritz G. Neue Aspekte zur Differenzialdiagnose des kindlichen Schwindels. HNO 1987; 35: 267-269

${ }^{144}$ Hilton M, Pinder D. Benign paroxysmal positional vertigo. BMJ 2003 326: 673

${ }^{145}$ Sakata E. Das neurootologische Studium über die Läsion des Kleinhirnwurms. Equilibrium Res 1971; Suppl 1: 30-48

${ }^{146}$ Sakata E, Uchida Y, Nakano Y, Takahashi K. Pathophysiology of positional vertigo of the malignant paroxysmal type. Auris Nasus Larynx 1984; 11: 79-90

147 Sakata E, Ohtsu K, Shimura H, Skai S. Positional nystagmus of benign paroxysmal type (BPPV) due to cerebellar vermis lesions: pseudoBPPV. Auris Nasus Larynx 1987; 14: 17-21

148 Del RioM, Arriaga MA. Benign positional vertigo: prognostic factors. Otolaryngol Head Neck Surg 2004; 130: 426-429

${ }^{149}$ Hilton M, Pinder D. The Epley (canalith repositioning) manoeuvre for benign paroxysmal positional vertigo. Cochrane Database Syst Rev 2004; 2: CD003162

${ }^{150}$ Asawavichianginda S, Isipradit P, Snidvongs K, Supiyaphun P. Canalith repositioning for benign paroxysmal positional vertigo: a randomized, controlled trial. Ear Nose Throat J 2000; 79: $732-734$, $736-737$

151 Woodworth BA, Gillespie MB, Lambert PR. The canalith repositioning procedure for benign positional vertigo: a meta-analysis. Laryngoscope 2004; 114: 1143 - 1146

152 Okaja M. ebm 00858 (038.072). In: The Cochrane Library, 2004:4. http://www.ebm-guidelines.com

153 Li JC, Li CJ, Epley J, Weinberg L. Cost-effective management of benign positional vertigo using canalith repositioning. Otolaryngol Head Neck Surg 2000; 122: 334-339

154 Stoll W. Morbus Menière. In: Stoll W (Hrsg). Differenzialdiagnose Schwindel. Berlin: Springer, 1998: 19-25

155 Michel O. Morbus Menière. Stuttgart: Thieme, 1997

156 Silverstein H, Hyman SM, Feldbaum J, Silverstein D. Use of streptomycin sulfate in the treatment of Menière's disease. Otolaryngol Head Neck Surg 1984; 92: 229-232

157 Schaaf H, Seling B, Rienhoff NK, Laubert A, Nelting M, Hesse G. Sind rezidivierende Tieftonhörverluste - ohne Schwindel - die Vorstufe eines Morbus Menière? HNO 2001; 49: 543-547

158 Rask-Andersen H, Stahle J. Immunodefence of the inner ear? Lymphocyte-macrophage interaction in the endolymphatic sac. Acta Otolaryngol 1980; 89: 283-294

${ }^{159}$ Arnold W, Altermatt HJ, Gebbers JO. Qualitativer Nachweis von Immunglobulinen im menschlichen Saccus endolymphaticus. Laryngo Rhino Otol 1984; 63: 464-467

160 Paparella MM, Djalilian HR. Etiology, pathophysiology of symptoms, and pathogenesis of Menière's disease. Otolaryngol Clin North Am 2002; 35: 529-545

161 Barbara M, Attanasio G, Petrozza V, Modesti A, Filipo R. The endolymphatic sac as the immunocompetent organ of the inner ear. Ann N Y Acad Sci 1997; 830: 243 -252

${ }^{162}$ Angelborg C. Pharmacological treatment of Menière's disease. A review of common remedies with special emphasis on vasodilators, including hyperosmolar substances and hearing. Scand Audiol Suppl 1986; 26: $33-36$

${ }^{163}$ Arenberg IK, Lemke C, Shambaugh GE Jr. Viral theory for Menière's disease and endolymphatic hydrops: overview and new therapeutic options for viral labyrinthitis. Ann N Y Acad Sci 1997; 830: 306-313

${ }^{164}$ Arnold W, Niedermeyer HP. Herpes simplex virus antibodies in the perilymph of patients with Menière disease. Arch Otolaryngol Head Neck Surg 1997; 123: 53-56

165 Morrison AW. Anticipation in Menière's disease. J Laryngol Otol 1995; 109: 499-502

166 Düwel P, Jüngling E, Westhofen M, Lückhoff A. Potassium currents in vestibular type II hair cells activated by hydrostatic pressure. Neuroscience 2003; 116: $963-972$

${ }^{167}$ Arab SF, Düwel P, Jüngling E, Westhofen M, Lückhoff A. Inhibition of voltage-gated calcium currents in type II vestibular hair cells by cinnarizine. Naunyn Schmiedebergs Arch Pharmacol 2004; 369: 570- 575

168 Haid CT. Evaluation of flunarizine in patients with Menière's disease. Subjective and vestibular findings. Acta Otolaryngol Suppl 1988; 460: $149-153$

169 Jäger L, Strupp M, Brandt T, Reiser M. Bildgebung von Labyrinth und Nervus vestibularis. Nervenarzt 1997; 68: 443 - 458 
${ }^{170}$ Krombach GA, Schmitz-Rode T, Tacke J, Düwel P, DiMartino E, Engelke JC, Günther RW, Westhofen M. Kernspintomografische Darstellung des Innenohrs bei Patienten mit sensorineuralem Hörverlust und Schwindel. Laryngo Rhino Otol 2001; 80: 177-181

${ }^{171}$ Fujita N, Nario K, Yamanaka T, Ueda T, Matsunaga T. Neurovascular compression syndrome with Menière's disease - a report of the treatment of a patient with microvascular decompression. Auris Nasus Larynx 1998; 25: $203-207$

172 Commitee on Hearing and Equilibrium of American Academy of Otolaryngology. Guidelines for diagnosis and evaluation for the therapy in Menière's disease. Otolaryngol Head Neck Surg 1995; 113: $1881-1885$

173 Waldfahrer F, Finke C, Iro H. Aktuelle Aspekte der medikamentösen Schwindeltherapie. In: Stoll W (Hrsg). Vestibuläre Erkrankungen. Stuttgart: Thieme, 2001: 98 - 107

174 Schmäl F, Stoll W. Medikamentöse Schwindeltherapie. Laryngo Rhino Otologie 2003; 28: 44-66

175 Deering RB, Prescott P, Simmons RL, Downey LJ. A double-blind crossover study comparing betahistine and cinnarizine in the treatment of recurrent vertigo in patients in general practice. Curr Med Res Opin 1986; 10: 209-214

${ }^{176}$ Novotny M, Kostrica R. Fixed combination of cinnarizine and dimenhydrinate versus betahistine dimesylate in the treatment of Ménière's disease: a randomized, double-blind, parallel group clinical study. Int Tinnitus J 2002; 8: 115-123

177 Laurikainen E, Miller JM, Nuttall AL, Quirk WS. The vascular mechanism of action of betahistine in the inner ear of the guinea pig. Eur Arch Otorhinolaryngol 1998; 255: 119-123

178 Kawabata A, Sasa M, Kishimoto T, Takaori S. Effects of anti-vertigo drugs on medial vestibular nucleus neurons activated by horizontal rotation. Jpn J Pharmacol 1991; 55: 101 - 106

${ }^{179}$ James AL, Burton MJ. Betahistine for Menière's disease or syndrome. Cochrane Database Syst Rev 2001; 1: CD001873

${ }^{180}$ Mierzwinski J, Kazmierczak H, Pawlak-Osinska K, Piziewicz A. The effect of betahistine on vestibular habituation: comparison of rotatory and sway habituation training. Acta Otolaryngol 2001; 121: 610-615

181 van Deelen GW, Huizing EH. Use of a diuretic (Dyazide) in the treatment of Menière's disease. A double-blind cross-over placebo-controlled study. ORL J Otorhinolaryngol Relat Spec 1986; 48: 287-292

182 van de Heyning PH. Therapeutic strategies for vertigo in Menière's disease. Abstract 2nd vertigo day Berlin: 1998

183 Vollrath M, Marangos N, Hesse G. Die Dehydratationstherapie des Tieftonhörverlustes. HNO 1990; 38: 154 - 157

184 Pappas DG, Banyas JB. A newly recognized etiology of Menière's syndrome. A preliminary report. Acta Otolaryngol Suppl 1991; 485: 104-107

${ }^{185}$ Vischer M, Arnold W. Kortisonsensible Innenohrschwerhörigkeit. Otorhinolaryngol Nova 1991; 1: $75-79$

${ }^{186}$ Niedermeyer HP, Zahneisen G, Luppa P, Busch R, Arnold W. Cortisol levels in the human perilymph after intravenous administration of prednisolone. Audiol Neurootol 2003; 8: 316-321

187 Waksman SA, Bugie E, Schatz A. Isolation of antibiotic substances from soil microorganisms with spezial reference to streptothricin and streptomycin. Proc Staff Meet Mayo Clin 1944; 19: 537

188 Hinshaw HC, Feldman WH. Streptomycin in treatment of clinical tuberculosis: A preliminary report. Proc Staff Meet Mayo Clin 1945; 20 : 313

189 Causse R, Gondet I, Vallancien B. Action vestibulaire de la streptomycine chez souris. C Soc Biol (Paris) 1948; 142: 747

${ }^{190}$ Fowler EP. Streptomycin treatment of vertigo. Trans Am Acad Ophthalmol Otolaryngol Head Neck Surg 1948; 113: 181 - 185

${ }^{191}$ Schuknecht HF. Ablation therapy for the relief of Menière's diesease. Trans Am Laryngol Rhinol Otol Soc (60th Meeting) 1956: 589-600

192 Schuknecht HF. Ablation therapy in the management of Menière's disease. Acta Otolaryngol. 1957; 47 (Suppl 132): 1-42

193 Weinstein MJ, Leudemann GM, Oden EM et al. Gentamicin: A new broad spectrum antibiotic complex. Antimicrob Agents Chemother 1963; 3: 1

194 Bagger-Sjöback D. Effect of streptomycin and gentamicin on the inner ear. Ann N Y Acad Sci 1997; 830: 120-129

${ }^{195}$ Holz E, Stange G, Terajama Y. Minderung der Ototoxizität basischer Streptomycesantibiotika anhand tierexperimenteller Untersuchungen. Vortrag IV. Int Kongr F Infektionskrankheiten. München: Schattauer, 1966
${ }^{196}$ Lange G. Isolierte medikamentöse Ausschaltung eines Gleichgewichtsorgans beim Morbus Menière mit Streptomycin-Ozothin. Arch Klin Exp Ohr Nas u Kehlk Heilk 1968; 191: 545

197 Lange G. Ototoxische Antibiotika in der Behandlung des Morbus Menière. Therapiewoche 1976; 26: 3366-3369

198 Schmidt CL, Beck C. Behandlung des Morbus Menière mit intratympanal appliziertem Gentamicin-Sulfat. Laryng Rhinol Otol 1980; 59: 804-807

${ }^{199}$ Nedzelski JM, Schessel DA, Bryce GE, Pfleiderer AG. Chemical labyrinthectomy: local application of gentamicin for the treatment of unilateral Meniere's disease. Am J Otol 1992; 13: 18-22

${ }^{200}$ Monsell EM, Shelton C. Labyrinthotomy with streptomycin infusion: early results of a multicenter study. The LSI Multicenter Study Group. Am J Otol 1992; 13: 416-422

${ }^{201}$ Monsell ED, Cass SP, Rybak LP. Chemical labyrinthectomy: Methods and results. Otolaryngol Clin N Amer 1993; 26: 737 - 746

${ }^{202}$ Nedzelski JM. Intratympanic Gentamicin results of an ongoing prospective outpatient treatment regimen (AAO-HNS criteria). XV. World Congress of ORL. Istanbul: 1993

${ }^{203}$ Katzke D. Die intratympanale Gentamicinbehandlung bei Morbus Menière. Laryng Rhinol Otol 1982; 61: 4-8

${ }^{204}$ Küppers P, Ahrens H, Blessing R. Die kontinuierliche intratympanale Gentamicin-Infusion beim Morbus Menière. HNO 1994; 42: 429-433

205 Küppers P, Bach-Quang M. Blessing R. Die Gentamicin-Titration mittels Infusionspumpe: Eine neue Form der Menière-Therapie. HNO-Information 1991; 16: 20

206 Jahnke K. Transtympanic application of Gentamicin with cochlea protection. In: Nudol JB (Hrsg). Second International Symposium on Menière's disease. Amsterdam, Berkeley, Milano: Kugler und Ghedini, 1989

${ }^{207}$ Jahnke K, Arweiler D. Die intravenöse Gentamicintherapie bei beidseitigem M. Menière. Laryngo Rhino Otol 1997; 76: 519-522

208 Marks S, Arenberg IK, Hoffer ME. Round-Window-Mikrokatheter-assistierte Mikrodosierung von Gentamicin: Alternative in der Behandlung des Tinnitus bei Patienten mit Morbus Menière. Laryngo Rhino Otol 2000; 79: 327 - 331

${ }^{209}$ Lange G. 27 Jahre Erfahrung mit der transtympanalen Aminoglykosid-Behandlung des Morbus Menière. Laryngo Rhino Otol 1995; 74: $720-723$

${ }^{210}$ Lange G. Die Gentamicin-Injektionstechnik. HNO 1998; 46: $1000-1002$

${ }^{211}$ Lange G. Transtympanic treatment for Menière's disease with Gentamicin-sulfate. In: Vosteen KH, Schuknecht $\mathrm{H}$ et al (Hrsg). Menière's disease. Stuttgart: Thieme, 1981

212 Schacht J, Weiner N. Aminoglykoside-induced hearing loss: a molecular hypothesis. ORL J Otorhinolaryngol Relat Spec 1986; 48: $116-123$

213 Schacht J. Molecular mechanisms of drug-induced hearing loss. Hear Res 1986; 22: $297-304$

${ }^{214}$ Schacht J. Biochemical basis of Aminoglykoside ototoxicity. Otolaryngol Clin North Am 1993; 26: 845-856

215 Park J, Cohen G. Vestibular ototoxicity in check: effects of streptomycin on equilibrium and on ampullary dark cells. Am J Otolaryngol 1982; 6: $117-127$

${ }^{216}$ Zenner HP, Schacht J. Hearing loss caused by Aminoglykoside antibiotics: affect on the membrane component PIP2 in outer hair cells as the mechanism of action. HNO 1986; 34: 417-423

217 Chia SH, Gamst AC, Anderson JP, Harris JP. Intratympanic gentamicin therapy for Menière's disease: a meta-analysis. Otol Neurotol 2004; 25: $544-552$

218 Pfleiderer AG. The current role of local intratympanic gentamicin therapy in the management of unilateral Menière's disease. Clin Otolaryngol 1998; 23: 34-41

${ }^{219}$ Atlas JT, Parnes LS. Intratympanic gentamicin titration therapy for intractable Menière's disease. Am J Otol 1999; 20: 357-363

${ }^{220}$ Martin E, Perez N. Hearing loss after intratympanic gentamicin therapy for unilateral Menière's disease. Otol Neurotol 2003; 24: 800 - 806

221 Quaranta A, Aloisi A, de Benedittis G, Scaringi A. Intratympanic therapy for Menière's disease. High-concentration gentamicin with roundwindow protection. Ann N Y Acad Sci 1999; 884: 410-424

222 Thomsen J, Charabi S, Tos M. Preliminary results of a new delivery system for Gentamicin to the inner ear in patients with Menière's disease. Eur Arch Otorhinolaryngol 2000; 257: 362 - 365 
${ }^{223}$ Hoffer ME, Kopke RD, Weisskopf P, Gottshall K, Allen K, Wester D, Balaban C. Use of the round window microcatheter in the treatment of Menière's disease. Laryngoscope 2001; 111: 2046 - 2049

${ }^{224}$ Minor LB. Intratympanic gentamicin for control of vertigo in Ménière's disease: vestibular signs that specify completion of therapy. Am J Otol 1999; 20: 209-219

225 Magnusson M, Padoan S, Karlberg M, Johansson R. Delayed onset of ototoxic effects of gentamicin in patients with Menière's disease. Acta Otolaryngol Suppl 1991; 485: 120-122

226 Ödkvist LM, Bergenius J, Möller C. When and how to use gentamicin in the treatment of Menière's disease. Acta Otolaryngol Suppl 1997; 526: $54-57$

227 Lange G, Mann W, Maurer J. Intratympanale Intervalltherapie des Morbus Menière mit Gentamicin unter Erhalt der Cochleafunktion. HNO 2003; 51: 898-902

${ }^{228}$ Lange G, Maurer J, Mann W. Long-term results after interval therapy with intratympanic gentamicin for Menière's disease. Laryngoscope 2004; 114: $102-105$

${ }^{229}$ Hoffmann F, Beck C, Beck C, Stratulat S. Subablative Gentamicintherapie beim Morbus Menière. HNO 1991; 41: 296-300

${ }^{230}$ Driscoll CL, Kasperbauer JL, Facer GW, Harner SG, Beatty CW. Low-dose intratympanic gentamicin and the treatment of Menière's disease: preliminary results. Laryngoscope 1997; 107: 83-89

231 Blakley BW. Update on intratympanic gentamicin for Menière's disease. Laryngoscope 2000; 110: 236 - 240

232 Shea JJ. Perfusion of the inner ear with streptomycin. Am J Otol 1989; 102: $150-155$

233 Shea JJ, Norris CH. Streptomycin perfusion of the labyrinth. In: Nadol JB (Hrsg). Proceedings of the second International Symposium on Menière's disease. Amsterdam: Kugler \& Ghedini, 1989

234 Wang D, Wang Z. Regeneration and functional restoration of vestibular hair cells in guinea pigs after gentamicin damage. Zhonghua $\mathrm{Er} \mathrm{Bi}$ Yan Hou Ke Za Zhi 1997; 32: 153 - 156

${ }^{235}$ Forge A, Li L, Nevill G. Hair cell recovery in the vestibular sensory epithelia of mature guinea pigs. J Comp Neurol 1998; 397: 69-88

${ }^{236}$ de Waele C, Meguenni R, Freyss G, Zamith F, Bellalimat N, Vidal PP, Tran BaHuy P. Intratympanic gentamicin injections for Menière disease: vestibular hair cell impairment and regeneration. Neurology 2002; 59: 1442 - 1444

237 Silverstein H, Rowan PT, Olds MJ, Rosenberg SI. Inner ear perfusion and the role of round window patency. Am J Otol 1997; 18: 586-589

238 Diamond C, O'Connell DA, Hornig JD, Liu R. Systematic review of intratympanic gentamicin in Menière's disease. J Otolaryngol 2003; 32: $351-361$

${ }^{239}$ Bárány R. Die Beeinflussung des Ohrensausens durch intravenös injizierte Localanästhetica. Acta Otolaryngol 1935; 23: 210-207

${ }^{240}$ Gstöttner W, Adunka O. Labyrinthanästhesie bei M. Menière. HNO 2004; 52: 265

${ }^{241}$ Ristow W. Zur Behandlung der Menière-Krankheit mittels temporärer Labyrinthanästhesie. Z Laryngol Rhinol 1968; 47: 442 - 448

${ }^{242}$ Fradis M, Podoshin L, Ben-David J, Reiner B. Treatment of Menière's disease by intratympanic injection with lidocaine. Arch Otolaryngol 1985; 111: $491-493$

${ }^{243}$ Adunka O, Moustaklis E, Weber A, May A, von Ilberg C, Gstoettner W, Kierner AC. Labyrinth anesthesia - a forgotten but practical treatment option in Menière's disease. ORL J Otorhinolaryngol Relat Spec 2003; 65: 84-90

${ }^{244}$ Sakata E, Kitago Y, Murata Y, Teramoto K. Behandlung der Menièreschen Krankheit. Paukenhöhleninfusion von Lidocain- und Steroidlösung. Auris Nasus Larynx 1986; 13: 79-89

245 Plontke SK, Salt AN. Quantitative interpretation of corticosteroid pharmacokinetics in inner fluids using computer simulations. Hear Res 2003; 182: $34-42$

246 Bachmann G, Su J, Zumegen C, Wittekindt C, Michel O. Permeabilität der runden Fenstermembran für Prednisolon-21-Hydrogensuccinat. HNO 2001; 49: $538-542$

247 Silverstein H. Use of a new device, the MicroWick ${ }^{\circledR}$ to deliver medication to the inner ear. Ear Nose Throat J 1999; 78: 595-598

${ }^{248}$ Charabi S, Thomsen J, Tos M. Round window gentamicin mu-catheter - a new therapeutic tool in Menière's disease. Acta Otolaryngol Suppl 2000; 543: $108-110$

${ }^{249}$ Schwab B, Lenarz T, Heermann R. Der Round-Window $\mu$ Cath zur Lokaltherapie des Innenohres - Ergebnisse einer plazebokontrollierten, prospektiven Studie beim chronischen Tinnitus. Laryngo Rhino Otol 2004; 83: $164-172$
${ }^{250}$ Plontke SK, Plinkert PK, Plinkert B, Koitschev A, Zenner HP, Löwenheim $\mathrm{H}$. Transtympanic endoscopy for drug delivery to the inner ear using a new microendoscope. Adv Otorhinolaryngol 2002; 59: $149-155$

${ }^{251}$ Goycoolea MV, Lundman L. Round window membrane. Structure function and permeability: a review. Microsc Res Tech 1997; 36: $201-211$

252 Rarey KE, Curtis LM. Receptors for glucocorticoids in the human inner ear. Otolaryngol Head Neck Surg 1996; 115: 38-41

${ }^{253}$ Hughes GB, Kinney SE, Barna BP, Calabrese LH. Practical versus theoretical management of autoimmune inner ear disease. Laryngoscope 1984; 94: $758-767$

${ }^{254}$ McCabe BF. Autoimmune sensorineural hearing loss. 1979. Ann Otol Rhinol Laryngol 2004; 113: 526-530

${ }^{255}$ Hillman TM, Arriaga MA, Chen DA. Intratympanic steroids: do they acutely improve hearing in cases of cochlear hydrops? Laryngoscope 2003; 113: 1903 - 1907

${ }^{256}$ Parnes LS, Sun AH, Freeman DJ. Corticosteroid pharmacokinetics in the inner ear fluids: an animal study followed by clinical application. Laryngoscope 1999; 109: 1 - 17

${ }^{257}$ Dodson KM, Woodson E, Sismanis A. Intratympanic steroid perfusion for the treatment of Menière's disease: a retrospective study. Ear Nose Throat J 2004; 83: 394 - 398

258 Barrs DM, Keyser JS, Stallworth C, McElveen JT Jr. Intratympanic steroid injections for intractable Menière's disease. Laryngoscope 2001; 111: $2100-2104$

259 Plontke SK, Salt AN. Quantitative interpretation of corticosteroid pharmacokinetics in inner fluids using computer simulations. Hear Res 2003; 182: $34-42$

${ }^{260}$ Alzamil KS, Linthicum FH Jr. Extraneous round window membranes and plugs: possible effect on intratympanic therapy. Ann Otol Rhinol Laryngol 2000; 109: 30-32

${ }^{261}$ Arslan M. Erwägungen über die Wahl des chirurgischen Verfahrens bei der Menièreschen Krankheit. Die neue Methode der „osmotischen Induktion“. HNO 1971; 19: 81 - 87

${ }^{262}$ Hüttenbrink KB. Vestibuläre Symptome durch mechanische Interaktionen zwischen Mittel- und Innenohr. In: Stoll W (Hrsg). Differenzialdiagnose Schwindel. Berlin: Springer, 1998: 85-90

${ }^{263}$ Hüttenbrink KB. Die Bewegungen von Stapes-Piston-Prothesen bei Änderungen des statischen Luftdruckes. Laryngo Rhino Otol 1988; 67: $250-244$

${ }^{264}$ Hüttenbrink KB. Die Mechanik der Gehörknöchelchen bei statischen Drucken. II. Behinderte Gelenkfunktion und operative Kettenrekonstruktion. Laryngo Rhino Otol 1988; 67: 100-105

${ }^{265}$ Hüttenbrink KB. Die Funktion der Gehörknöchelchenkette und der Muskeln des Mittelohres. Eur Arch Oto Rhino Laryngol 1995; Suppl I: $1-52$

${ }^{266}$ Tumarkin A. Thoughts on the treatment of labyrinthopathy. J Laryngol Otol 1966; 80: 1041 - 1053

${ }^{267}$ Lall M. Menière's disease and the grommet (a survey of its therapeutic effects). J Laryngol Otol 1969; 83: 787 - 791

268 Thomsen J, Bonding P, Becker B, Stage J, Tos M. The non-specific effect of endolymphatic sac surgery in treatment of Menière's disease: a prospective, randomized controlled study comparing „classic“ endolymphatic sac surgery with the insertion of a ventilating tube in the tympanic membrane. Acta Otolaryngol 1998; 118: 769-773

269 Montandon P, Guillemin P, Hausler R. Prevention of vertigo in Ménière's syndrome by means of transtympanic ventilation tubes. ORL J Otorhinolaryngol Relat Spec 1988; 50: 377-381

${ }^{270}$ Häusler R, Guillemin P, Montandon P. Surgical treatment of Menière's disease by sacculotomy, cochleo-sacculotomy and transtympanic aerators. Rev Laryngol Otol Rhinol (Bord) 1991; 112: 149-152

${ }^{271}$ Hall MC, Brackmann DE. Eustachian tube blockage and Menière's disease. Arch Otolaryngol 1977; 103: $355-357$

272 Franz P, Hamzavi JS, Schneider B, Ehrenberger K. Do middle ear muscles trigger attacks of Menière's disease? Acta Otolaryngol 2003; 123: $133-137$

273 Kitahara M, Kodama A, Ozawa H, Izukura H. Pressure test for the diagnosis of Menière's disease. Acta Otolaryngol Suppl 1994; 510: $107-110$

${ }^{274}$ Konradsson KS, Svensson O, Carlborg B, Grenner J. Tympanic pressure gradients and otoacoustic emissions. Ear Hear 1999; 20: 403-409

275 Konradsson KS, Carlborg B, Grenner J, Tjernström O. Electrocochleographic and audiometric evaluation of hypobaric effect in Menière's disease. Laryngoscope 1999; 109: 59-64 
276 Ödkvist LM, Arlinger S, Billermark E, Densert B, Lindholm S, Wallqvist J. Effects of middle ear pressure changes on clinical symptoms in patients with Menière's disease - a clinical multicentre placebo-controlled study. Acta Otolaryngol Suppl 2000; 543: 99-101

277 Densert B, Densert O, Arlinger S, Sass K, Ödkvist L. Immediate effects of middle ear pressure changes on the electrocochleographic recordings in patients with Menière's disease: a clinical placebo-controlled study. Am J Otol 1997; 18: 726 - 733

${ }^{278}$ Densert B, Arlinger S, Ödkvist LM. New technology to control symptoms in Menière's disease. Acta Otolaryngol 2000; 120: 672 - 674

${ }^{279}$ Densert B, Sass K. Control of symptoms in patients with Menière's disease using middle ear pressure applications: two years follow-up. Acta Otolaryngol 2001; 121: 616-621

${ }^{280}$ van Deelen GW, Hulk J, Huizing EH. The use of the underpressure chamber in the treatment of patients with Menière's disease. J Laryngol Otol 1987; 101: 229-35

281 Gruber J. Über Morbus Menière. Mschr Ohrenheilk 1895; 29: $181-184$

${ }^{282}$ Lacher G. Current historical perspectives on endolymphatic sac surgery. Acta Otolaryngol Stockh Suppl 1997; 526: 50-53

283 Portmann G. Recherches sur la physiologie du sac et du canal endolymphatiques: valeur fonctionelle de l'organe endolymphatique des Sèlaciens. C R Soc Biol 1921; 85: 1070-1077

${ }^{284}$ Portmann G. Le traitement chirurgical des vertiges par l'ouverture du sac endolymphatique. Paris: Presse Médical, 1926

285 Portmann G. The saccus endolymphaticus and an operation for draining the same for the relief of vertigo. L Laryngol 1927; 42: 809-817

286 Paparella MM, Sajjadi H. Endolymphatic sac enhancement. Principles of diagnosis and treatment. Am J Otol 1987; 8: 294-300

287 Paparella MM, Sajjadi H. Endolymphatic sac revision for recurrent Menière's disease. Am J Otol 1988; 9: 441 - 447

288 Paparella MM, Hamid RD. Etiology, pathophysiology of symptoms, and pathogenesis of Menière's disease. Otolaryngol Clin N Am 2002; 35: $529-545$

289 Paparella MM. Revision of endolymphatic sac surgery for recurrent Menière's disease. Otolaryngol Clin N Am 2002; 35: 607-619

${ }^{290}$ House WF. Subarachnoid shunt for drainage of endolymphatic hydrops. A preliminary report. Laryngoscope 1962; 72: 713-729

291 Plester D. Surgical treatment of Menière's disease. HNO (Berl) 1970; 18: $205-210$

292 Strutz J, Mann W (Hrsg). Praxis der HNO-Heilkunde, Kopf- und Halschirurgie. Stuttgart: Thieme, 2000

293 Thomsen J, Bretlau P, Tos M, Johnsen NJ. Placebo effect in surgery for Menière's disease. Arch Otolaryngol 1981; 107: 271 - 277

294 Thomsen J, Bretlau P, Tos M, Johnsen NJ. Menière's disease: a 3-year follw-up of patients in a double-blind placebo-controlled study on endolymphatic sac shunt surgery. Adv Oto Rhino Laryng 1983; 30: $350-354$

295 Thomsen J, Bretlau P, Tos M. Johnsen NJ. Endolymphatic sac suc-mastoid shunt surgery. A non-specific treatment modality? Ann Otol Rhinol Laryngol 1986; 95: $32-35$

${ }^{296}$ Bretlau P, Thomsen J, Tos M, Johnsen NJ. Placebo effect in surgery for Menière's disease: nine-year follow-up. Am J Otol 1989; 10: 259-261

297 Thomsen J, Kerr A, Bretlau P, Olsson J, Tos M. Endolymphatic sac surgery: why we do not do it. The non-specific effect of sac surgery. Clin Otolaryngol 1996; 21: $208-211$

${ }^{298}$ Vaisrub N. Summary statement to „placebo effect in surgery for Menière's disease sac shunt surgery disputed“. (Letter to the editor). Arch Otolaryngol 1981; 107: 174

${ }^{299}$ Pillsbury HC 3rd, Arenberg IK, Ferraro J, Ackley RS. Endolymphatic sac surgery. The Danish sham surgery study: an alternative analysis. Otolaryngol Clin North Am 1983; 16: 123-127

${ }^{300}$ Huang TS, Lin CC, Chang YL. Endolymphatic sac surgery for Menière's disease. A cumulative study of twelve years' experience. Acta Otolaryngol Suppl 1991; 485: 145-154

${ }^{301}$ Kerr AG, Toner JG, McKee GJ, Smyth GD. Role and results of cortical mastoidectomy and endolymphatic sac surgery in Menière's disease. J Laryngol Otol 1989; 103: 1161 - 1166

${ }^{302}$ Silverstein H, Smouha E, Jones R. Natural history vs. surgery for Menière's disease. Otolaryngol Head Neck Surg 1989; 100: 6-16

${ }^{303}$ Schuknecht HF, Rüther A. Blockage of longitudinal flow in endolymphatic hydrops. Eur Arch Otolaryngol 1990; 248: 209-217

${ }^{304}$ Wilschowitz M, Sanchez-Hanke M, Ußmüller J. Zur Wertigkeit der Saccotomie beim M. Menière - Eine Langzeitanalyse von 42 Fällen. HNO 2001; 49: 180-187
305 Ußmüller J, Sanchez-Hanke R, Leuwer R. Klinische Relevanz entwicklungsbedingter Veränderungen des Saccus endolymphaticus. Laryngo Rhino Otol 2001; 80: 308-312

306 Welling DB, Nagaraja HN. Endolymphatic mastoid shunt: a reevaluation of efficacy. Otolaryngol Head Neck Surg 2000; 122: 340-345

307 Pensak ML, Friedman RA. The role of endolymphatic mastoid shunt surgery in the managed care era. Am J Otol 1998; 19: 337-340

${ }^{308}$ Kato BM, LaRouere MJ, Bojrab DI, Michaelides EM. Evaluating quality of life after endolymphatic sac surgery: The Menière's disease outcomes questionnaire. Otol Neurotol 2004; 25: 339-344

${ }^{309}$ Huang TS. Endolymphatic sac surgery for Menière's disease: experience with over 3000 cases. Otolaryngol Clin North Am 2002; 35: $591-606$

310 Stahle J, Friberg U, Svedberg A. Long-term progression of Menière's disease. Acta Otolaryngol (Stockh) Suppl 1991; 485: 78-83

${ }^{311}$ Huang TS, Lin CC. Endolymphatic sac ballooning surgery for Ménière's disease. Ann Otol Rhinol Laryngol 1994; 103: 389-394

312 Huang TS, Hsu JC, Lee FP. Electrocochleographic monitoring in endolymphatic sac surgery for Menière's disease. Arch Otolaryngol Head Neck Surg 1994; 120: $552-529$

313 Bagger-Sjöback D. Surgical anatomy of the endolymphatic sac. Am J Otol 1993; 14: $576-579$

314 Yin S, Ke G, Gu N, Shen P, Zhang S, Wu Y, Zang W. Long-term results of surgical treatment of intractable Menière's disease for control of vertigo. Lin Chuang Er Bi Yan Hou Ke Za Zhi 1999; 13: 291 - 292

315 Kitahara T, Horii A, Mishiro Y, Fukushima M, Kondoh K, Okumura S, Takeda N, Kubo T. Changes in plasma inner ear hormones after endolymphatic sac drainage and steroid-instillation surgery (EDSS). Nippon Jibiinkoka Gakkai Kaiho 2002; 105: 557-563

${ }^{316}$ Huang TS. Topical mitomycin C and cephalosporin in endolymphatic sac surgery. Laryngoscope 2002; 112: $243-247$

317 Welling DB, Pasha R, Roth LJ, Barin K. The effect of endolymphatic sac excision in Menière disease. Am J Otol 1996; 17: 278-282

318 Westhofen M, Koch U. Therapieerfolge nach Saccotomie - Postoperativer Verlauf der vestibulären Kompensation. HNO 1988; 36: $315-317$

319 Schwager K, Baier G, El-Din N, Shehata-Dieler W, Carducci F, Helms J. Revision surgery after saccotomy for Menière's disease: does it make sense? Eur Arch Otorhinolaryngol 2002; 259: 239-242

${ }^{320}$ Iro H, Waldfahrer F. Chirurgische Therapie bei Morbus Menière. In: Haid CT (Hrsg). Schwindel aus interdisziplinärer Sicht. Stuttgart: Thieme, 2003: 217-224

${ }^{321}$ Schuknecht HF. Cochleosacculotomy for Menière's disease: theory, technique and results. Laryngoscope 1982; 92: 853-858

${ }^{322}$ Montandon PB, Häusler RJ, Kimura RS. Treatment of endolymphatic hydrops with cochleosacculotomy. Clinical results and experimental findings. Otolaryngol Head Neck Surg 1985; 93: 615-621

${ }^{323}$ Schuknecht HF. The cochlear endolymphatic (CE) shunt: Update on results. Spring Meeting of the American Neurotology Society, New Orleans, April 8, 1983

${ }^{324}$ Kangsanarak J, Navacharoen N, Prawatmuang W, Supamanee T. Surgery for intractable vertigo: Chiang Mai experience. J Med Assoc Thai 1995; 78: 289-297

${ }^{325}$ Kinney WC, Nalepa N, Hughes GB, Kinney SE. Cochleosacculotomy for the treatment of Menière's disease in the elderly patient. Laryngoscope 1995; 105: 934-937

${ }^{326}$ Rosenberg SI. Vestibular surgery for Menière's disease in the elderly: a review of techniques and indications. Ear Nose Throat J 1999; 78: $443-446$

${ }^{327}$ Huang TS, Lin CC. Delayed endolymphatic hydrops: study and review of clinical implications and surgical treatment. Ear Nose Throat J 2001; 80: 76-78, 81-82

${ }^{228}$ Dandy WE. Menière's disease. Its diagnosis and a method of treatment. Arch Surg 1928; 16: 1127-1152

${ }^{329}$ Dandy WE. Menière's disease: diagnosis and treatment. Report of thirty cases. Am J Surg 1933; 20: 693-398

${ }^{330}$ McKenzie KG. Intracranial division of the vestibular portion of the auditory nerve for Menière's disease. CMAJ 1936; 34: 369-381

${ }^{331}$ House WF. Surgical exposure of the internal auditory canal and its contents through the middle cranial fossa. Laryngoscope 1961; 71: $1363-1385$

332 Fisch U. Neurectomy of the vestibular nerve: surgical technique: indications and results obtained in 70 cases. Rev Laryngol Otol Rhinol (Bord) 1969; 90: 661-672 
${ }^{333}$ Wigand ME, Haid CT, Berg M, Rettinger G. The enlarged transtemporal approach to cerebello-pontine angle; technique and indications. Acta Otorhinolaryngol (Ital) 1982; 2: 571

334 Silverstein $\mathrm{H}$. Transmeatal labyrinthectomy with and without and cochleovestibular neurectomy. Laryngoscope 1976; 36: 1777-1791

${ }^{335}$ Fisch U. Die chirurgische Behandlung des Morbus Menière. Arch Otolaryngol 1976; 212: 385-391

${ }^{336}$ Molony TB. Decision making in vestibular neurectomy. Am J Otol 1996; 17: $421-424$

${ }^{337}$ Thomsen JC, Berner AS, Tos M. Vestibular neurectomy in the treatment of Menière's disease. Ugeskr Laeger 2000; 162: 5501 - 5503

${ }^{338}$ Hillman TA, Chen DA, Arriaga MA. Vestibular nerve section versus intratympanic gentamicin for Menière's disease. Laryngoscope 2004; 114: $216-222$

339 Rosenberg S, Silverstein H, Flanzer J, Wanamaker H. Bilateral Ménière's disease in surgical versus nonsurgical patients. Am J Otol $1991 ; 12: 336-340$

${ }^{340}$ van de Heyning PH, Verlooy J, Schatteman I, Wuyts FL. Selective vestibular neurectomy in Menière's disease: a review. Acta Otolaryngol (Stockh) Suppl 1997; 526: 58-66

${ }^{341}$ Silverstein H, Wanamaker H, Flanzer J, Rosenberg S. Vestibular neurectomy in the United States -1990. Am J Otol 1992; 13: 23-30

${ }^{342}$ Schuknecht $\mathrm{H}$. Ablation therapy for the relief of Menière's disease. Laryngoscope 1956; 66: 859-871

${ }^{343}$ Cawthorne T. Membraneous labyrinthectomy via oval window for Menière's disease. J Laryngol Otol 1957; 71: 524-527

${ }^{344}$ Helms J. Chirurgie an Labyrinth und innerem Gehörgang bei Gleichgewichtsstörungen. In: Naumann HH, Helms J, Herberhold C, Jahrsdoerfer RA, Kastenbauer ER, Panje WR, Tardy ME Jr (Hrsg). Kopf- und Hals-Chirurgie, Bd 2. Stuttgart: Thieme, 1996: 277-300

345 Jones R, Silverstein H, Smouha E. Long-term results of transmeatal cochleovestibular neurectomy: an analysis of 100 cases. Otolaryngol Head Neck Surg 1989; 100: 22 - 29

346 Peacock R. Alcoholic labyrinthine injection through the oval window in the treatment of aural vertigo. Lancet 1938; 1: 421-423

${ }^{347}$ Mollison WW. Surgical treatment of vertigo by opening the external semicircular canal and injecting alcohol. Lancet 1938; 1: 421-423

348 Day KM. Labyrinth surgery for Menière's disease. Laryngoscope 1943; 53: $617-630$

${ }^{349}$ Westhofen M, Mangold U, Wöllmer W, Wehner M. Lasertherapie von Otolithenstörungen. In: Stoll W (Hrsg). Differenzialdiagnose Schwindel. Berlin: Springer, 1998: 73-82

350 Nomura Y, Hara M, Okuno T. Application of argon laser to the inner ear. Acta Otolaryngol 1988; 105: 439-444

${ }^{351}$ Nomura Y, Okuno T, Young YH, Hara M. Laser labyrinthectomy in humans. Acta Otolaryngol 1991; 111: 319-326

352 Nomura Y, Okuno T, Mizuno M. Treatment of vertigo using laser labyrinthectomy. Acta Otolaryngol 1993; 113: $261-262$

${ }^{353}$ Clarke A. Sensory interaction in the vestibular system. Habilitationsarbeit für die Freie Universität Berlin 1992
${ }^{354}$ Scherer H, Teiwes W, Clarke A. Measuring three dimensions of eye movement in dynamic situations by means of videooculography. Acta Otolaryngol (Stockh) 1991; 111: $182-187$

355 Brandt T. Bilateral vestibulopathy revisited. Eur J Med Res 1995/96; 1 : $361-368$

${ }^{356}$ Rinne T, Bronstein AM, Rudge P, Gresty MA, Luxon LM. Bilateral loss of vestibular function: clinical findings in 53 patients. J Neurol 1998; 245: $314-321$

357 Bechterew W. Ergebnisse der Durchschneidung des Nervus acusticus, nebst Erörterung der Bedeutung der semicirculären Kanäle für das Körpergleichgewicht. Pflügers Arch f d ges Physiologie 1883; 30: $312-347$

358 Schmidt CL, Maurer J. Bechterew-Phänomen beim Menschen. Laryngo Rhino Otol 1999; 78: $455-461$

${ }^{359}$ Dandy WE. The surgical treatment of Menière's disease. Am J Surg 1941; 20: $52-0$

${ }^{360}$ Lange G, Keller R. Beiderseitiger Funktionsverlust der peripheren Gleichgewichtsorgane. Laryngo Rhino Otol 2000; 79: 77-80

${ }^{361}$ Reimann IR, Meier-Hellmann A, Pfeifer R, Traut T, Schilling A, Stein G Reinhart K, Hoffmann A. Serumspiegelorientierte Dosierung der einmal täglichen Aminoglykosidtherapie beim kritisch Kranken: Ergebnisse einer prospektiven Untersuchung. Anästhesiol Intensivmed Notfall 1999; 34: 288-296

362 Orsoni JG, Zavota L, Pellistri I, Piazza F, Cimino L. Cogan syndrome. Cornea 2002; 21: 356-359

${ }^{363}$ Herdmann SJ. Vestibular rehabilitation. Philadelphia: Davis, 2000

${ }^{364}$ Link W, Schneider D. Lebensqualität beim Altersschwindel in Deutschland. Fortschritte der Medizin 2003; 212: 47-50

365 Jeschke D, Zeilberger K. Altern und körperliche Aktivität. Dtsch Ärztebl 2004; 101: 789-798

${ }^{366}$ Judge JO, Whipple RH, Wolfson LI. Effects of resistive and balance exercises on isokinetic strength in older persons. J Am Geriatr Soc 1994; 42: 937-946

${ }^{367}$ von Renteln-Kruse W, Micoll W, Oster P, Schlierf G. Arzneimittelverordnung, Schwindel und Stürze bei über 75jährigen Krankenhauspatienten. Z Gerontol Geriat 1998; 31: 286-289

368 Allum JHJ. Neue Ansätze zur Sturzprävention mittels Gleichgewichtsprothesen. Jahrestagung Deutsche Gesellschaft für Audiologie 2004; Leipzig, Vortrag

${ }^{369}$ Noppens R, Hennes HJ. Kinetosen bei Hubschraubereinsätzen. Notfall \& Rettungsmedizin 2001; 4: 426-430

${ }^{370}$ Helling K, Hausmann S, Flöttmann T, Scherer H. Untersuchungen zur interindividuell unterschiedlichen Kinetoseempfindlichkeit. HNO 1997; 45: 210-215

${ }^{371}$ Diamond SG, Markham CH. Validating the hypothesis of otolith asymmetry as a cause of space motion sickness. Ann N Y Acad Sci 1992; 656: $725-731$

372 Schmäl F, Stoll W. Kinetosen. HNO 2000; 48: 346-356 